\title{
Pathways to Delinquent and Sex Offending Behavior: The Role of Childhood Adversity and Environmental Context in a Treatment Sample of Male Adolescents
}

Kelcey Puszkiewicz

East Tennessee State University

Follow this and additional works at: https://dc.etsu.edu/etd

Part of the Clinical Psychology Commons

\section{Recommended Citation}

Puszkiewicz, Kelcey, "Pathways to Delinquent and Sex Offending Behavior: The Role of Childhood Adversity and Environmental Context in a Treatment Sample of Male Adolescents" (2019). Electronic Theses and Dissertations. Paper 3443. https://dc.etsu.edu/etd/3443

This Dissertation - unrestricted is brought to you for free and open access by the Student Works at Digital Commons @ East Tennessee State University. It has been accepted for inclusion in Electronic Theses and Dissertations by an authorized administrator of Digital Commons @ East Tennessee State University. For more information, please contact digilib@etsu.edu. 
Pathways to Delinquent and Sex Offending Behavior: The Role of Childhood Adversity and Environmental Context in a Treatment Sample of Male Adolescents

\author{
A dissertation \\ presented to \\ the faculty of the Department of Psychology \\ East Tennessee State University \\ In partial fulfillment \\ of the requirements for the degree \\ Doctor of Philosophy in Psychology \\ with concentration in Clinical Psychology \\ by \\ Kelcey L. Puszkiewicz \\ August 2019 \\ Jill Stinson, PhD, Chair \\ Ginni Blackhart, $\mathrm{PhD}$ \\ Julia Dodd, $\mathrm{PhD}$ \\ Megan Quinn, DrPH, MSc \\ Stacey Williams, PhD
}

Keywords: adverse childhood experiences, ACEs, adolescent sexual offending, community, delinquency, structural equation modeling 


\begin{abstract}
Pathways to Delinquent and Sex Offending Behavior: The Role of Childhood Adversity and Environmental Context in a Treatment Sample of Male Adolescents
\end{abstract}

by

Kelcey L. Puszkiewicz

Exposure to more types of Adverse Childhood Experiences (ACEs) has been associated with a greater likelihood of general and sexual offending behaviors. However, few studies exist that consider both the impact of varied ACE exposures and community correlates on pathways to offending behaviors in adolescents who have engaged in sexually abusive behaviors. The current study examined these pathways using data collected from archival records of male adolescents $(N=285)$ who had received treatment for sexually abusive behavior at a youth facility. Structural equation modeling revealed a three-factor model for ACEs, which included: nonsexual abuse and neglect; household dysfunction; and sexual abuse and more passive indicators of sexual boundary problems in the home of origin. Direction and significance of paths between ACEs and the onset, persistence, and nature of maladaptive behaviors differed. Household dysfunction was related to an earlier onset and more persistent nonsexual delinquent offending and contact sexual offending. Conversely, sexual abuse and exposure to sexual boundary problems were associated with an earlier onset of sexually abusive behavior as well as indicators of adolescent-onset, less persistent, and nonviolent delinquency. Nonsexual abuse and neglect were uniquely associated with contact sexual offending. Thus, these findings suggest variations in ACE exposures differentially influence the development, severity, and continuance of nonsexual delinquent and sexually abusive behaviors among these youths. Socioecological variables associated with 
participants' counties of origin, including social and economic environment and percentage of rurality, were not retained as covariates due to producing a poor model fit for the data.

Additional study with regard to the role of community characteristics on delinquent and sexual offending behaviors is warranted. 


\section{ACKNOWLEDGMENTS}

First and foremost, I would like to thank my dissertation chair and advisor, Dr. Jill Stinson, for your expertise, guidance, and encouragement in the development of this dissertation and throughout my graduate study. I am so grateful for your mentorship and the valuable opportunities that you have provided me with during my training that have helped me grow as a researcher and professional. I would also like to express my gratitude to the other members of my committee, Dr. Ginni Blackhart, Dr. Julia Dodd, Dr. Megan Quinn, and Dr. Stacey Williams. I appreciate your kindness, guidance, and feedback throughout this dissertation process. Additionally, I would like to thank my family and friends for their unwavering support. To my parents, thank you for always believing in me and being my biggest supporters. I am forever grateful for everything you both have done for me. To my siblings and nephew, thank you for always being there for me and making me laugh when I need to most. To my husband, thank you

for encouraging me when I doubted myself and showing me patience daily. Finally, I would like to acknowledge that this work was funded in part by a grant from the East Tennessee State University Research Development Committee Major Grants Program. 


\section{TABLE OF CONTENTS}

Page

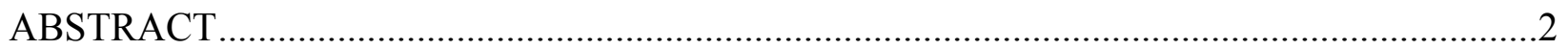

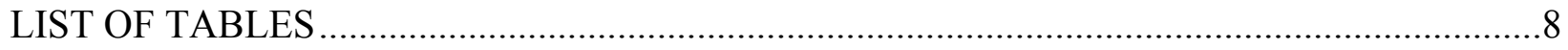

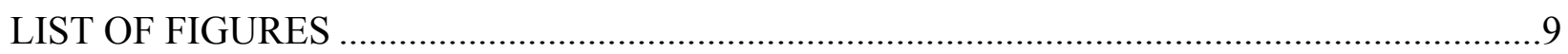

Chapter

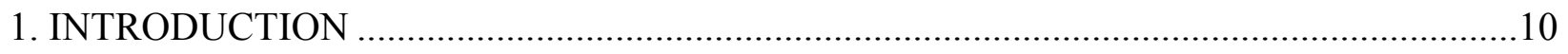

Adolescents Who Have Engaged in Sexually Abusive Behavior...................................12

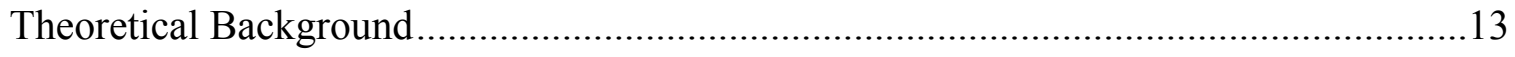

Social disorganization and the theory of collective efficacy .............................15

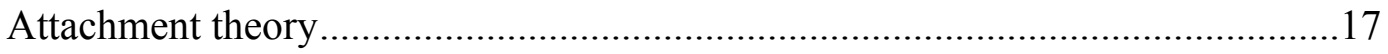

Developmental Life Course (DLC) criminology ............................................20

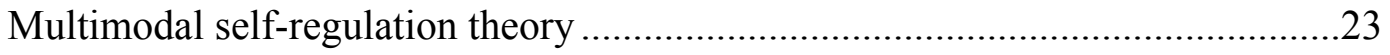

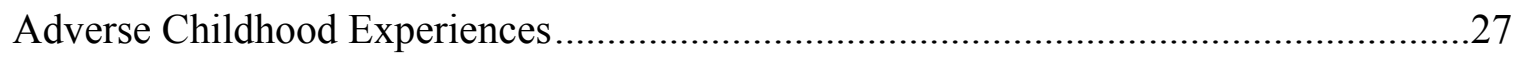

Environmental and Community Context ................................................................. 31

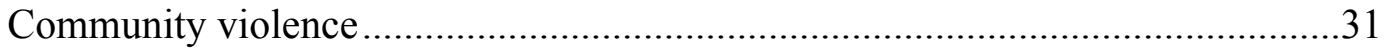

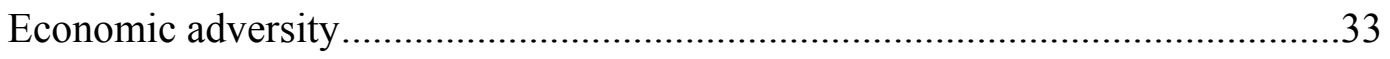

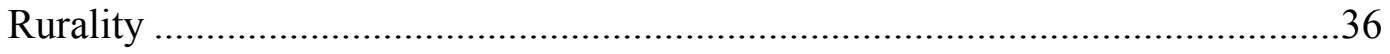

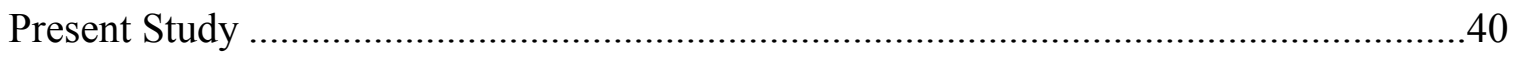

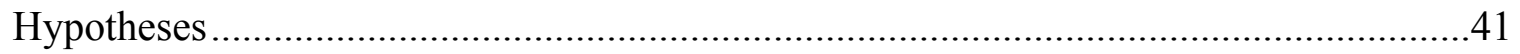

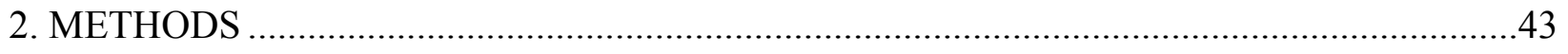

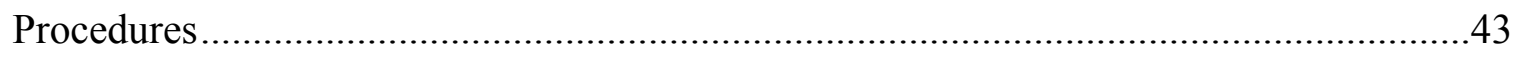

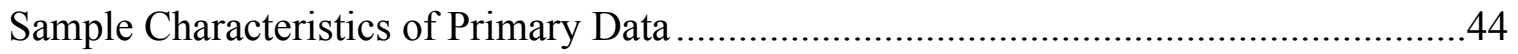




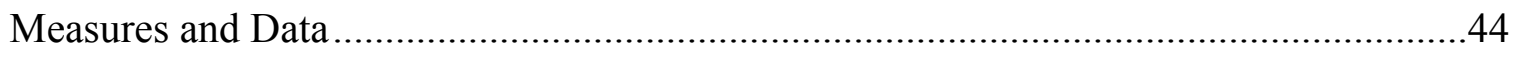

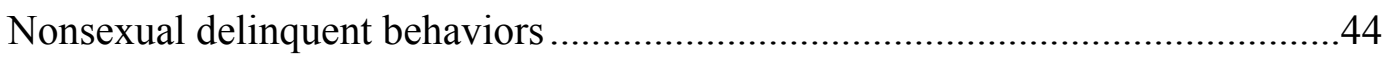

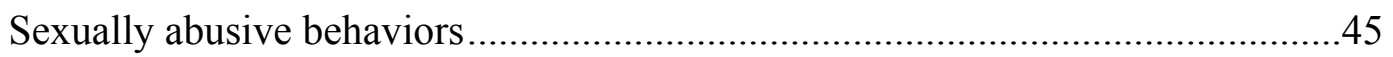

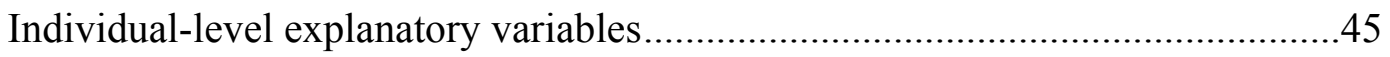

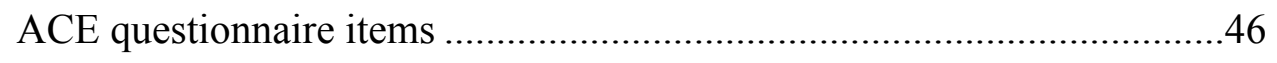

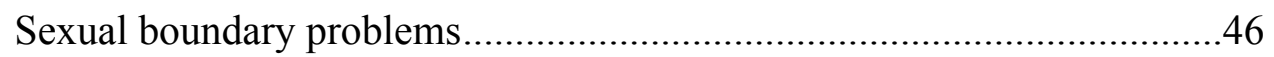

County-level explanatory variables .....................................................................

Social and economic environment ............................................................

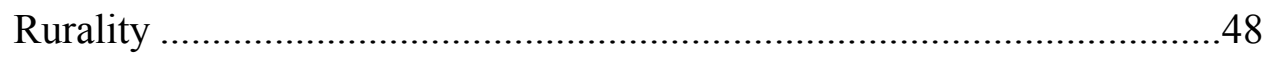

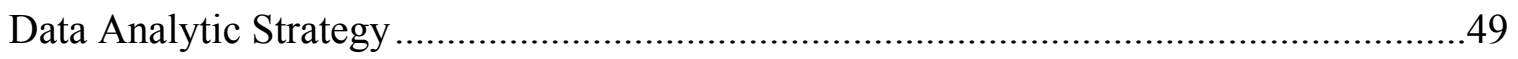

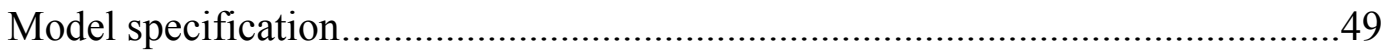

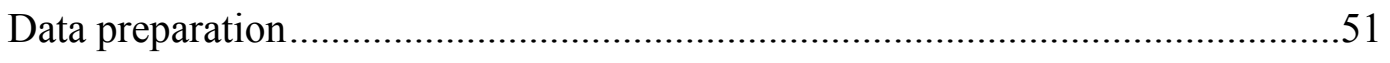

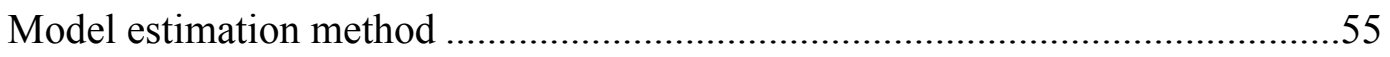

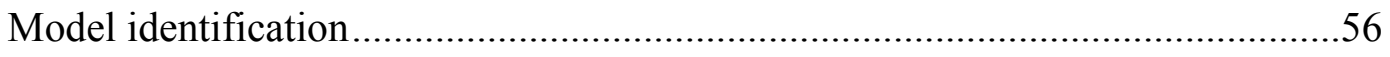

Model and parameter interpretation.................................................................57

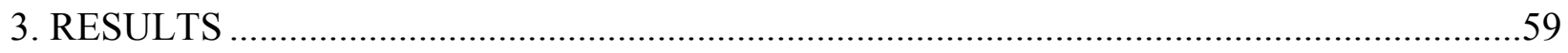

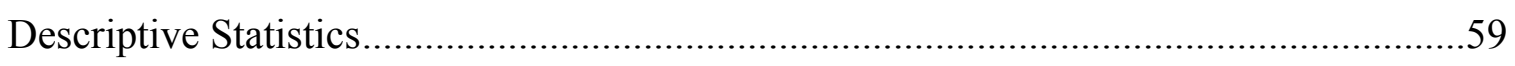

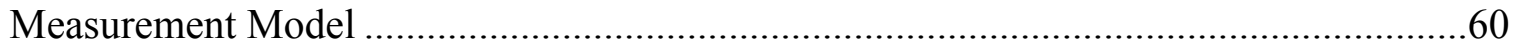

Nonsexual Delinquent Behaviors …………………….............................................64

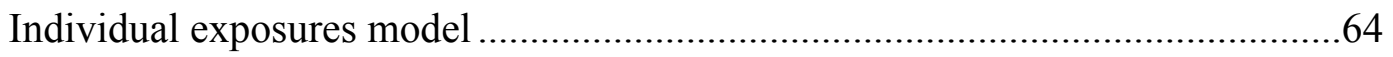

Modified exploratory model ............................................................................67

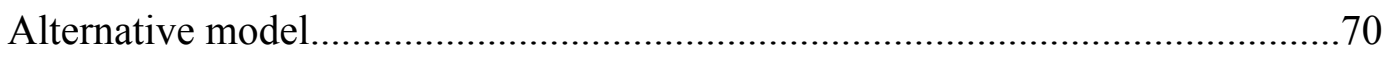

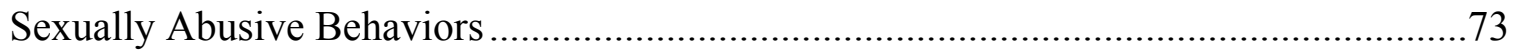




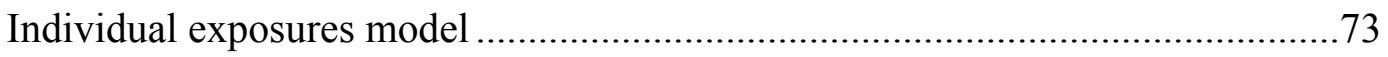

Alternative model............................................................................... 76

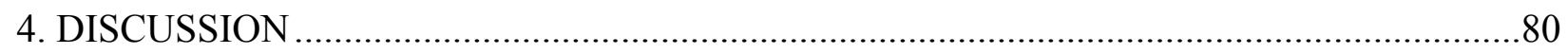

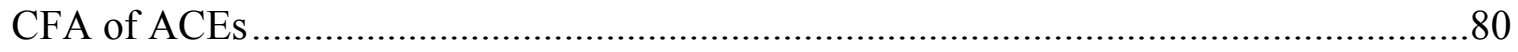

ACEs and Pathways to Delinquent and Sexually Abusive Behaviors............................82

Nonsexual delinquent behavior............................................................... 83

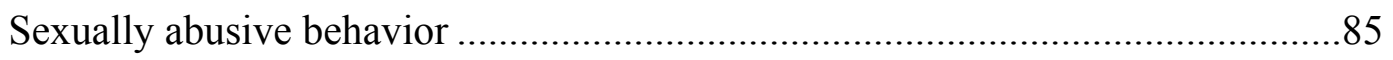

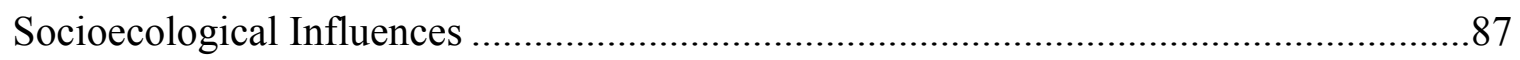

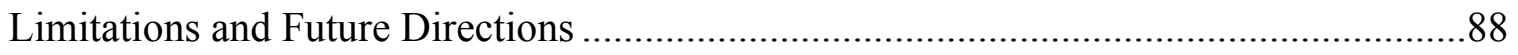

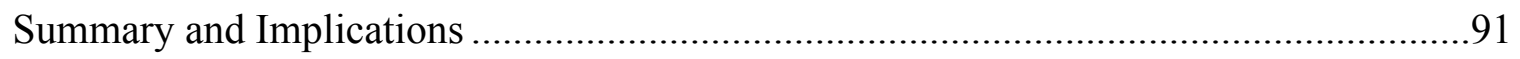

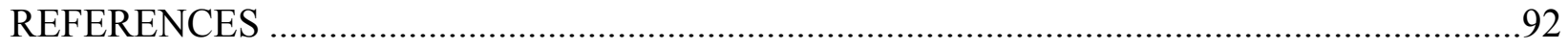

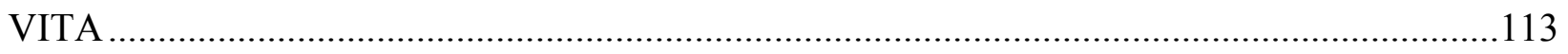




\section{LIST OF TABLES}

Table

Page

1. Characteristics of County-Level Data Related to Social \& Economic Environment

2. Correlations and Standard Deviations of Input Data ..................................................54

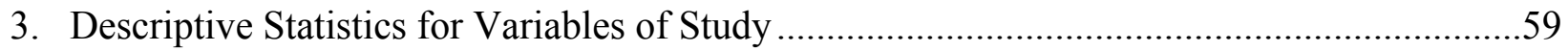

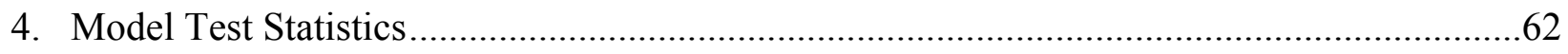

5. Unstandardized and Standardized (StdYX) Regression Coefficients, Standard Errors, Critical Ratios, Confidence Intervals, $\mathrm{R}^{2}$ Values, and Covariances between Latent Variables for the Measurement Model .....

6. Unstandardized and Standardized (StdYX) Regression Coefficients, Standard Errors, Critical Ratios, and Confidence Intervals in the Individual Exposures Model for Nonsexual Delinquent Behaviors

7. Unstandardized and Standardized (StdYX) Regression Coefficients, Standard Errors, Critical Ratios, and Confidence Intervals in the Modified Exploratory Model for Nonsexual Delinquent Behaviors

8. Unstandardized and Standardized (StdYX) Regression Coefficients, Standard Errors, Critical Ratios, and Confidence Intervals in the Alternative Model for Nonsexual Delinquent Behaviors.

9. Unstandardized and Standardized (StdYX) Regression Coefficients, Standard Errors, Critical Ratios, and Confidence Intervals in the Individual Exposures Model for Sexually Abusive Behaviors

10. Unstandardized and Standardized (StdYX) Regression Coefficients, Standard Errors, Critical Ratios, and Confidence Intervals in the Alternative Model for Sexually Abusive Behaviors 


\section{LIST OF FIGURES}

Figure

Page

1. Measurement Model for Individual Adverse Experiences

61

2. Initial Structural Model for Individual Exposures to ACEs and Nonsexual Delinquent Behaviors

3. Modified Exploratory Structural Model for Individual Exposures to ACEs, Rurality, and Nonsexual Delinquent Behaviors .68

4. Alternative Structural Model for Nonsexual Delinquent Behaviors

5. Initial Structural Model for Individual Exposures to ACEs and Sexually Abusive Behaviors

6. Alternative Structural Model for Sexually Abusive Behaviors .77 


\section{CHAPTER 1}

\section{INTRODUCTION}

Roughly one-third of all known perpetrators of sexual offenses are minors, with the majority engaging in sexually abusive behaviors between the ages of 12 to 18 (Finkelhor, Ormrod, \& Chaffin, 2009). Although there is a widely held assumption that sexually abusive behavior in adolescence persists into adulthood, the available literature suggests that only a small percentage of these youths will go on to commit a sexual offense as an adult (Association for the Treatment of Sexual Abusers [ATSA], 2017; Beaudry-Cyr, Jennings, Zgoba, \& Tewksbury, 2017; Caldwell, 2010; Letourneau \& Miner, 2005; McCann \& Lussier, 2008). Despite low sexual recidivism risk, the majority of adolescents who exhibit sexually abusive conduct tend to be versatile in the type of abusive behaviors that they engage in and are at much greater risk of engaging in nonsexual delinquent and criminal behavior (Caldwell, 2010; McCann \& Lussier, 2008). What is more, general delinquent and sexually abusive behaviors share many consistent risk factors, such as childhood abuse and neglect, familial dysfunction, early violence exposure, and psychopathology (Seto \& Lalumiére, 2010). These findings have resulted in a shift in professional views of adolescents who engage in sexually abusive behavior, and these youths are now theorized to be a unique group divergent from adults who sexually offend, exhibiting differential risk and protective factors (ATSA, 2012; Seto \& Lalumiére, 2010). Thus, conclusions drawn from studies of adults who sexually offend may have limited value in conceptualizing the etiology of and risk factors for sexually abusive behavior in adolescence as well as in generating appropriate therapeutic and systemic responsiveness.

Many risk factors for adolescent sexually abusive behavior have been clearly identified, but there are still significant gaps in our understanding of this population. What we do know is 
that adolescents who engage in sexually abusive behavior are a diverse group with varied demographics and histories of developmental adversity, nonsexual delinquent behavior, and community characteristics (ATSA, 2012, 2017; Chaffin et al., 2008). Child maltreatment is one well-established risk factor for violence and criminal offending in adolescence and adulthood (Mersky, Topitzes, \& Reynolds, 2012; Reavis, Looman, Franco, \& Rojas, 2013; Topitzes, Mersky, \& Reynolds, 2012; Widom \& Maxfield, 2001). However, most studies have examined maltreatment in singular or otherwise limited ways, and there are few investigations that explore interactions between varied types of adversity. For instance, some studies operationalize maltreatment histories as simply absent or present without investigation into the type of maltreatment experienced. Other studies do not account for the impact of neglect or household dysfunction in the context of maltreatment.

A multilevel approach that distinguishes the unique effects of a multitude of variables can assist in clarifying the influence of mixed forms of developmental adversity (e.g., abuse, neglect, familial dysfunction, poverty, community violence, interpersonal relationships) on the evolution of delinquent and sexually abusive conduct. Additionally, the relationship between child maltreatment and general and sexual offending can likely be better understood in the context of other factors (e.g., socioeconomic status, peer rejection) and the neighborhood and community in which participants reside (e.g., Baglivio, Wolff, Epps, \& Nelson, 2017; Finkelhor, Shattuck, Turner, \& Hamby, 2013; Maguire-Jack \& Font, 2017). Moreover, further study of the impact of developmental adversities alongside these environmental factors can be useful in advancing our understanding of etiology and risk factors that inform prevention and treatment efforts. The present study aims to contribute by examining the interrelatedness of Adverse Childhood Experiences (ACEs) and other environmental factors on patterns of delinquent and sexual 
offending in a sample of male adolescents who have received treatment for sexually abusive behavior.

\section{Adolescents Who Have Engaged in Sexually Abusive Behavior}

Children and adolescents who exhibit atypical sexual behavior are classified by age and differential characteristics in the available literature and within evidence-based guidelines disseminated by ATSA, an international, multidisciplinary organization aimed at preventing sexual abuse through research and education (ATSA, 2017; Chaffin, Letourneau, \& Silovsky, 2002). "Children with sexual behavior problems" is a term defined as "children ages 12 and younger that initiate behaviors involving sexual body parts (i.e., genitals, anus, buttocks, or breasts) that are developmentally inappropriate or potentially harmful to themselves or others" (p. 3). Conversely, the designation "adolescents who have engaged in sexually abusive behavior" refers to all types and documented occurrences of sexual behavior displayed by youths around the ages of 13 to 18 that are not considered developmentally normative and are interpersonally harmful (ATSA, 2017). Additionally, it is important to note that the term "sexually abusive behavior" is not dependent on whether or not the conduct was reported to legal or child welfare authorities, nor on the legal or child welfare response if reported (ATSA, 2012, 2017).

For many years, adolescents who exhibited these behaviors were referred to as juvenile sexual offenders (JSOs) or adolescent sex offenders (ASOs), but the use of these terms has been criticized because they label children based on behavior, engender negative connotations associated with the broader "sex offender" label, such as being unresponsive to treatment or at high risk for recidivism, and fail to distinguish the wide range of behaviors constituting sexually abusive behavior in clinical and/or legal settings (ATSA, 2017; Harris \& Socia, 2014). In addition, referring to these youths as adolescents who have engaged in sexually abusive behavior 
demonstrates that the individual's conduct occurred in the past and does not presume that the adolescent will continue such behaviors, which is a clinically beneficial perspective (ATSA, 2017). Therefore, in the current study and consistent with recommendations from ATSA (2012, 2017), "adolescents who have engaged in sexually abusive behavior" will be used to describe the sample.

\section{Theoretical Background}

Numerous prevailing theories emphasize the role of early developmental adversities in the etiology of delinquent and sexually abusive behaviors (e.g., Grady, Levenson, \& Bolder, 2016; Lussier, 2015; Moffitt, 1993; Piquero, Jennings, \& Barnes, 2012; Stinson, Sales, \& Becker, 2008; Ward \& Beach, 2005). Others focus primarily on sociological explanations of crime and use a macro-level approach to conceptualizing these problem behaviors (e.g., Bandura, 1969, 1977; Braithwaite, 2015; Sampson \& Groves, 1989; Shaw \& McKay, 1942). While no theoretical framework is without criticisms and limitations, some models have prevailed in receiving substantial empirical support thus far. The present review is limited to a brief description and critique of two single factor and two multifactorial theories of delinquency and sexually abusive behavior that consider childhood adversity and/or the context of community and that are supported by existing empirical evidence. The four prominent philosophies to be discussed include: social disorganization theory/theory of collective efficacy (Sampson, 2012; Sampson \& Groves, 1989; Shaw \& McKay, 1942); attachment theory (Bowlby, 1973; Grady, Levenson, \& Bolder, 2016); developmental life-course (DLC) criminology (Lussier, 2015; Moffitt, 1993; Piquero et al., 2012); and, the multimodal self-regulation theory of sexual offending (Stinson, Sales, \& Becker, 2008). 
It is important to note that there is significant overlap in the theoretical frameworks used to conceptualize delinquency and sexually abusive behavior, consistent with the criminal versatility commonly seen in youth who engage in sexually abusive behavior. Additionally, several risk factors have been fairly reliably identified in previous etiological investigations of delinquent and sexually abusive youth samples, including antisocial personality traits, substance use, peer associations, conduct problems, childhood adversity, and household dysfunction (e.g., Seto \& Lalumiére, 2010; Wanklyn, Ward, Cormier, Day, \& Newman, 2012). However, sexually abusive behaviors are more often precipitated by sexual victimization and atypical sexual interests (e.g., ATSA, 2012; Seto \& Lalumiére, 2010). For instance, in one study, researchers found that adults who committed sexual offenses were three times more likely to have been sexually abused compared to adults with nonsexual criminal offenses (Jespersen, Lalumiére, \& Seto, 2009). Further, differential exposures to childhood abuse, neglect, and household dysfunction have been shown to influence distinct patterns of sexual offending and paraphilic behaviors (e.g., Burton, Duty, \& Leibowitz, 2011; Levenson \& Grady, 2016; Simons, Wurtele, \& Durham, 2008). Childhood sexual abuse (CSA) has been correlated with an earlier onset of sexual offending (Burton et al., 2011; Cooper, Murphy, \& Haynes, 1996), a greater number of sexual abuse victims (Cooper et al., 1996), a higher number of sexual offense related arrests (Levenson \& Socia, 2016), and pedophilia diagnoses (Lee, Jackson, Pattison, \& Ward, 2002). Therefore, the relationships between identified risk factors and delinquent and sexually abusive behavior are complex and depend on a number of factors. In fact, it may be impossible to ultimately tease them apart within the context of any singular theory, since many of these individuals engage in multiple and varied forms of maladaptive behaviors. 
Social disorganization and the theory of collective efficacy. Shaw and McKay (1942)

proposed a macro-criminological theory, called social disorganization theory, to explain how structural characteristics of communities and neighborhoods impact violence and criminal offending behaviors. The theory originated from observations of persistent delinquency rates in Chicago neighborhoods despite changes in the racial and ethnic profiles of area residents (Shaw \& McKay, 1942). Significant social disorganization is believed to reduce a neighborhood's ability to regulate public behavior, subsequently leading to an increase in crime (Kubrin \& Weitzer, 2003). Social disorganization theory proposes that four neighborhood exogenous factors (i.e., poverty, residential instability or mobility, ethnic heterogeneity, and weak social networks) serve as representations of the level of social disorganization and thus regulate the behavior of residents in a given area (Kubrin \& Weitzer, 2003). In other words, neighborhoods with high rates of poverty and significant residential instability and ethnic heterogeneity tend to have weak social networks and inadequate informal social control, and these shortcomings contribute to higher rates of delinquency and crime.

Social disorganization theory has persisted for the past seven decades, but the original theory has been harshly critiqued for two significant flaws (Sampson, 2012; Sampson \& Groves, 1989; Sun, Triplett, \& Gainey, 2004). First, critics argue that Shaw and McKay’s theory has not been directly tested due to limitations in how crime has been historically measured and utilized in macro-level analyses of delinquency (Sampson \& Groves, 1989). Specifically, previous studies have relied on the same official crime demographics (e.g., poverty, SES), and critics contend that these data alone fail to represent factors that may mediate the relationship between neighborhood and crime (e.g., other possible indicators of social disorganization; Sampson \& Groves, 1989). Second, researchers have criticized the lack of specificity in definitions in the 
theory of social disorganization as originally presented (Sun et al., 2004). For a more thorough discussion of these criticisms, refer to Sampson (2012), Sampson and Groves (1989), and Sun and colleagues (2004).

Sample and Groves (1989) and later Sampson (2012) proposed the theory of collective efficacy as a revised framework to address the two major criticisms of traditional social disorganization theory. This revision has been cited as a positive step towards establishing empirical evidence on how social disorganization influences crime and delinquency across neighborhoods (Kubrin \& Weitzer, 2003; Sun et al., 2004). The theory of collective efficacy incorporates the main premise of social disorganization theory in that social control impacts variations in crime rates and overall welfare across neighborhoods and is not solely determined by individuals (Sampson, 2012). Collective efficacy, a main premise of this theory, is a concept that combines social cohesion and the willingness of residents to intervene when necessary for the good of the neighborhood (i.e., informal social control; Sampson, 2012). In contrast with traditional social disorganization theory, Sampson rejects the idea that communities with strong and intimate relationships between residents are absolutely necessary for social control, a revision to better explain contemporary urban settings. Moreover, studies indicate that in certain disadvantaged neighborhoods, strong social ties between residents can in fact impede social control efforts, as social cohesion is not always prosocial (Kubrin \& Weitzer, 2003; Sampson, 2012). Due to the varied nature and mixed findings related to social ties, many researchers theorize that another mechanism - referred to as social capital - is more important (Kubrin \& Weitzer, 2003). Social capital refers to intangible resources transferred through social ties, such as information, trust, commitments, and other cultural factors (Kubrin \& Weitzer, 2003). 
Regarding empirical study, previous research demonstrated how the disorganization of communities and neighborhoods is associated with criminal offending and delinquency (Shaw \& McKay, 1942; Sampson \& Groves, 1989), violence (Sampson, Raudenbush, \& Earls, 1997), and sexual offending (Braithwaite, 2015; Tewksbury, Mustaine, \& Covington, 2010). Furthermore, indicators of social disorganization have been identified as so-called "concentrated disadvantage", a concept which includes community poverty level, use of public assistance, unemployment rates, percentage of ethnic minorities, number of female-headed households, residential stability, and concentration of immigrants (Mustaine, Tewksbury, Huff-Corzine, Corzine, \& Marshall, 2014). In one study by Sampson and colleagues (1997), these variables accounted for over 70 percent of the variance in violence across neighborhoods. In addition, studies have indicated that a lack of both collective efficacy and community cohesion are associated with higher crime rates (Morenoff, Sampson, \& Raudenbush, 2001; Sampson et al., 1997). In sum, there is substantial evidence suggesting that indicators of social disorganization are related to rates of delinquency and sexual offending in a given area. However, there are few studies investigating community correlates of sexual offending patterns, particularly in rural and underserved communities (Braithwaite, 2015).

Attachment theory. Attachment theory (Bowlby, 1973) has been applied to explain how early developmental adversity is associated with criminal and sexual offending behaviors (Grady et al., 2016; Hoeve et al., 2012; Sroufe, Carlson, Levy, \& Egeland, 1999; Ward, Hudson, Marshall, \& Siegert, 1995). While Bowlby (1969) argued that there is a biological component to attachment, it is largely influenced by environment and interactions with primary caregivers. In this theory, attachment refers to a component of the caregiver-infant relationship that elicits feelings of security and safety in the infant (Grady et al., 2016). These feelings serve as a 
"secure-base" in which the individual can discover his/her environment (Fraley \& Shaver, 2000). The fundamental idea of attachment theory is that interactions with one's primary caregiver(s) and the subsequent attachment relationship influences long-term functioning with regard to interpersonal relationships, cognitive and emotional self-regulation, beliefs and expectations, and behavior (Bretherton, 1992; Grady et al., 2016). Children develop an internal working model (IWM) through relationships with their caregivers, which is used as a framework for expectations and guidelines for future relationships and basis for their sense of self (Bretherton, 1992, 2005; Fraley \& Shaver, 2000). As children become more developmentally competent with regard to behavioral, cognitive, and emotional abilities, their IWM is theorized to gradually change accordingly, but foundational attachment security/insecurity remains a relatively stable construct across the lifespan (Bretherton, 2005; Crowell \& Waters, 2005). Studies have similarly shown that attachment styles are largely stable from infancy to adulthood (Bretherton, 2005; Fraley \& Shaver, 2000; Hazan \& Shaver, 1987).

Styles of caregiver responsiveness and subsequent attachment are theorized to be secure or insecure, with a secure attachment being optimal for development (Grady et al., 2016; Simpson \& Belsky, 2008). When caregivers display empathy and consistent responsiveness, children develop secure attachments (Bretherton, 1992). Secure attachments result in the infant learning to regulate his/her emotions and behaviors based on expectations of future situations and interpersonal relationships, as well as a stable sense of self-worth (Bretherton, 1992; Grady et al., 2016; Ward et al., 1995). In contrast, insecure attachments result from interactions with caregivers that are inconsistent, abusive, inattentive, impassive, or controlling (Ainsworth, Blehar, Waters, \& Wall, 1978; Grady et al., 2016). Insecure attachments can lead to poor understanding of acceptable expectations and subsequently maladaptive patterns and low self- 
worth within interpersonal relationships (Grady et al., 2016). Not surprisingly, delinquency, aggression, intimacy difficulties, and severe psychopathology are theorized as consequences of poor or insecure attachment (Grady et al., 2016; Hoeve et al., 2012). Regarding the role of attachment in the development of sexually abusive behavior, researchers propose that emotional dysregulation, atypical or deviant sexual interests, deficits in intimacy and social skills, and belief systems supportive or tolerant of offenses contribute to engaging in sexually abusive behavior, which are consistent with empirically supported difficulties associated with insecure attachment (Grady et al., 2016; Ward, 2014).

There are three further subclassifications of insecure attachment in childhood with varied associated patterns of maladaptive behavior: anxious-ambivalent, avoidant, and disorganized (see Ainsworth et al., 1978; Benoit, 2004; Grady et al., 2016). The anxious-ambivalent insecure attachment style is characterized by caregivers who are inconsistent and erratic in responding to infants for various reasons, such as neglectful parenting or those with poor parenting skills (Ainsworth et al., 1978; Grady et al., 2016; Simpson \& Belsky, 2008; Ward et al., 1995). Anxious-ambivalent attachment children learn to engage in certain behaviors, often maladaptive, to elicit more attention from caregivers (Simpson \& Belsky, 2008). Behaviorally, this attachment style may manifest as hypervigilance related to relationship loss, attention-seeking, submissiveness, impulsivity, low self-esteem, low self-confidence, and extreme neediness (Grady et al., 2016; Simpson \& Belsky, 2008; Stinson, Sales, \& Becker, 2008; Ward et al., 1995). Sexually abusive behavior exhibited by adolescents with anxious-ambivalent attachments may be related to significant rejection anxiety or feelings of discomfort in their relationships with same-aged peers (e.g., Marshall, Hudson, \& Hodkinson, 1993; Ward et al., 1995). 
In contrast to anxious-ambivalent attachment, avoidant attachment forms in response to detached caregivers who are generally unresponsive and inadequate in expressions of emotion towards the infant (Ward et al., 1995). As a result, children learn to isolate and avoid their caregivers when upset or dysregulated because negative emotional expressions are rejected or ignored (Benoit, 2004; Grady et al., 2016; Simpson \& Belsky, 2008). Furthermore, children with avoidant attachments are less likely to view interpersonal relationships as essential and are more likely to develop inadequate empathy skills, be emotionally disconnected, hostile, and aggressive towards others, and engage in antisocial behaviors (Stinson, Sales, \& Becker, 2008; Ward et al., 1995). While these children act as if interpersonal relationships are unimportant to them, it is theorized that fear of rejection underlies these behaviors, and that antisocial and sexually abusive behaviors are a result of growing frustration, resentment, and a desire for control or power over other people (Marshall et al., 1993; Stinson, Sales, \& Becker, 2008).

Disorganized attachment refers to an inability to develop expectations of relationships with a primary caregiver or others due to abusive, traumatizing, and/or atypical interactions with primary caregiver(s) (Benoit, 2004; Grady et al., 2016). While other types of insecure attachment are still characterized by an organized strategy of behavior regulation, children with disorganized attachment may display a variety of maladaptive responses in a relatively inconsistent manner (Grady et al., 2016). Disorganized attachment is identified as the most common predictor of poor long-term outcomes, including severe psychopathology, emotional and behavioral dysregulation, and maladaptive behavioral patterns (Benoit, 2004).

Developmental Life Course (DLC) criminology. DLC criminology is a theoretical model of delinquency that has since been applied to conceptualize the onset, sequence, and cessation of sexual offending (Lussier, 2015; Moffitt, 1993; Piquero et al., 2012). In contrast to 
trait-based or variable-oriented approaches focused on identifying risk factors for delinquency and sexual offending (e.g., Knight \& Sims-Knight, 2003; Seto \& Lalumiére, 2010), the DLC model emphasizes the heterogeneity of youth sexual offending trajectories as evidenced in the empirical literature (Finkelhor et al., 2009). As such, this perspective conceptualizes sex offending in a manner that explains between- and within-group differences in this diverse population, while also investigating the developmental pathways associated with maladaptive and problematic sexual behavior patterns (Lussier, 2015). Critics of variable-oriented methods argue that averaging patterns across individuals can lead to a misinterpretation of true individual patterns (e.g., Bergman \& Trost, 2006; McCuish \& Lussier, 2017). In contrast, the DLC model attends to dynamic processes between personal development, life events, and the patterns of nonsexual criminal and sexually abusive behavior engaged in by an individual across his/her life to provide a more comprehensive picture (see Lussier, 2015; McCuish \& Lussier, 2017, for a more detailed discussion of these critiques).

The main parameters of assessment for this model include "boundary parameters" (e.g., age of onset, age of cessation, and duration of sexually abusive behaviors), and "generic parameters", such as the qualitative nature of the seriousness of sexual offending, the incidence of sexual offending (i.e., number of victims and number of sexual offenses), persistence of sex offending, and versatility (i.e., different types of offenses committed; Lussier, 2015). These factors are chronologically ordered to illustrate three offending processes, including: 1) activation or onset; 2) escalation or course; and, 3) desistance (Lussier, 2015). Based on these processes, the DLC theory suggests a dual-developmental classification of juveniles who sexually offend (JSOs) - the adolescent-limited and the high-rate/slow-desister - similar to the dual taxonomy applied to antisocial and other delinquent behaviors (Moffitt, 1993; Piquero et al., 
2012). Adolescent-limited JSOs are highly prevalent within the JSO population and are characterized by: having normal sexual development until puberty; onset of sex offending during adolescence; limited frequency, persistence, and/or recidivism; and rapid cessation of offending during adolescence (Lussier, 2015). In contrast, high-rate/slow desisters are rarer and exhibit an onset of sexual behavior problems in childhood, more than one offense, often continue into adulthood, and demonstrate gradual and low desistence during adulthood. Regarding the role of child maltreatment, the DLC perspective theorizes distinct developmental risk factors differentiating early- and adolescent-onset of sexually abusive behavior (Lussier, 2015). For adolescent-limited JSOs, factors specific to adolescent development (e.g., changes related to puberty, general patterns of offending, peer influence and relationships) are most salient, and child maltreatment may be more relevant to early-onset of sexually problematic behaviors. While this theory classifies youth who have engaged in sexually abusive behavior into two divergent groups, individualized interventions are most beneficial due to the significant heterogeneity of this population.

Regarding empirical support, one study of the trajectory of nonsexual offending and sexually abusive behaviors in nearly 500 adjudicated JSOs aged 12-32 provided some support for this dual taxonomy of juvenile sexual offending (Lussier, van den Berg, Bijleveld, \& Hendriks, 2012). Specifically, two models resulted in the best trajectory model fit with one being consistent with the adolescent-limited pattern and a second similar to the high-rate/slow-desister group. Additionally, as theorized, a large majority of the sample (89.6\%) demonstrated a pattern of sexually abusive behavior that was consistent with the adolescent-limited pattern (Lussier et al., 2012). Notably, both groups had similar trajectories during adolescence (Lussier et al., 2012), 
and so additional study of divergent developmental risk factors are essential to accurately classify these typologies during adolescence (Lussier, 2015).

Only a small proportion of adolescents engage in severe or persistent delinquent and/or sexually abusive behaviors but are overrepresented in treatment and juvenile justice settings (Lussier, 2015). Because of this overrepresentation, it has been argued that the DLC framework, which aims to differentiate risk factors based on trajectory of offending behavior, may not be sufficient to adequately conceptualize these behaviors in adolescents (Lussier, 2015). Additionally, data from clients in these facilities cannot be generalized using the DLC framework to describe the pathways of children who engage in less serious nonsexual offending and sexually abusive behavior, or who cease prior to adolescence. Due to the low reporting rates of transient and less severe delinquency and sexually abusive behavior, it is difficult to identify these perpetrators prospectively, leaving few opportunities to empirically test the DLC model in this subpopulation. Moreover, studies in treatment and justice settings are also imperfect, as studying these youths longitudinally and at multiple time points is extremely difficult due to the mobility of the population in question. Thus, there is currently only minimal empirical support for the DLC model due to these methodological limitations. However, this framework is promising toward developing a more comprehensive understanding of the etiology and course of delinquent and sexually abusive behaviors.

Multimodal self-regulation theory. The multimodal self-regulation theory of sexual offending (Stinson, Sales, \& Becker, 2008) is an integrative theory that conceptualizes sexually abusive behaviors as maladaptive self-regulatory strategies resulting from substantial deficits in self-regulatory processes, distorted views of the world and self, certain personality characteristics, and conditioned responses to environmental and internal stimuli (p. 204). These 
mechanisms are theorized as mediators of a direct relationship between developmental adversity and later sexually abusive behavior (Stinson, Sales, \& Becker, 2008). A brief overview of the various components of this theory are detailed below, and readers are referred to Stinson, Sales, and Becker (2008), for a more comprehensive description of this theory.

Self-regulation refers to the "ability to monitor, examine, interpret, and respond to internal and external stimuli in a way that is consistent with both immediate and delayed goals" (Stinson, Sales, \& Becker, 2008, p. 177). Within this definition, self-regulation includes emotional, cognitive, behavioral, and interpersonal regulation, and the mentioned goals may be to reduce distress internally, increase feelings of security within interpersonal relationships, and behavioral gratification (Stinson, Sales, \& Becker, 2008). Adaptive or maladaptive strategies can be used to achieve the goal of emotion regulation, or emotional homeostasis, and reducing internal distress in response to overwhelming emotions is theorized as an intense motivator to engage in such strategies.

According to the multimodal self-regulation theory, self-regulatory deficits are theorized to result from a combination of biological factors and early developmental experiences. First, this theory emphasizes a biological underpinning to self-regulatory difficulties in that individuals are born with certain predispositions and fundamental abilities that affect interactions with their environment (Stinson, Sales, \& Becker, 2008). For instance, some individuals tend to be more emotionally sensitive to stimuli than others and more prone to negative emotionality (e.g., more likely to respond with aggression or irritability; Stinson, Sales, \& Becker, 2008). Furthermore, studies suggest that certain people tend to have increased activity in the brain structures associated with emotional reactions (e.g., limbic system, amygdala) in response to emotional stimuli, along with inhibited activity in areas associated with impulse control and executive 
functioning, such as the prefrontal cortex (Heatherton \& Wagner, 2011; Koenigsberg et al., 2009; Minzenberg, Fan, New, Tang, \& Siever, 2008). Other neurological processes like one's ability to learn from their environment and ability to attend to relevant stimuli are also theorized as essential in developing adaptive self-regulatory abilities (Stinson, Sales, \& Becker, 2008). Individuals who are more emotionally sensitive may react quickly and strongly to emotional stimuli, with reduced ability to regulate their impulses and behavior. However, these findings have not been thoroughly explored in sex offending populations, and so it is difficult to confirm a link between these biological vulnerabilities and sexually abusive behavior (Stinson, Sales, \& Becker, 2008).

As noted, this theory holds that biological predisposition and temperament interact with one's environment, particularly interactions with family members and peers, to influence the development and use of self-regulatory strategies (Stinson, Sales, \& Becker, 2008). Those who tend to react strongly to emotional stimuli, display negative emotions more often, and have greater difficulty regulating reactiveness and behavior may be treated differently than siblings or peers without such struggles. Unfortunately, many children who experience these difficulties grow up in environments with caregivers who are not equipped to teach them to manage internal distress and inconsistently respond to expressions of emotion, leading to increased distress and a sense of lacking control. Additionally, experiences of abuse, trauma, and household dysfunction are problematic, as children may not be taught adaptive coping strategies and instead, learn to engage in maladaptive behaviors, such as aggression. These experiences are also theorized to be significantly impacted by gender, as responsiveness to emotional and behavioral dysregulation vary between males and females (Stinson, Sales, \& Becker, 2008) and may explain differences in selection of both adaptive and maladaptive regulatory strategies. 
Deficits in adaptive regulatory skills often result in problems with self-control and an impaired impulse regulation (Stinson, Sales, \& Becker, 2008). Not surprisingly, these problems are similarly common in the general offending and substance using populations, as they experience difficulties with considering long-term consequences and delaying gratification. People utilize varied self-regulatory techniques depending on the setting and situational circumstances, and maladaptive self-regulatory strategies can include a wide range of conduct including aggression toward self or others, substance use, impulsivity, delinquency, risky sexual or sexually abusive behavior, and gambling (Stinson, Sales, \& Becker, 2008). Thus, a strength of this theoretical approach is that although it was conceptualized as an etiological theory of sexual offending, it accounts for versatility in offending behaviors, as people who engage in sexually abusive behavior often participate in a wide range of criminal and impulsive behavior.

While the multimodal self-regulation theory considers an assortment of problem behaviors, it primarily explains why some individuals engage in sexually inappropriate or deviant behavior versus alternate strategies. The authors propose that during sexual development, sexual arousal may become associated with a reduction in internal or interpersonal distress, and subsequently, individuals learn that sexual gratification and even sexually inappropriate behavior are stronger self-regulatory strategies than available or ineffective alternatives. The behavior may be reinforced consistently over time, and there are likely inadequate efforts to correct this learned association and subsequent behavior, as a great deal of sexual fantasy and behavior remains private (Stinson, Sales, \& Becker, 2008). Additionally, certain personality traits and "offense-supportive cognitive beliefs" serve as mediating variables in this theoretical model and support the development and maintenance of sexually abusive behavior as a self-regulatory strategy (Stinson, Sales, \& Becker, 2008). Some of these factors include limited empathy, 
sensation seeking, impulsivity, a sense of entitlement, feelings of resentment, and irresponsibility (Stinson, Sales, \& Becker, 2008). Certain cognitive beliefs may also result from inappropriate sexual activity in one's home of origin that leads to non-normative sexual behavior (e.g., sexual behavior between children and adults, lack of sexual boundaries) being normalized.

Although the multimodal self-regulation theory of sexual offending is relatively new, there is empirical support of the theorized association between self-regulatory deficits and maladaptive behavior including self-harm and suicidality in a sample of forensic psychiatric inpatients (Stinson, Robbins, \& Crow, 2011), as well as general offending and sexual offending behavior in a sample of civilly committed sexually violent persons (Stinson, Becker, \& Sales, 2008). More specifically, emotional dysregulation was a shared predictor of both sexual deviance and antisocial behaviors in the latter study. Additional research is needed to further clarify the link between early adversity, self-regulatory difficulties, and patterns of nonsexual and sexual offending behavior. Additionally, it may be beneficial to examine other factors indicative of environmental dysfunction that have long been linked to problem behavior including poverty, child welfare involvement, or social disorganization. There is also a need for further investigation of the impact of early developmental adversity and self-regulation difficulties within a shorter time frame of the onset of sexually abusive behavior. Investigating the shortterm effects on behavior, cognition, and emotion during the adolescent developmental stage may provide insight into how these impairments lead to long-term patterns of nonsexual and sexual offending behaviors.

\section{Adverse Childhood Experiences}

The Centers for Disease Control and Prevention (CDC) alongside Kaiser Permanente initiated the ACE Study in the 1990s in an effort to clarify the link between early developmental 
adversity and adult health. This original ACE survey research lead to the development of a 10item index to assess exposure before the age of 18 to three types of abuse (emotional, physical, and sexual), two types of neglect (emotional and physical/medical), and five indicators of household dysfunction (caregiver mental illness, caregiver substance use, caregiver divorce, caregiver incarceration, and domestic violence towards the respondent's mother; Felitti et al., 1998). An endorsement of each of these ten items results in one point added to a total ACE score, ranging from zero to 10 , with higher scores indicating exposure to more types of adversity and cumulative trauma. Research using the ACE survey items has confirmed a dose-responsive relationship between higher ACE scores and significant physical and mental health concerns and maladaptive behaviors later in life (CDC, 2016b; Felitti et al., 1998). Exposure to ACEs is similarly correlated with a greater likelihood of engaging in aggressive, delinquent, and criminal conduct (Mersky et al., 2012; Widom \& Maxfield, 2001) as well as sexually abusive behaviors (Levenson, Willis, \& Prescott, 2014; Reavis et al., 2013).

Exposure to one ACE increases the chance of additional ACE exposure, as ACEs are often interrelated (Baglivio \& Epps, 2016; Dong et al., 2004). This is particularly problematic due to the cumulative relationship between childhood adversity and the risk for negative outcomes (e.g., Felitti et al., 1998; Merrick et al., 2017). For instance, Felitti and colleagues (1998) reported that adults in the community who reported exposure to four or more ACEs were in a "high risk group" and at four to 12 times greater risk for poor outcomes, including substance use, suicide attempts, and other health risk behaviors. Likewise, in a sample of juvenile-justice involved adolescents, Fox and colleagues (2015) found that with each additional ACE exposure, the risk for becoming a serious, violent, and chronic juvenile offender increased by a magnitude of 35\%. Higher ACE scores were also correlated with more arrests for nonsexual crimes, violent 
or forceful sexual offending, and contact sexual offending in adults with sex offending histories (Levenson et al., 2014). While relatively few respondents living in the community report exposure to four or more ACEs (9\% of males; CDC, 2016c), a large proportion of criminal offending male adult (48\%; Reavis et al., 2013), sex offending male adult (46\%; Levenson et al., 2014), justice-involved male juveniles ( 47\%; Baglivio et al., 2014), and sexually abusive adolescent male treatment (76\%; Hall, Stinson, \& Moser, 2018) populations fall within this highest risk group. These findings support the consideration of childhood maltreatment in determining risk and more effective intervention strategies.

Presently, the ACE literature is largely dominated by studies of adults living in the community, and investigations into the prevalence of ACEs and later functioning in forensic samples, including juvenile justice-involved youth, are scarce. While examining long term outcomes in adulthood is important, studies of adolescents can provide insight into the mechanisms responsible for the association between developmental adversity and functional trajectories associated with criminality and sexually abusive behavior. Recent evidence also suggests that other factors must be considered when investigating these relationships, as the impact of ACEs on outcomes are often exacerbated by additional environmental elements. Potential environmental considerations include supplemental indicators of household dysfunction, such as having a history of foster care placements (Stinson, Quinn, \& Levenson, 2016) and instability in out-of-home placements (Hall et al., 2018). Community and neighborhood features like socioeconomic status (Finkelhor et al., 2013; Finkelhor, Shattuck, Turner, \& Hamby, 2015; Font \& Maguire-Jack, 2015), exposure and proximity to community violence (Finkelor et al., 2013; Osofsky, 1997), and peer victimization and/or rejection (Finkelhor et al., 2013; Johnson et al., 2002) have similarly demonstrated importance while 
examining the effects of ACE exposure. A meta-analysis of the effects of exposure to community violence have also revealed that age, gender, ethnicity, proximity in relationship to victims of witnessed violence, and length of violence exposure influence symptoms of psychopathology and severity of aggression and other maladaptive behaviors (Fowler, Tompsett, Braciszewski, Jacques-Tiura, \& Baltes, 2009). For individuals who engage in sexually abusive behaviors in particular, other early developmental experiences, such as early and persistent exposure to sexual activity between others and to pornography, have been supported as relevant risk factors in previous research (Beauregard, Lussier, \& Proulx, 2004; Seto \& Lalumiére, 2010; Seto, Maric, \& Barbaree, 2001). Thus, there are several additional components of the environment that are not adequately accounted for within ACE survey methodology that may account for variation in outcomes in high risk populations.

Therefore, while the ACE literature has been beneficial in demonstrating a link between the cumulative nature of childhood adversity and poor long-term outcomes, there is little evidence to differentiate ACE exposure and patterns of criminal and/or sexual behavior amongst high risk forensic samples. Few studies have attempted to disentangle the effects of various types of violence exposure, such as violence in the community versus within the home, and how differences in experiences of adversity influence disparate conduits to violence, delinquency, and sexually abusive behavior. Further study into how ACEs and other relevant factors simultaneously influence the course of delinquent and sexually abusive behavior are necessary and can benefit the development of early interventions that aim to disrupt pathways to criminality and sex offending behavior. 


\section{Environmental and Community Context}

Characteristics of the community or neighborhood in which one lives have been found to substantially influence early development and the onset of behavioral concerns (Jutte, Miller, \& Erickson, 2015; Leventhal \& Brooks-Gunn, 2011). Both exposure to community violence and community economic adversity have been identified as factors associated with poor outcomes among youth (Finkelhor, Shattuck, et al., 2015; Jutte et al., 2015; Tolan, 2016). A third community variable, rurality, has similarly been noted in the criminological research as deserving of consideration in clarifying pathways to criminality and sexually abusive behavior (Braithwaite, 2015; Kaylen \& Pridemore, 2013; Osgood \& Chambers, 2000). Thus, these three community-level factors - community violence, economic adversity, and rurality - will be reviewed in the context of how they interact with individual-level adversity to influence pathways to delinquent and sexual offending.

Community violence. Emerging evidence suggests that residing in neighborhoods with high rates of violence, and subsequently being at greater risk of witnessing violence or knowing victims of violent acts, can negatively impact development (Tolan, 2016). The magnitude is significant - community violence exposure has been associated with several negative outcomes, including symptoms of posttraumatic stress disorder (PTSD) and depression, antisocial behavior, aggression, involvement in the criminal justice system, and poor academic performance (Overstreet, 2000; Tolan, 2016). These consequences are particularly concerning considering the pervasiveness of community violence in the United States (U.S.). In the most recent National Survey of Children's Exposure to Violence, conducted in 2014, more than one third of children surveyed (38.3\%) reported witnessing interpersonal violence previously (Finkelhor, Turner, Shattuck, \& Hamby, 2015). Furthermore, community violence exposure was exceptionally 
prevalent in this sample (27.7\%), with males (30.5\%) and adolescents (ages $14-17 ; 57.9 \%$ ) witnessing community violence most frequently (Finkelhor, Turner, et al., 2015). Socioeconomic status and race also contribute to differences in community violence exposure (Garbarino \& Kostelny, 1997). Ethnic minorities are more likely to be exposed to community violence, which is likely related to greater likelihood of residing in intercity neighborhoods characterized by persistent poverty, higher rates of violence rates, and disproportionate gun violence (Garbarino \& Kostelny, 1997; Tolan, 2016).

Witnessing community violence is often an additional traumatic experience for children already vulnerable to direct abuse, neglect, or household dysfunction in their home of origin, contributing to additional cumulative effects of ACEs (Garbarino \& Kostelny, 1997). For example, Zimmerman and Posick (2016) found that Chicago youth who experienced direct victimization were very likely to experience indirect violence also, and that the cumulative effects of violence were stronger predictors than type of violence exposure on suicidality, substance use, and criminal offending. Finkelhor and colleagues (2013) reported that adding exposure to community violence to the ten original ACE items statistically improved the model predicting mental health symptoms. In contrast, however, a study by Fleckman and colleagues (2016) suggested possible desensitization to the effects of indirect violence exposure on externalizing problems (e.g., aggression) for youth who routinely experience direct violence by their caregiver. Thus, the unique and compounded effects of varied types of violence exposure have not yet been thoroughly explored, and questions persist (Overstreet, 2000; Tolan, 2016). Furthermore, other characteristics of community violence exposure, such as age of witness, extent of exposure, perception of event, closeness to direct victim and perpetrator, and level of social support following exposure, may also be important considerations when 
investigating its impact (Marans \& Adelman, 1997; Osofsky, 1997; Tolan, 2016). For example, family support and cohesion have served as protective or buffering variables for children who witness community violence (Overstreet, 2000; Tolan, 2016). Additional research is needed to clarify the interactional effects of varied characteristics of exposure to community violence in populations disproportionately impacted by direct violence victimization in the context of additional family and environmental factors.

Economic adversity. According to the U.S. Census Bureau, in 2015, 43.1 million people in the U.S., or $13.5 \%$ of the total population, were living in poverty, including 14.5 million children (Proctor, Semega, \& Kollar, 2016). Black Americans had the highest poverty rates (24.1\%) compared to non-Hispanic White Americans (9.1\%), Asian Americans (11.4\%), and Hispanic Americans (21.4\%). More than a quarter of Americans aged 25 and older who have not obtained their high school diploma, and approximately $12.9 \%$ of those with a high school degree who do not go on to college, live below the poverty line. Indicators of economic adversity, such as poverty, low socioeconomic status, and low income, have been routinely associated with behavioral concerns and negative psychological, social, and physical health but are not captured in the original ACE survey research (Finkelhor, Shattuck, et al., 2015; Wadsworth, Evans, Grant, Carter, \& Duffy, 2016). More specifically, economic adversity has been linked to symptoms of psychopathology (e.g., anxiety, depression; PTSD; Finkelhor et al., 2013), lower academic achievement (Nikulina, Widom, \& Czaja, 2011), chronic conduct problems (Schonberg \& Shaw, 2007), and being arrested (Nikulina et al., 2011), all of which can exacerbate already perilous situations (Hetling \& Zhang, 2010). With regard to sexual offenses, Braithwaite (2015) found that resource disadvantage - measured as an aggregate of poverty level, family disruption, low educational achievement, and unemployment - explained a significant variation in sexual offense 
rates in urban and urbanizing communities. Hence, economic adversity is a public health concern that impacts millions of U.S. residents each year and has a wide range of consequences.

Various terms have been used to describe economic adversity at the individual-, family-, school-, and community levels. It is important to clarify the use of these terms, as they are measured differently across data sources; however, findings are generally consistent in identifying poor outcomes regardless of the definition used for economic hardship or disadvantage (Wadsworth et al., 2016). Poverty describes when a family's before-tax income falls lower than a specific threshold identified annually by the U.S. government based on the number of adults and children included in the family (U.S. Census Bureau, 2014). Similarly, community or neighborhood poverty is commonly represented by calculating the percentage of residents in a given area that live below the poverty threshold, with $30-40 \%$ generally indicating high-poverty neighborhoods (Levanthal \& Brooks-Gunn, 2011; Wadsworth et al., 2016).

Measuring multiple indicators of a neighborhood's quality (e.g., percentage of unemployed adults, percentage of female-headed households, high school drop-out rate, percentage on public assistance programs, residential stability) has been superior in depicting neighborhood-level poverty and economic disadvantage in prior studies (Braithwaite, 2015; Nikulina et al., 2011; Wadsworth et al., 2016). An argument in support of using multiple indicators of economic disadvantage is that simple measures of poverty often underestimate the actual expenses of families, such as clothing, utilities, and housing costs, as well as representations of community-level disadvantage (e.g., lack of resources and facilities; Roux, 2003; Wadsworth et al., 2016). For this reason, the current study will utilize the term economic adversity to refer to multiple community factors suggestive of economic disadvantage in an area, such as proportion of single-parent families, unemployment, declines in job opportunities, low 
wages, low household income, residential instability, and use of social welfare programs (Weatherburn \& Schnepel, 2015).

Economic adversity has several individual-, familial-, and community-level mechanisms through which it influences development in children (Wadsworth et al., 2016). First, children who experience economic adversity may be affected by hunger, toxin exposures, and other types of environmental and physical neglect - all of which can impede physical growth and cause cognitive and physical and mental health problems (Evans, 2004). Additionally, while individual indicators of economic adversity have detrimental effects on health and well-being, communitylevel poverty contributes an additional component to developmental adversity and uniquely contributes to unwanted physical and mental health, social, and behavioral outcomes in youth (Jutte et al., 2015; Leventhal \& Brooks-Gunn, 2011). For example, individuals in high poverty neighborhoods may have less access to healthcare and pharmaceutical resources, which can exacerbate existing health concerns. From this perspective, a multilevel approach to measuring economic adversity would be beneficial, as average income in an area may be more representative of the resources available in an area (e.g. recreational facilities, school resources, healthcare services) compared to individual income measures (Roux, 2003).

Second, economic hardship is a risk factor for additional exposures to abuse, family disruption, family violence, and substance use (Wadsworth et al., 2008; Wadsworth et al., 2016). To further illustrate potential interactions between community-level economic and individuallevel adversities, communities with higher levels of poverty and socioeconomic disadvantage and inequality are associated with higher ACE scores in juvenile justice-involved youth, providing support for the argument that area-level economic disadvantage can influence ACE exposure (Baglivio et al., 2017). Furthermore, these children are simultaneously less likely to 
have known protective factors to counteract developmental adversity, such as enriching school atmospheres, warm parenting, and prosocial peers (Wadsworth et al., 2016). In summary, economic adversity is associated with a wide range of negative consequences and is considered to be an important factor in identifying causal pathways to negative outcomes (Braithwaite, 2015; Finkelhor, Shattuck, et al., 2015; Jutte et al., 2015).

Rurality. Nearly 65 million Americans, or $21 \%$ of the total population, reside in rural or small town communities (Housing Assistance Council, 2012), yet there is little empirical evidence regarding the role of community size in the etiology of delinquency and sexually abusive behavior (Braithwaite, 2015). The prevailing literature on these topics is largely dominated by investigations in urban areas with few studies assessing intercommunity variations and rurality (Berg \& DeLisi, 2005; Braithwaite, 2015; Osgood \& Chambers, 2000). One major methodological concern is that criminal behavior, particularly sexual and domestic violence, is believed to be drastically underreported in rural communities due to cultural norms supportive of informal social controls versus official interventions, victim-offender familiarity, and a general mistrust of "outsiders" (i.e., government agencies, researchers) collecting information, such as national survey data (Bouffard \& Muftic, 2006; Braithwaite, 2015; Cordner, 2013; Lewis, 2008; Ruback, 1993). Despite this limitation, from available data, the prevalence, nature, and environmental responsiveness to nonsexual and sexual criminal offending appear to be generally inconsistent with what is known in rural communities (Braithwaite, 2015; Deller \& Deller, 2011; Ruback \& Menard, 2001).

Differential structural antecedents have been proposed as causal mechanisms of crime in rural versus non-rural communities due to discrepancies in spatial organization, social structure, cultural norms, and racial heterogeneity (Kaylen \& Pridemore, 2013; Osgood \& Chambers, 
2000). For example, rural residents may live a substantial difference from their nearest neighbors, which could influence social interactions and community cohesion (Kaylen \& Pridemore, 2013). Racial heterogeneity is also scarcer in rural areas, and so measures of diversity may not be strong predictors of rural crime (Kaylen \& Pridemore, 2013). Braithwaite (2015) similarly demonstrated that differential structural mechanisms preceding various types of sexual violence across urban and rural areas, such as resource disadvantage (i.e., poverty, disruption in family, low educational achievement, unemployment) were strong predictors of within-home sexual offenses in urban and urbanizing communities but not in rural communities. Additionally, Braithwaite found that indicators of social disorganization only influenced sexual violence occurring outside of the home in rural and urbanizing areas, whereas the opposite was found true for urban and urbanizing areas. It is relevant to note that Braithwaite's findings contrast with previously reported associations between resource disadvantage and rural general violent crime (Barnett \& Mencken, 2002; Braithwaite, 2015), which further supports potential discrepancies in pathways between general violent and sexual offending in rural settings.

There are several factors (e.g., poverty rates, housing practices, resource availability, cultural norms, environmental responsiveness to crime) that may differentiate the influence of early developmental adversity in rural versus non-rural communities, and multilevel investigations permit consideration of individual experiences within the context of rurality. First, rural locales are disproportionately affected by poverty due to fewer job opportunities, reduced income, and lower educational achievement (Annan, 2008; Gallup-Black, 2004; Lewis, 2008). According to the U.S. Department of Agriculture (USDA; 2013), communities classified as nonmetropolitan had a poverty rate of $17.7 \%$ in 2012 versus $14.5 \%$ in metropolitan areas. As 
previously discussed, poverty has substantial effects on development and pathways to criminal and sexually abusive behavior.

A second factor related to poverty rates is homelessness, which is represented differently in rural compared to urban communities (Wodahl, 2006). Rural homelessness is often referred to as "hidden homelessness" and is usually characterized by individuals and families staying with family members or friends temporarily, residing in overcrowded or substandard homes, or sleeping in tents or abandoned vehicles (Shamblin, Williams, \& Bellaw, 2012). Overcrowding and extended family members residing in the home may lead to more chaos, family disruption, and even abuse in the home. Moreover, urban measures of residential stability may not adequately account for rural homelessness and residential movements of this nature. As a result, rural homelessness is believed to be grossly underreported due to studies measuring rural and urban homelessness in the same manner (Wodahl, 2006).

Third, rural areas have considerably fewer formal services for victims, perpetrators, and families affected by violence compared to urban communities, including medical and mental health providers, crisis services, youth programs, and emergency shelters (e.g., Belanger \& Stone, 2008; Gamm, Stone, \& Pittman, 2010; Peek-Asa et al., 2011). To illustrate, Belanger and Stone (2008) reported that one-fourth of rural counties surveyed did not have family preservation and domestic violence services, financial or budgeting assistance emergency services, and afterschool programs for youth - all services that are available in more than two-thirds of urban counties surveyed. One contributing systemic factor is that rural counties have fewer financial resources and a smaller tax base to fund law enforcement, social service, child welfare, and healthcare agencies (Cebulak, 2004). Rural residents also commonly have difficulty accessing services due to long travel distances to receive services, limited income, insufficient health 
insurance, and fear of stigma for help-seeking in certain areas (Averill, Padilla, \& Clements, 2007; Bruley, Hatfield, \& Markel, 2012; Lanier \& Maume, 2009).

Fourth, rural cultural factors also influence efforts to address violence and the provision of social services, law enforcement, and healthcare (Lewis, 2008; McCall-Hosenfeld, Weisman, Perry, Hillemeier, \& Chuang, 2014; Wodahl, 2006). For example, firearms are more prevalent and generally accepted culturally in rural settings, increasing the risk of violent confrontations or other acts of violence (Averill et al., 2007). Ruback, Shaffer, and Clark (2011) similarly found that among adolescents, being White, male, and residing in rural neighborhoods increased the likelihood of having easy access to guns, and that easy access to firearms was associated with higher rates of both violence perpetration and victimization. Interestingly, youth living in a twoparent household and those whose parents scored as above the median on a measure of socioeconomic status were more likely to report having easy access to firearms (Ruback et al., 2011). Thus, male adolescents routinely report having easy access to firearms, especially in rural communities, and accessibility can be linked to greater risk of violence perpetration and victimization.

Gender norms common in many rural towns that tend to favor patriarchy and masculinity may also contribute to difficulties in help-seeking and intervention efforts for victims of family and sexual violence, as some community members may view these occurrences as a "family matter" or normative corrective behaviors (Anderson, Renner, \& Bloom, 2013). For instance, in a study investigating the legal handling of rural domestic violence cases, Bruley and colleagues (2012) found that cases in which perpetrators requested jury trials in rural courts were more likely to be dropped than cases against perpetrators who did not request a jury trial. The authors propose that the prosecutor's decision to drop these cases may be related to funding and resource 
limitations, as well as cultural factors that support familial and other informal interventions in response to familial violence. Responsiveness to juvenile offending also appears to be influenced by the size of the community in which the offender resides. For example, juveniles arrested in large cities (64\%) were less likely to be referred to juvenile court than juveniles arrested in moderate-size (74\%) and small cities (68\%; Sickmund \& Puzzanchera, 2014). This finding is likely related to smaller communities arresting fewer juveniles overall, saving formal interventions for the most serious criminal acts, and lower reporting rates. In sum, rural areas have structural characteristics that differ drastically from urban settings, and rurality is an important environmental consideration when investigating individual- and community-level indicators of delinquent and sexually abusive behaviors.

\section{Present Study}

The available ACE literature demonstrates a strong association between childhood adversity and poor long-term outcomes, including a greater likelihood of engaging in delinquent, criminal, and sexual offending behavior. Further, the consideration of the cumulative nature of developmental adversity, including individual experiences and community factors when examining causal pathways to nonsexual and sexual offending behaviors, has been well-justified in previous empirical investigation (Baglivio et al., 2017; Finkelhor et al., 2013; Maguire-Jack \& Font, 2017). Nonetheless, further clarification on how differential exposure to adversities influences the onset and nature of nonsexual delinquent and sexually abusive behavior is necessary. Additionally, factors, such as early introduction to sexual activity between others and pornography, have not been fully explored in the context of ACE methodology. Presently, there are also few studies that investigate inter-community variation in structural factors preceding sexual offending (e.g., rural versus non-rural; Braithwaite, 2015). Continued study of the 
interrelatedness of early psychosocial experiences and nonsexual and sexual offending across varied communities may highlight important considerations for targeted practices that balance community safety with therapeutic responsiveness to perpetrators. Therefore, the purpose of the current study is to examine the impact of (1) exposures to individual adverse experiences and sexual boundary problems within the home and (2) community factors, including social and economic factors, size of the community, and proximity to resources on the development of delinquent and sexually abusive behavior in a sample of male adolescents who have engaged in sexually abusive behavior.

\section{Hypotheses}

This study examined the influences of individual adverse experiences and exposure to community adversities on delinquent nonsexual and sexually abusive behaviors through structural equation modeling (SEM). The following is hypothesized:

1) Confirmatory factor analysis (CFA) will confirm a three-factor model for individual experiences of adversity including: one factor consisting of emotional and physical abuse and neglect; a second factor representing household dysfunction; and, a third factor consisting of sexual abuse and more passive indicators of sexual boundary problems in the home.

2) Individual exposures to emotional and physical abuse, neglect, and household dysfunction will directly influence the onset, seriousness, and persistence of nonsexual delinquent behaviors.

3) Exposures to nonsexual abuse, neglect, and household dysfunction will directly influence the onset, nature, and persistence of sexually abusive behaviors. Further, sexual abuse and exposure to sexual boundary problems in the home will have a 
direct influence on early onset, persistent, and more severe sexually abusive behavior, in particular.

4) Social and economic characteristics and rurality of county of origin will moderate the relationship between individual exposures to adversities and nonsexual delinquent and sexually abusive behaviors. 


\section{CHAPTER 2}

\section{METHODS}

\section{Procedures}

Data for the present study originate from two sources. First, the faculty primary investigator and trained graduate and undergraduate research assistants collected data from archival records at a private non-profit facility in rural southern Appalachia that provides residential and intensive outpatient treatment to adolescents who have engaged in sexually abusive behaviors. Files were reviewed for all male adolescents who received residential and/or outpatient treatment at the facility since its opening in 2003 and who were discharged prior to the commencement of data collection in September 2014. Content of available records was mixed, but the majority included information describing medical needs, psychiatric diagnoses, medications, histories of trauma and maltreatment, prior out-of-home placements, arrest history, sexual behavioral problems, location of origin, and assessments of treatment progress. The East Tennessee State University Medical Institutional Review Board and the Board of Directors of the participating treatment facility approved all data collection procedures.

Second, county-level secondary data were obtained from the County Health Rankings \& Roadmaps (CHR\&R) program, which is publicly available data produced by the University of Wisconsin Population Health Institute (2017) in collaboration with the Robert Wood Johnson Foundation. The CHR\&R data has been published annually since 2010 and includes county-level markers of overall health and various factors that impact the health of counties grouped into four categories: physical environment, social and economic factors, clinical care, and health behaviors (University of Wisconsin Population Health Institute, 2017). Weighted composite scores for each category are calculated using data from a variety of sources and z-scores are produced as a 
method of comparing counties in each state. For this study, only the social and economic factor composite score was considered to represent economic and social environment. Additionally, the percentage of each county considered rural were also retained from the CHR\&R program data. These data were downloaded from the CHR\&R website by state, delineated by county using Federal Information Processing Standard (FIPS) codes.

\section{Sample Characteristics of Primary Data}

The sample $(N=285)$ is $83.5 \%$ Caucasian, $9.8 \%$ African American, $4.6 \%$ mixed race, and $2.1 \%$ unspecified or another ethnicity. The sample has a mean age of 14.81 years $(S D=1.55$, Range: $10-17)$ at time of first admission into the facility. The majority were referred to the facility by the child welfare department (68.4\%), with the remaining mandated by court representatives $(21.4 \%)$, or referred by mental health providers $(4.6 \%)$, parents or guardians $(3.5 \%)$, or other referral sources $(2.1 \%)$, such as, insurance representatives. Facility referrals were often made as a form of diversion from formal legal sanctions through the family and juvenile court system. Most of the adolescents only experienced one admission to the facility (89.1\%), while $9.8 \%$ had two admissions and a small percentage of the sample $(1.1 \%)$ had three

to five admissions. The adolescents in the present sample received treatment for sexually abusive behavior for periods ranging from one week to four-and-a-half years $(M=13.19$ months, $S D=$ 9.81).

\section{Measures and Data}

Nonsexual delinquent behaviors. To depict delinquent, nonsexual offense patterns and involvement with the juvenile justice system, data concerning lifetime arrest history were documented and coded into three variables. Lifetime arrest history was operationalized as being charged with a nonsexual violent offense (e.g., aggravated assault, murder), substance-related 
offense (e.g., possession of controlled substance, manufacturing a controlled substance), property offense (e.g., vandalism, burglary), and/or status offense (e.g., truancy, curfew violation). History of having a nonsexual violent offense arrest was coded categorically $(N o=0, Y e s=1)$. Additionally, the total number of nonsexual arrests and if their first nonsexual arrest was before age 14 (i.e., adolescence; $N o=0, Y e s=1$ ) were noted for each subject. Arrest charges, compared to convictions, are commonly used to depict delinquent behavior in the literature (e.g., Cale, Smallbone, Rayment-McHugh, \& Dowling, 2016; Seto \& Lalumiére, 2010), and this approach is theoretically more accurate than using number of convictions due to the significant discretion used in sentencing practices in juvenile courts (Cale et al., 2016). Furthermore, during data collection, it was discovered that treatment was often employed as a diversionary program.

Sexually abusive behaviors. Sexually abusive behaviors were coded using parameters commonly used to illustrate the trajectory and nature of sexually abusive behavior, including the onset and course of sexually abusive behavior, as well as characteristics and the seriousness of the behavior (Cale et al., 2016; Lussier, 2015; Seto \& Lalumiére, 2010). This included instances where the participants engaged in behaviors that were considered developmentally inappropriate and harmful, as well as sexual offenses as codified by state statute. The onset, nature, and seriousness of sexually abusive behavior was operationalized using three variables including: early onset (age at first documented sexually abusive behavior); noncontact versus contact offenses (Noncontact $=0$, Contact $=1)$; and number of sexual offense arrests.

Individual-level explanatory variables. Data regarding exposure to abuse, neglect, household dysfunction, and sexual boundary problems in each participant's home(s) of origin were collected to illustrate individual experiences of developmental adversity. 
ACE questionnaire items. The ACE questionnaire (CDC, 2016b; Felitti et al., 1998) is a 10-item measure that assesses experiences of emotional, physical, and sexual abuse; emotional and physical neglect; and household dysfunction (i.e., domestic violence, divorce or separation, or the presence of a substance-abusing, mentally ill, or incarcerated household family member). For this study, research assistants provided a dichotomous code $($ Absent $=0$, Present $=1)$ for each of the ten items depending on whether the type of adverse experience was documented within the adolescent's file. If no information was given regarding the adversity, then the data were coded as "missing."

Sexual boundary problems. Early exposure to sex or pornography as well as atypical sexual interests have been linked to later sexual offending (Beauregard et al., 2004; Seto \& Lalumiére, 2010; Seto et al., 2001). Thus, in addition to sexual abuse, more passive indicators of sexual boundary problems in the home were examined to determine their relationship with the onset and nature of sexually abusive behavior in this sample. Sexual boundary problem indicators consisted of two dichotomously coded variables $($ Absent $=0$, Present $=1)$ including being introduced to pornography by an adult in one's home of origin and witnessing sexual behaviors or sexual abuse of others in the home (e.g., siblings, caregiver). Age at first exposure to pornography was originally included in the analyses, but this variable was excluded due to the abundance of missing data $(n=119)$.

County-level explanatory variables. As noted, the consideration of community characteristics that may contribute to the onset and nature of delinquent and sexually abusive behavior is essential. For the present study, county-level indicators of social and economic factors as well as rurality were examined based on documented zip code of origin for each subject. 
Social and economic environment. A weighted composite z-score representing countylevel social and economic factors relative to other counties in the state was utilized for the present study (University of Wisconsin Population Health Institute, 2017). The composite score representing county-level social and economic indicators incorporates data regarding education, employment, income, family and social support, and community safety. A significant benefit of this approach is that this weighted composite score incorporates several factors, which likely improves the reliability and validity of the construct being examined. For instance, the literature suggests that economic adversity in a given area is more accurately depicted when multiple indicators are measured (Braithwaite, 2015; Nikulina et al., 2011; Wadsworth et al., 2016). The reader is referred to Table 1 to see the variables that contribute to these z-scores as well as each variables' source, weight, and year collected.

Table 1

Characteristics of County-Level Data Related to Social \& Economic Environment

\begin{tabular}{|c|c|c|c|}
\hline Focus Area/Measure & Data Source & Years & Weight $^{\mathrm{a}}$ \\
\hline \multicolumn{4}{|l|}{ Education } \\
\hline High School Graduation ${ }^{\mathrm{b}}$ & EDFacts & $2014-2015$ & $12.5 \%$ \\
\hline Some college ${ }^{b}$ & American Community Survey & $2011-2015$ & $12.5 \%$ \\
\hline \multicolumn{4}{|l|}{ Employment } \\
\hline Unemployment & Bureau of Labor Statistics & 2015 & $25 \%$ \\
\hline \multicolumn{4}{|l|}{ Income } \\
\hline Children in poverty & $\begin{array}{l}\text { Small Area Income \& Poverty } \\
\text { Estimates }\end{array}$ & 2015 & $18.75 \%$ \\
\hline Income inequality & American Community Survey & $2011-2015$ & $6.25 \%$ \\
\hline \multicolumn{4}{|l|}{ Family \& Social Support } \\
\hline Children in single-parent households & American Community Survey & $2011-2015$ & $6.25 \%$ \\
\hline Social associations ${ }^{\mathrm{b}}$ & County Business Patterns & 2014 & $6.25 \%$ \\
\hline
\end{tabular}


Table 1 Continued

\begin{tabular}{lccc}
\hline \multicolumn{1}{c}{ Focus Area/Measure } & Data Source & Years & Weight $^{\mathrm{a}}$ \\
\hline Community Safety & & & \\
Violent crime & Uniform Crime Reporting - FBI & $2012-2014$ & $6.25 \%$ \\
Injury deaths & CDC WONDER Mortality Data & $2011-2015$ & $6.25 \%$ \\
\hline
\end{tabular}

Note. ${ }^{\text {a}}$ Weights recommend relative importance of the different measures and are applied to each zscore to contribute to overall weighted composite score (University of Wisconsin Population Health Institute, 2017). ${ }^{\mathrm{b}}$ These measures are reverse coded prior to computation of composite score by multiplying the $\mathrm{Z}$-scores for these measures by -1 .

Rurality. Rural-specific research is limited by fluctuating definitions of rural areas and changes in classifying and describing areas by size (Belanger \& Stone, 2008). Many experts warn against relying on definitions of rurality that only use population counts, as these measures are theorized to not adequately illustrate effects of rural-specific challenges, such as, limited accessibility to healthcare, law enforcement, and social service programs. This study utilized data from the CHR\&R program indicating the percentage of each county considered rural in the 2010 U.S. Census Population Estimates (University of Wisconsin Population Health Institute, 2017). According to the U.S. Census Bureau (2017), statistical areas are grouped into Census Blocks and classified as Urban or Rural. Census Blocks are defined as "statistical areas bounded by visible features, such as streets, roads, streams, and railroad tracks, and by nonvisible boundaries, such as selected property lines and city, township, school district, and county limits and short line-of-sight extensions of streets and roads" (U.S. Census Bureau, 2017). Counties are made up of a varying number of Census Blocks. This study utilized the percentage of Census Blocks in each county that are considered "rural" as an interval, continuous between county variable. Although the U.S. Census Bureau definitions for rurality relies largely on population density, this measure also incorporates the use of land and extent of structural development in an area to inform classification (Ratcliffe, Burd, Holder, \& Fields, 2016). Therefore, the U.S. 
Census Bureau's measure of percentage of rurality in a given county was utilized for the present study due to consideration of structural and land development and the interval nature of the data, which permits further distinction of variance within the larger county of measurement, compared to categorical approaches.

\section{Data Analytic Strategy}

SEM was used to measure the direct effects of ACE exposure and county-level characteristics on several indicators of delinquent and sexually abusive behaviors.

Model specification. Testing the hypothesized hybrid SEM consisted of four processes. First, a measurement model was tested for the purpose of CFA for indicators of individual adverse experiences and exposure to sexual behaviors in their home of origin. This model is referred to as the "measurement model". For the measurement model, a three-factor model was hypothesized with Factor 1 including emotional abuse, physical abuse, and neglect; Factor 2 consisting of five indicators of household dysfunction (IPV in home and caregiver with mental illness, substance use concern, or history of incarceration); and, Factor 3 including sexual abuse, witnessing sexual behaviors between others in the home, and exposure to pornography by adult in the home of origin. A previous factor analysis of data on 11 ACEs included on the Behavioral Risk Factor Surveillance System (BRFSS) survey revealed a three-factor modeling consisting of household dysfunction, emotional/physical abuse, and sexual abuse (Ford et al., 2014). This factor model was used to guide the CFA but modified due to differences in available survey items and focus of study. Specifically, there are 11 BRFSS ACE module items: emotional and physical abuse; three indicators of sexual abuse; caregiver separation/divorce; incarcerated family member; household physical violence, mental illness, alcohol abuse, and substance use (CDC, 2016a). Therefore, neglect, which is not included on BRFSS ACE module, was theorized 
as being more consistent with nonsexual abuse experiences as a type of child maltreatment. Additionally, sexual abuse was theorized as factoring with more passive indicators of sexual behavior problems due to the commonality across these experiences in the present sample as well as the statistical assumptions necessary for SEM including the necessity of three or more observed variables for each latent variable to improve reliability (Kline, 2016).

After obtaining a good-fitting measurement model, initial individual-level structural models including the individual ACE exposures and exposure to sexual boundary problems were then tested. All pathways, both non-significant and significant, were retained for these final models because of the theoretical basis for their inclusions in the models; specifically, the interrelatedness of ACEs and impact of cumulative adversity on the likelihood of problematic behaviors (e.g., Fox et al., 2015; Levenson et al., 2014). For clarification purposes, the initial models incorporating individual exposures to ACEs and nonsexual delinquent and sexually abusive behaviors will be referred to as "individual exposures models".

Although the original design planned to employ multilevel SEM analyses to measure the moderated effects of county-level characteristics on the relationships between ACE exposure and delinquent and sexually abusive behaviors, preliminary review of the data showed that nearly half $(n=30 ; 46.2 \%)$ of the total clusters of data (i.e., counties of origin; $N=65)$ consisted of only one participant, which cannot be analyzed and interpreted due to lack of representation and generalizability to the total cluster population. Therefore, using multilevel SEM to investigate individual- and between-cluster variations amongst ACEs, socioecological influences, and delinquent and sexually abusive behaviors was statistically implausible for this study. Instead, a more exploratory approach was taken by examining correlations between outcome behaviors and two variables representing county-level characteristics (social/economic environment and rural 
origin). If correlations were significant, the specific county-level characteristic(s) were retained into modified individual exposures models as covariates to control for possible initial inequalities among participants. Nonsignificant pathways from the initial individual exposures models were not retained in the final modified exploratory models for the purposes of simplification and parsimony. The models incorporating both individual exposures and county characteristics as covariates will be referred to as "modified exploratory models".

Finally, alternative models for individual ACE and sexual boundary problems exposures variables were tested. This last step was necessary because the initial individual-level models hypothesized were theoretically based, but due to the cross-sectional nature of available data, directionality cannot be confirmed. Thus, these alternative structural models, referred to as "alternative models", were tested in accordance with SEM guidelines to rule out alternative theories for the individual indicators of nonsexual delinquent and sexually abusive behaviors (Weston \& Gore, 2006).

Data preparation. Preliminary examination of the data, using SPSS, Version 24.0 (IBM Corp, 2016) revealed some instances of missing data. Five cases were removed from the original sample $(N=290)$ because of significant amount of missing data due to limited information available in these individuals' records. Because these data did not appear to be missing at random (i.e., cases who did not receive treatment at facility), these five cases were removed from analyses to prevent biased parameter estimates (Allison, 2003), resulting in a final sample size of 285 for the measurement, individual exposures, and alternative models. Within the final sample, data were missing at random for zero to 22 cases, depending on the variable, with county-level characteristics being the most frequent missing data points. 
The remaining missing data were addressed in two ways in Mplus, depending on the type of variable in question. Full information maximum likelihood (FIML) for missing data is unavailable in Mplus when employing the mean- and variance-adjusted weighted least squares (WLSMV) estimation method. Instead, in WLSMV estimation, missing data for is addressed using a pairwise deletion process that incorporates as much available information as possible (Asparouhov \& Muthén, 2010). More specifically, WLSMV estimates parameters, chi-square statistic, and standard errors using various portions of the weight matrix (Liang \& Yang, 2014). WLSMV has demonstrated excellence in producing consistent and unbiased estimates compared to listwise deletion strategies (Asparouhov \& Muthén, 2010). Unfortunately, pairwise deletion is not available for observed covariates, and so the modified exploratory models that incorporated county-level characteristics had a smaller sample size of 263. With regard to the sample size necessary to test the model, guidelines suggest a sample size of at least 200 for SEM models (Weston \& Gore, 2006). However, guidelines also indicate a larger sample size should be used if reliability of measures is low or if measures of a construct are not at least moderately associated with one another. Thus, our sample sizes of $263-285$ are sufficient, particularly with several indicators per latent variable and reliable estimates of variables.

Concerning additional assumptions, review of skewness and kurtosis revealed some slight assumption violations for number of nonsexual and sexual arrests. However, no transformations will be performed as the WLSMV estimation method does not require normal distributions (Kline, 2016). In review of potential multivariate normality assumption violations, a substantially large variance for the variable indicating percentage of rurality in county of origin (556.01) compared to values ranging from 0.06 to 8.72 for the remaining continuous variables was revealed. As noted in Kline (2016), if the ratio between the largest to smallest variance 
among variables is very large (i.e., more than 100), then high or low variables should be transformed and rescaled by multiplying the variable data by a constant to prevent an "ill-scaled covariance matrix" (p. 81). Thus, percentage of rurality was transformed by multiplying the data by a constant of 0.01 , which resulted in a revised variance of 5.56. This variance was acceptable relative to other continuous variables, and so the revised variable was utilized for remaining analyses. To note, this transformation will not affect relationships between variables as it is considered a linear transformation (Kline, 2016).

After preliminary investigation of the data, they were imported into Mplus Version 8.0 (Muthén \& Muthén, 1998-2017b) for the purpose of testing the hypothesized model using SEM. To investigate potential multicollinearity concerns within the variables of interest, the correlation matrix was examined. Mplus provides appropriate correlation estimates depending on the type of variables being compared (Muthén \& Muthén, 1998-2017a). For two binary variables, tetrachoric correlations are preferable to alternate correlational analyses to produce unbiased estimates. For binary and continuous variables, biserial correlations are produced. For correlations between two continuous variables, Pearson correlations are superior. The correlation matrix revealed a large tetrachoric correlation between emotional and physical neglect $\left(r_{\mathrm{t}}=\right.$ 0.943, $p<.001)$, and so a variable representing any instances of neglect $($ Absent $=0$, Present $=1)$ was substituted to prevent problems with multicollinearity. No other multicollinearity issues were found. For the modified exploratory models, county-level covariate variables were retained in the models if significant correlations were revealed. Review of correlations revealed only one significant association between rurality and number of arrests for nonsexual offenses (Pearson's $r=0.121, p<.005)$. Therefore, rurality was the only covariate included in the nonsexual delinquent behavior model. No county-level characteristics were significant for the sexually 
abusive outcomes model, and so no modified exploratory model was estimated. Remaining correlations between variables of interest and associated significance levels are in Table 2.

Table 2

Correlations and Standard Deviations of Input Data

\begin{tabular}{|c|c|c|c|c|c|c|c|c|c|}
\hline Variable & 1 & 2 & 3 & 4 & 5 & 6 & 7 & 8 & 9 \\
\hline 1. Emotional abuse $\mathrm{e}^{\mathrm{a}}$ & 1.00 & & & & & & & & \\
\hline 2. Physical abuse $\mathrm{a}^{\mathrm{a}}$ & $.67 * *$ & 1.00 & & & & & & & \\
\hline 3. Any neglect ${ }^{\mathrm{a}}$ & $.49 * *$ & $.63 * *$ & 1.00 & & & & & & \\
\hline $\begin{array}{l}\text { 4. Caregiver } \\
\text { separation/ divorce }^{\text {a }}\end{array}$ & $.27^{*}$ & $.27 * *$ & .13 & 1.00 & & & & & \\
\hline 5. IPV in Home $\mathrm{a}^{\mathrm{a}}$ & $.44 * *$ & $.63 * *$ & $.43^{* *}$ & $.58 * *$ & 1.00 & & & & \\
\hline $\begin{array}{l}\text { 6. Caregiver substance } \\
\text { use }^{\mathrm{a}}\end{array}$ & $.25 * *$ & $.49 * *$ & $.46^{* *}$ & $.31 * *$ & $.45^{* *}$ & 1.00 & & & \\
\hline $\begin{array}{l}\text { 7. Caregiver mental } \\
\text { illness } \mathrm{s}^{\mathrm{a}}\end{array}$ & $.30 * *$ & $.37 * *$ & $.25^{* *}$ & .20 & $.41 * *$ & $.45^{* *}$ & 1.00 & & \\
\hline $\begin{array}{l}\text { 8. Caregiver } \\
\text { incarceration }^{\mathrm{a}}\end{array}$ & $.36^{* *}$ & $.26^{* *}$ & $.25^{* *}$ & $.31 * *$ & $.37 * *$ & $.56^{* *}$ & $.22 *$ & 1.00 & \\
\hline 9. Sexual abuse ${ }^{a}$ & $.27 * *$ & $.39 * *$ & $.31 * *$ & .14 & $.26^{* *}$ & $.33 * *$ & $.30 * *$ & .16 & 1.00 \\
\hline $\begin{array}{l}\text { 10. Exposure to porn } \\
\text { by adult }\end{array}$ & .19 & .15 & $.23^{*}$ & .11 & .19 & .21 & .15 & -.04 & $.44 * *$ \\
\hline $\begin{array}{l}\text { 11. Witness sex } \\
\text { between others }\end{array}$ & .21 & $.28 *$ & $.40 * *$ & .24 & $.26^{*}$ & $.23 *$ & $.22 *$ & $.20^{*}$ & $.47 * *$ \\
\hline $\begin{array}{l}\text { 12. Early arrest } \\
{\text { (before age } 14)^{d}}^{d}\end{array}$ & .18 & .16 & .05 & $.34 * *$ & .14 & .21 & .13 & $.23^{*}$ & .05 \\
\hline $\begin{array}{l}\text { 13. Nonsexual violent } \\
{\text { offense } \text { arrest }^{\mathrm{a}}}^{\text {a }}\end{array}$ & .18 & .18 & .16 & .11 & .15 & .13 & .13 & $.24 * *$ & -.04 \\
\hline $\begin{array}{l}\text { 14. No. nonsexual } \\
\text { offense arrests }^{\mathrm{a}}\end{array}$ & .09 & .15 & .13 & -.04 & .10 & .16 & .07 & $.27 * *$ & -.06 \\
\hline $\begin{array}{l}15 . \text { Age at } 1^{\text {st }} \text { sexually } \\
\text { abusive behavior }\end{array}$ & -.08 & -.11 & -.12 & $-.35^{* *}$ & -.09 & -.21 & -.18 & -.17 & $-.37 * *$ \\
\hline 16. Contact offense $\mathrm{e}^{\mathrm{e}}$ & .04 & .12 & -.17 & .07 & .14 & -.10 & .01 & $-.28 * *$ & -.03 \\
\hline $\begin{array}{l}\text { 17. No. sexual offense } \\
\text { arrests }^{\text {a }}\end{array}$ & -.09 & -.04 & -.05 & .13 & .03 & .07 & -.05 & -.07 & -.10 \\
\hline $\begin{array}{l}\text { 18. Social/ economic } \\
\text { environment } \mathrm{f}^{\mathrm{f}}\end{array}$ & -.03 & $.16^{*}$ & $.16^{*}$ & -.03 & -.00 & -.11 & -.13 & .04 & .04 \\
\hline 19. Rurality ${ }^{\mathrm{f}}$ & .05 & .14 & .14 & -.13 & .10 & -.08 & -.07 & -.05 & -.05 \\
\hline
\end{tabular}


Table 2 Continued

\begin{tabular}{|c|c|c|c|c|c|c|c|c|c|c|}
\hline Variable & 10 & 11 & 12 & 13 & 14 & 15 & 16 & 17 & 18 & 19 \\
\hline $\begin{array}{l}\text { 10. Exposure to } \\
\text { porn by adult }{ }^{\mathrm{b}}\end{array}$ & 1.00 & & & & & & & & & \\
\hline $\begin{array}{l}\text { 11. Witness sex } \\
\text { between others }\end{array}$ & $.32 * *$ & 1.00 & & & & & & & & \\
\hline $\begin{array}{l}\text { 12. Early arrest } \\
{\text { (before age } 14)^{d}}^{d}\end{array}$ & .12 & .10 & 1.00 & & & & & & & \\
\hline $\begin{array}{l}\text { 13. Nonsexual } \\
\text { violent offense } \\
\text { arrest }^{\mathrm{a}}\end{array}$ & -.03 & .02 & $.63 * *$ & 1.00 & & & & & & \\
\hline $\begin{array}{l}\text { 14. No. nonsexual } \\
\text { offense arrests }^{\mathrm{a}}\end{array}$ & $-.22 * *$ & -.06 & $.49 * *$ & $.66^{* *}$ & 1.00 & & & & & \\
\hline $\begin{array}{l}\text { 15. Age at } 1^{\text {st }} \\
\text { sexually abusive } \\
\text { behavior }^{\mathrm{a}}\end{array}$ & -.21 & -.10 & $-.16^{*}$ & .08 & .10 & 1.00 & & & & \\
\hline $\begin{array}{l}\text { 16. Contact } \\
\text { offense }^{\mathrm{e}}\end{array}$ & .01 & -.17 & .16 & -.21 & -.14 & $-.39 * *$ & 1.00 & & & \\
\hline $\begin{array}{l}\text { 17. No. sexual } \\
\text { offense arrests }\end{array}$ & -.10 & .02 & $.28 * *$ & $.17^{*}$ & $.19 *$ & $.15^{*}$ & $.32 * *$ & 1.00 & & \\
\hline $\begin{array}{l}\text { 18. Social/ } \\
\text { economic } \\
\text { environment }\end{array}$ & .09 & .15 & .09 & -.03 & .04 & -.02 & .11 & -.02 & 1.00 & \\
\hline 19. Rurality ${ }^{\mathrm{f}}$ & .14 & -.09 & .11 & .08 & $.12 *$ & .01 & .06 & -.06 & $.49 * *$ & \\
\hline
\end{tabular}

Note. ${ }^{\mathrm{a}} n=285 ;{ }^{\mathrm{b}} n=267 ;{ }^{\mathrm{c}} n=280 ;{ }^{\mathrm{d}} n=277 .{ }^{\mathrm{e}} n=282 .{ }^{\mathrm{f}} n=263$. Tetrachoric correlations are produced for two binary variables. Biserial correlations are calculated for binary and continuous variables. Pearson correlations are calculated for two continuous variables. ${ }^{*} p<.05 * * p<.01$

Model estimation method. The WLSMV estimation method was used for models because of its superiority for categorical variables (Muthén \& Muthén, 1998-2017a). The WLSMV estimation is considered a robust weighted least squares method (Kline, 2016). For continuous outcome variables, WLSMV estimates simple linear regression coefficients. For binary factor indicators and outcome variables, WLSMV estimates probit regression coefficients. Theta parameterization was utilized for the measurement, individual exposures, and alternative 
models, as it is a superior method with categorical outcome variables that influence and are influenced by latent variables (Muthén \& Muthén, 1998-2017a). More specifically, theta parameterization fixes the residual variance of each latent variable to 1.0 and is consistent with the scaling used in probit regression (Kline, 2016). One factor loading for each latent variable was set at 1.0 to scale the latent variables within the measurement portion of the models (Weston \& Gore, 2006). For the individual exposures and modified model, pathways between the endogenous variables (e.g., arrest histories) were constrained at zero and not free to estimate. This method was chosen to avoid entering additional error into the models through testing unnecessary pathways since the primary goal of the current study was to investigate relationships between individual exposures to adversity and the endogenous maladaptive behavior variables.

Model identification. Model identification was completed for the measurement model, two individual exposures models, one modified exploratory model, and two alternative models due to these models having varied number of observations and parameters. To evaluate model identification, degrees of freedom were calculated by subtracting the number of parameters to be estimated from the number of observations (i.e., observed variables). If the degrees of freedom were greater than zero, then the model can be considered over-identified because the model specifies fewer associations between variables than the number of elements in a correlation matrix (Weston \& Gore, 2006). Over-identified models are preferred, compared to just-identified models with zero degrees of freedom that lead to biased fit interpretations and under-identified models, which necessitate additional information to converge.

According to existing guidelines, observations are calculated by the formula: $v(v+1) / 2$, where $v$ is the number of observed variables (Weston \& Gore, 2006). The number of parameters is calculated by summing the number of directional effects, variances, and covariances (Weston 
\& Gore, 2006). Directional effects consist of all direct effects between indicators and latent variables, referred to as factor loadings, as well as pathways between latent and manifest variables. Estimates of variances, or error associated with observed and latent variables, are also considered in the calculation of parameters. Covariances are nondirectional relationships among exogenous variables.

For the present study, the degrees of freedom for the measurement model was 41, calculated by subtracting 25 parameters from 66 total observations. For the individual exposures models for nonsexual delinquent and sexually abusive behaviors, the degrees of freedom were equal to 68 with 105 observations and 37 parameters. The modified exploratory model for nonsexual delinquent behavior had 85 degrees of freedom with 120 observations and 35 parameters. Degrees of freedom for the alternative models differed slightly from one another due to varied models. In the model for nonsexual delinquent behavior, the degrees of freedom were 70 including 105 observations and 35 parameters. The alternative model for sexually abusive behavior consisted of 105 observations and 34 parameters resulting in 71 degrees of freedom. Because all models have degrees of freedom greater than zero, they are considered overidentified.

Model and parameter interpretation. For overall model fit, the normal model $\chi^{2}$ test statistic cannot be used to compare baseline and hypothesized models when using the WLSMV estimation method (Muthén \& Muthén, 1998-2017a). Instead, a two-step approach comparing the model to a more restrictive baseline model $\left(\mathrm{H}_{0}\right)$ and enforces equality restrictions on the factor variances using the DIFFTEST was used (Muthén \& Muthén, 1998-2017a; Wang \& Wang, 2012). If the resulting $\chi^{2}$ test statistic indicated a model with a significant $p$-value, the 
baseline model was rejected and the hypothesized model was interpreted to be an inadequate fit for the data (Wang \& Wang, 2012).

Next, Bentler's (1990) Comparative Fit Index (CFI) was examined as a measure of incremental fit index with values equal to or greater than 0.95 suggesting a good fit. Root Mean Square Error of Approximation (RMSEA; Steiger, 1990; Steiger \& Lind, 1980) was also utilized with values equal to or less than 0.06 suggesting adequate fit. The Standardized Root Mean Square Residual (SRMR) is not available for categorical outcomes using the WLSMV method. Instead, the Weighted Root-Mean-Square Residual (WRMR; Muthén \& Muthén, 1998-2017a) was used, which is also a measure of the weighted average differences between a sample and the estimated population variances and covariances (Yu \& Muthén, 2002). According to Yu \& Muthén (2002), WRMR values that are less than 1.0 signify a well-fitted model.

To compare model fit between non-nested models, consideration was given to observable discrepancies in model fit indices, significance of pathways, parsimony of model, and theoretical foundation. When using the WLSMV estimation method, it is not possible to compare model fit between non-nested models using traditional statistical significance testing methods (e.g., $\chi^{2}$ difference testing, AIC/BIC comparison; Muthén, 2017). For parameters, unstandardized and StdYX standardization estimates and associated standard errors were retained per guidelines described by Muthén \& Muthén (1998-2017a). Standardized estimates were interpreted to ease interpretation when using theta parameterization, as described by Kline (2016), and to permit comparison of the relative importance of variables in each model. According to the authors, StdYX standardizes estimates using the variances of the continuous latent, background, and outcome variables. 


\section{CHAPTER 3}

\section{RESULTS}

\section{Descriptive Statistics}

Individual exposures to adversities were highly prevalent in the present sample.

Caregiver separation or divorce was the most commonly experienced adversity $(84.9 \%)$, followed by caregiver substance abuse $(65.6 \%)$ and sexual abuse $(61.8 \%)$. The average percentage of rurality in county of origins was $40.6 \%(S D=23.58)$. With regard to behavioral concerns, over one-third of the sample (35.1\%) was arrested for a nonsexual offense prior to age 14 , and the average age of first documented sexually abusive behavior was 11.93 years $(S D=$ 2.95). The mean number of arrests for nonsexual and sexual offenses were 1.67 and 0.63 , respectively. Descriptive statistics for variables of interest are further detailed in Table 3.

Table 3

Descriptive Statistics for Variables of Study

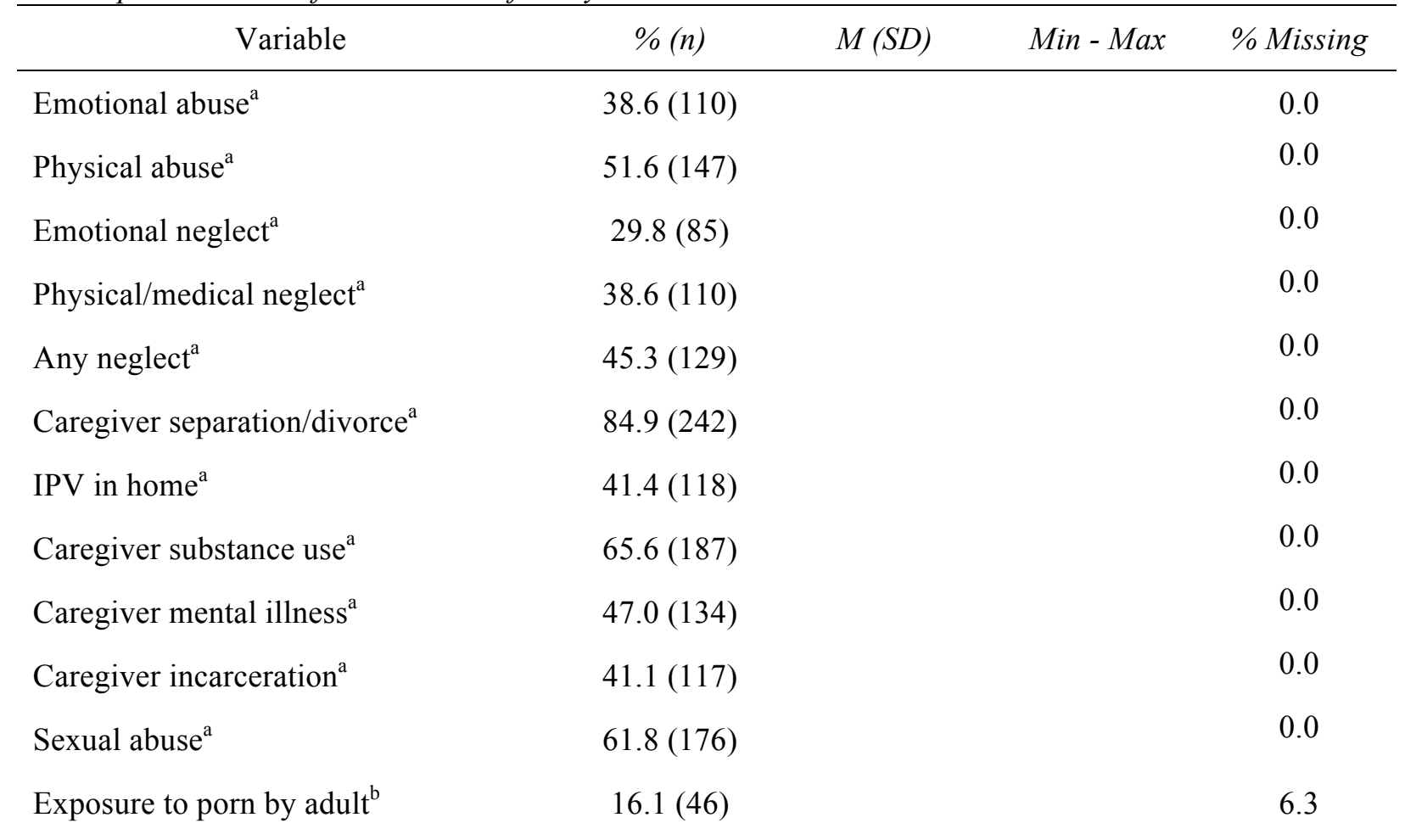


Table 3 Continued

\begin{tabular}{|c|c|c|c|c|}
\hline Variable & $\%(n)$ & $M(S D)$ & Min - Max & $\%$ Missing \\
\hline Witness sex between others ${ }^{c}$ & $14.4(41)$ & & & 1.8 \\
\hline Early arrest (before age 14$)^{d}$ & $35.1(100)$ & & & 2.8 \\
\hline Nonsexual violent offense arrest ${ }^{\mathrm{a}}$ & $23.5(67)$ & & & 0.0 \\
\hline No. nonsexual offense arrests ${ }^{a}$ & & $1.67(2.72)$ & $0-15$ & 0.0 \\
\hline Age at $1^{\text {st }}$ sexually abusive behavior ${ }^{\mathrm{a}}$ & & $11.93(2.95)$ & $4-17$ & 0.0 \\
\hline Contact offense $\mathrm{e}^{\mathrm{e}}$ & $89.1(254)$ & & & 1.1 \\
\hline No. sexual offense arrests ${ }^{\mathrm{a}}$ & & $0.63(0.68)$ & $0-5$ & 0.0 \\
\hline Social/economic environment ${ }^{\mathrm{f}}$ & & $-0.11(0.24)$ & $-0.88-0.78$ & 7.7 \\
\hline$\%$ Rurality of county ${ }^{\mathrm{f}}$ & & $40.63(23.58)$ & $0-100$ & 7.7 \\
\hline
\end{tabular}

Note. ${ }^{\mathrm{a}} n=285 ;{ }^{\mathrm{b}} n=267 ;{ }^{\mathrm{c}} n=280 ;{ }^{\mathrm{d}} n=277 .{ }^{\mathrm{e}} n=282 .{ }^{\mathrm{f}} n=263 . \%=$ Frequency in total sample. $n=$ number of subjects who had documented instance of exposure or behavior. $M=$ mean. $S D=$ standard deviation.

\section{Measurement Model}

The hypothesized measurement model, shown in Figure 1, fit the data well, $\chi^{2}$ for difference testing $(41, N=285)=4.51, p=0.105, C F I=0.996, R M S E A=0.01[C I=0.00,0.04]$, $W R M R=0.69$, with all fit indices within the recommended limits. 


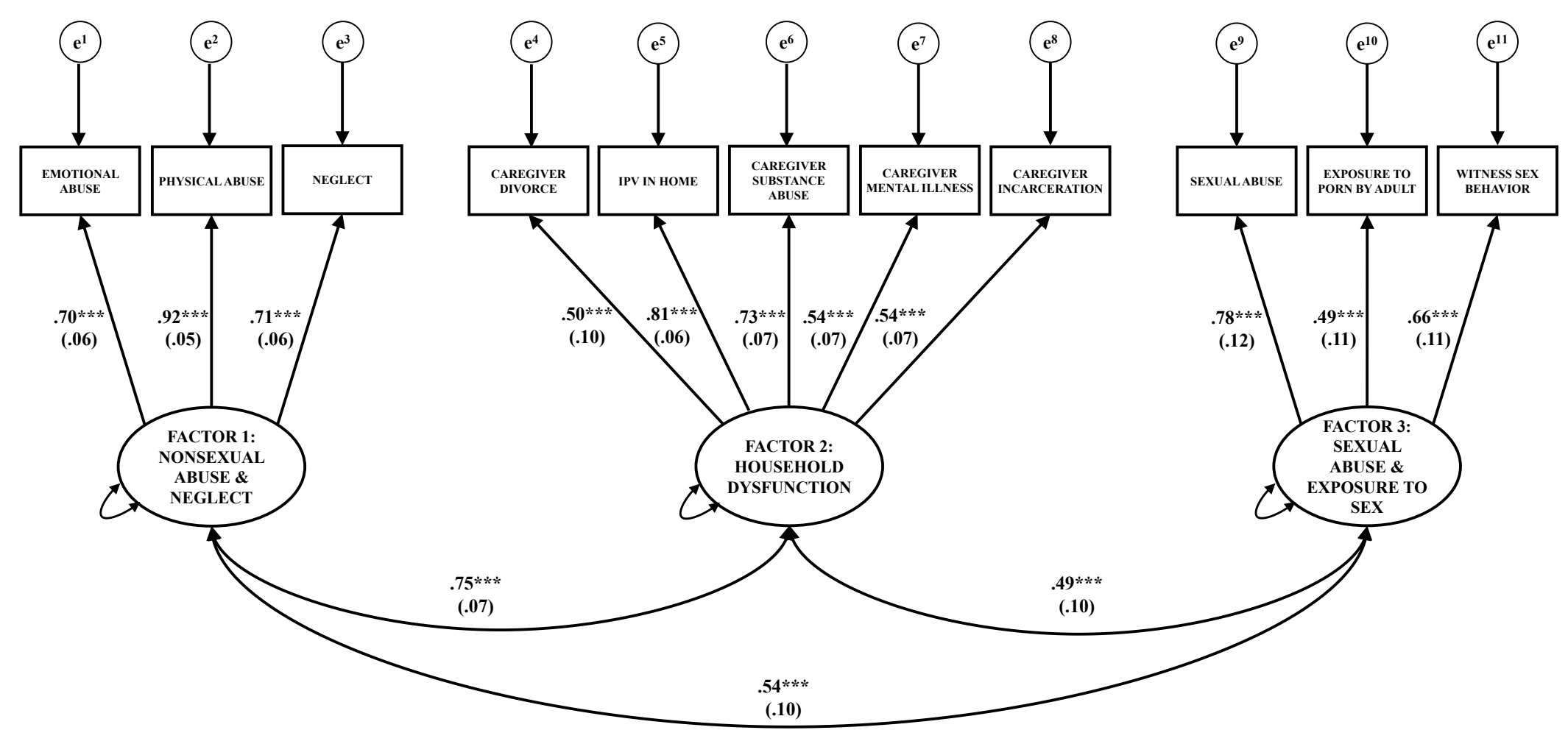

Figure 1. Measurement Model for Individual Adverse Experiences. Estimates included are standardized (StdYX) regression and covariance coefficients and corresponding standard errors. Unstandardized and standardized estimates, standard errors, critical ratios, confidence intervals, and covariance coefficients are included in Table 5.

$* * * p<.001$ 
All factor loadings were well above the standard 0.40 recommended for retaining a factor in factor analysis (Kahn, 2006). Covariances between the factors were permitted in the CFA due to the theoretical interrelatedness of adverse experiences (Baglivio \& Epps, 2016; Dong et al., 2004). Covariances between the three derived factors were significant, ranging from the moderate to strong range. The relationship within the strong range $(r=.75)$ exists between the Factors representing nonsexual abuse and neglect (Factor 1) and household dysfunction (Factor 2). Test statistics for all tested models are displayed in Table 4.

Table 4

Model Test Statistics

\begin{tabular}{lccccccc}
\hline & $N$ & $d f$ & $\chi_{\text {diff }}^{2}$ & $p$ & CFI & RMSEA [90\% CI] & WRMR \\
\hline Measurement Model & $\mathbf{2 8 5}$ & $\mathbf{4 1}$ & $\mathbf{4 . 5 1}$ & $\mathbf{. 1 0 5}$ & $\mathbf{0 . 9 9 6}$ & $\mathbf{0 . 0 1}[\mathbf{0 . 0 0 , 0 . 0 4}]$ & $\mathbf{0 . 6 9}$ \\
$\begin{array}{c}\text { Nonsexual Delinquent Behavior } \\
\text { Individual exposures model }\end{array}$ & $\mathbf{2 8 5}$ & $\mathbf{6 8}$ & $\mathbf{3 . 1 6}$ & $\mathbf{. 2 0 6}$ & $\mathbf{0 . 9 8}$ & $\mathbf{0 . 0 3}[\mathbf{0 . 0 0 , 0 . 0 5}]$ & $\mathbf{0 . 8 0}$ \\
$\quad$ Modified exploratory model & 263 & 85 & 7.20 & .027 & 0.84 & $0.08[0.06,0.09]$ & 1.29 \\
$\quad$ Alternative model & 285 & 70 & 1.67 & .434 & 0.78 & $0.10[0.08,0.11]$ & 1.50
\end{tabular}

Sexually Abusive Behavior

$\left.\begin{array}{llllllll}\text { Individual exposures model } & 285 & 68 & 2.57 & .276 & 0.95 & 0.04 & {[0.02,0.06}\end{array}\right]$

$\begin{array}{llllllll}\text { Alternative model } & 285 & 71 & 9.11 & .011 & 0.74 & 0.10[0.08,0.11] & 1.53\end{array}$

Note. $d f=$ degrees of freedom. $\chi_{\text {diff }}^{2}=$ Chi-square difference testing. CFA $=$ Comparative Fix Index. RMSEA $=$ Root Mean Square Error of Approximation. $\mathrm{CI}=$ Confidence Interval. WRMR $=$ Weighted Root-Mean-Square Residual. Retained models are displayed in bold font.

The unstandardized and standardized estimates and standard errors for the measurement model are shown in Table 5. 
Table 5

Unstandardized and Standardized (StdYX) Regression Coefficients, Standard Errors, Critical Ratios, Confidence Intervals, $R^{2}$ Values, and Covariances between Latent Variables for the Measurement Model

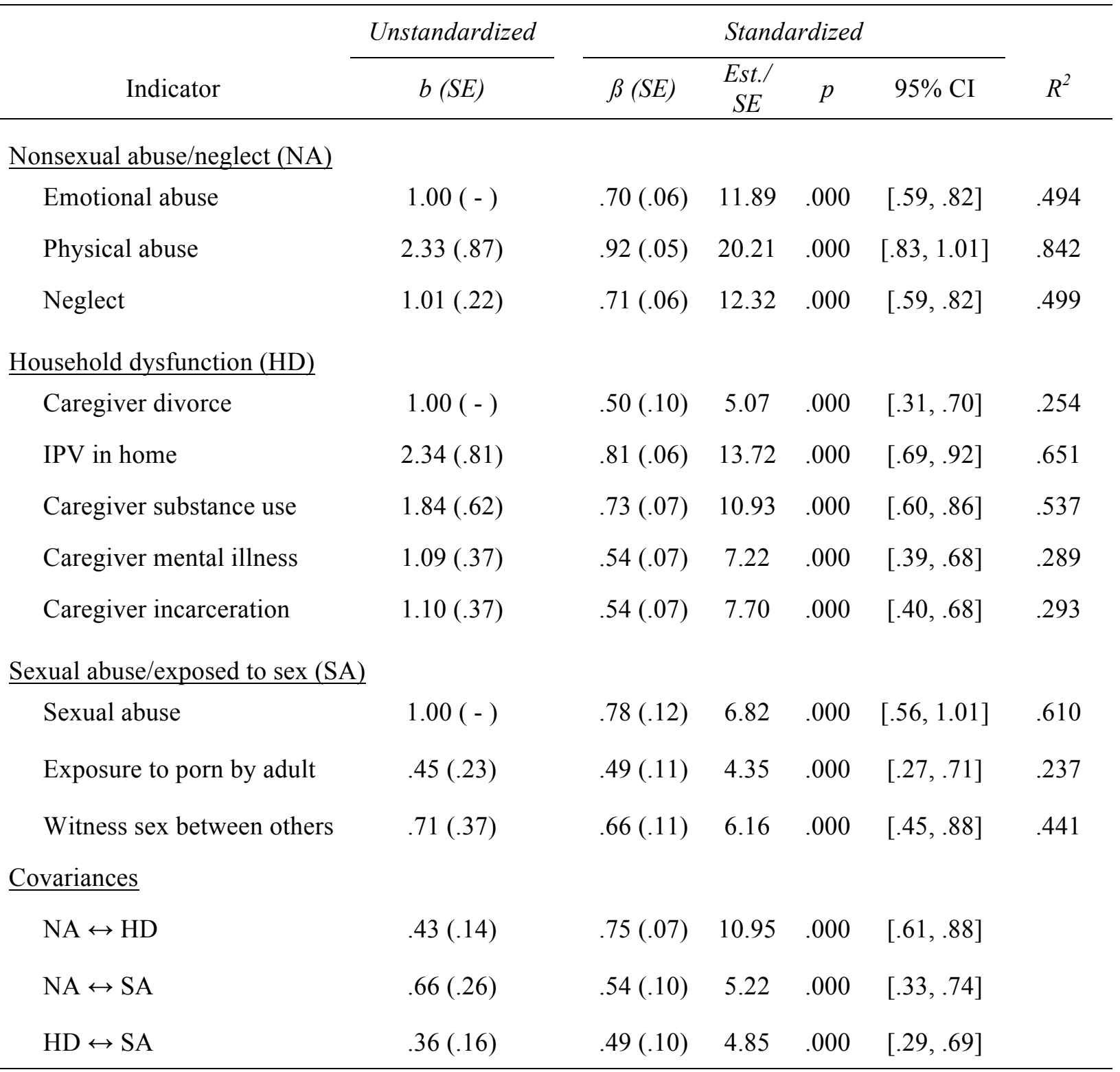

Note. Model Fit: $\chi_{\text {diff }}^{2}(41, N=285)=4.51, p=.0 .105, C F I=0.996, R M S E A=0.01[90 \% C I=0.00$, $0.04], W R M R=0.69 . \mathrm{NA}=$ Nonsexual abuse/neglect. $\mathrm{HD}=$ Household dysfunction. $\mathrm{SA}=$ Sexual abuse/exposure to sexual boundary concerns in home of origin. Residual variance of each latent response variable is fixed to 1.0 with Theta parameterization option. $b=$ unstandardized regression coefficient. $\beta=$ standardized probit regression coefficient (StdYX). $S E=$ standard error. $\mathrm{CI}=$ confidence interval. $R^{2}=$ percentage explained of variance. 


\section{Nonsexual Delinquent Behaviors}

Individual exposures model. The initial structural model for the association between individual adverse experiences and nonsexual delinquent behaviors, shown in Figure 2, fit the data well, $\chi^{2}$ for difference testing $(68, N=285)=3.16, p=0.206, C F I=0.98, R M S E A=0.03$ $[C I=0.00,0.05], W R M R=0.80$, with all fit indices within the recommended limits of estimates. 


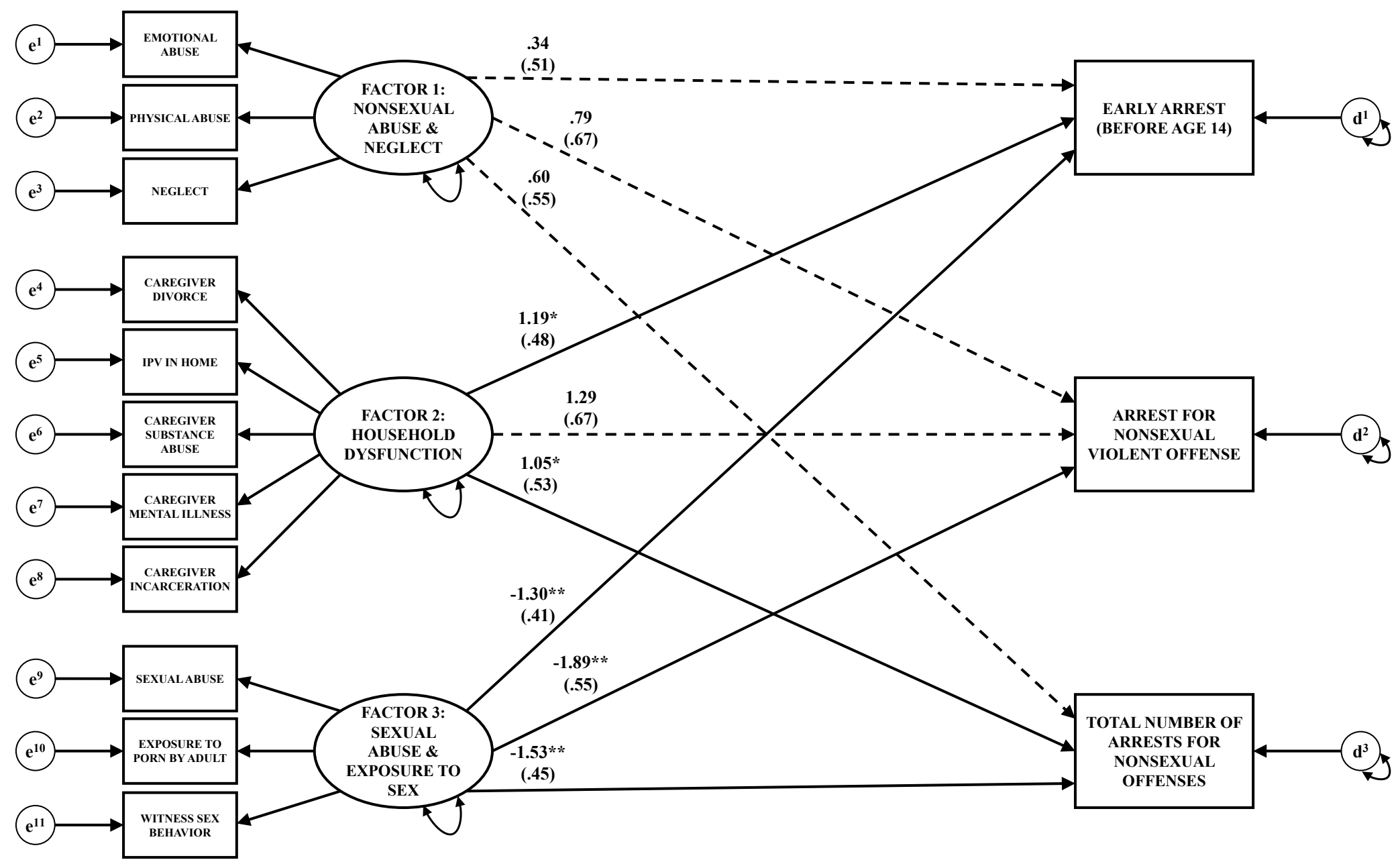

Figure 2. Initial Structural Model for Individual Exposures to ACEs and Nonsexual Delinquent Behaviors. Estimates included are standardized (StdYX) regression coefficients and corresponding standard errors. Factor loadings and covariances between latent variables were significant but not included in this figure to simplify depiction. Dotted lines indicate non-significant pathways. Unstandardized and standardized estimates and standard errors for direct pathways and covariances are included in Table 6.

${ }^{*} p<.05 * * p<.01$ 
However, the pathways between nonsexual abuse/neglect and all three arrest-related outcome variables were not statistically significant, including the pathways between nonsexual abuse/neglect and early arrest $(\beta=0.34, p=0.500)$, history of arrest for a nonsexual violent offense $(\beta=0.79, p=0.243)$, and number of arrests for nonsexual offenses $(\beta=0.60, p=0.272)$. Additionally, the pathway between Factor 2 (household dysfunction) was not significantly associated with having an arrest for a nonsexual, violent offense $(\beta=1.29, p=0.053)$. In contrast, Factor 2 (household dysfunction) was related to a greater likelihood of being arrested before the age of $14(\beta=1.19, p=0.013)$ and having a greater number of arrests for nonsexual offenses $(\beta=1.05, p=.048)$. Furthermore, Factor 3 (sexual abuse/exposure to sexual boundary problems) was associated with all three nonsexual, arrest-related outcomes. Unstandardized and standardized estimates, standard errors, test estimates, and $p$-values for direct pathways and covariances for the initial structural model for nonsexual delinquent behaviors are shown in Table 6.

Table 6

Unstandardized and Standardized (StdYX) Regression Coefficients, Standard Errors, Critical Ratios, and Confidence Intervals in the Individual Exposures Model for Nonsexual Delinquent Behaviors

\begin{tabular}{|c|c|c|c|c|c|c|c|}
\hline \multirow[b]{2}{*}{ Parameter } & \multicolumn{2}{|c|}{ Unstandardized } & \multicolumn{5}{|c|}{ Standardized } \\
\hline & $b$ & $S E$ & $\beta$ & $S E$ & $\begin{array}{c}\text { Est./ } \\
S E\end{array}$ & $p$ & $95 \% \mathrm{CI}$ \\
\hline \multicolumn{8}{|l|}{ Direct effects } \\
\hline $\mathrm{NA} \rightarrow$ Early arrest & .48 & .73 & .34 & .51 & 0.68 & .500 & {$[-.66,1.35]$} \\
\hline HD $\rightarrow$ Early arrest & 2.89 & 1.47 & 1.19 & .48 & 2.48 & .013 & {$[.25,2.13]$} \\
\hline $\mathrm{SA} \rightarrow$ Early arrest & -2.83 & 1.15 & -1.30 & .41 & -3.16 & .002 & {$[-2.10,-.49]$} \\
\hline $\mathrm{NA} \rightarrow$ Violent arrest $^{\mathrm{a}}$ & 1.92 & 1.80 & .79 & .67 & 1.17 & .243 & {$[-.53,2.11]$} \\
\hline HD $\rightarrow$ Violent arrest & 5.45 & 3.70 & 1.29 & .67 & 1.94 & .053 & {$[-.02,2.59]$} \\
\hline SA $\rightarrow$ Violent arrest & -7.14 & 3.53 & -1.89 & .55 & -3.45 & .001 & {$[-2.96,-.82]$} \\
\hline NA $\rightarrow$ No. arrests $^{b}$ & 1.65 & 1.53 & .60 & .55 & 1.10 & .272 & {$[-.47,1.68]$} \\
\hline
\end{tabular}


Table 6 Continued

\begin{tabular}{|c|c|c|c|c|c|c|c|}
\hline \multirow[b]{2}{*}{ Parameter } & \multicolumn{2}{|c|}{ Unstandardized } & \multicolumn{5}{|c|}{ Standardized } \\
\hline & $b$ & $S E$ & $\beta$ & $S E$ & $\begin{array}{c}\text { Est./ } \\
S E\end{array}$ & $p$ & $95 \% \mathrm{CI}$ \\
\hline HD $\rightarrow$ No. arrests & 5.00 & 2.91 & 1.05 & .53 & 1.98 & .048 & {$[.01,2.10]$} \\
\hline $\mathrm{SA} \rightarrow$ No. arrests & -6.49 & 2.40 & -1.53 & .45 & -3.39 & .001 & {$[-2.41,-.65]$} \\
\hline \multicolumn{8}{|l|}{$\underline{\text { Covariances }}$} \\
\hline $\mathrm{NA} \leftrightarrow \mathrm{HD}$ & .43 & .14 & .75 & .07 & 10.78 & .000 & {$[.62, .89]$} \\
\hline $\mathrm{NA} \leftrightarrow \mathrm{SA}$ & .51 & .15 & .81 & .11 & 7.42 & .000 & {$[.59,1.02]$} \\
\hline $\mathrm{HD} \leftrightarrow \mathrm{SA}$ & .31 & .11 & .85 & .09 & 9.58 & .000 & {$[.68,1.03]$} \\
\hline
\end{tabular}

Note. Model Fit: $\chi_{\text {diff }}^{2}(68, N=285)=3.16, p=0.206, C F I=0.98, R M S E A=0.03[90 \% C I=0.00$, $0.05], W R M R=0.80$. ${ }^{\mathrm{a}}$ Previous arrest for nonsexual violent offense. ${ }^{\mathrm{b}}$ Number of arrests for nonsexual offenses. NA $=$ Nonsexual abuse/neglect. HD $=$ Household dysfunction. SA = Sexual abuse/exposure to sexual boundary concerns in home of origin. Residual variance of each latent response variable is fixed to 1.0 with Theta parameterization option. $b=$ unstandardized regression coefficient. $\beta=$ standardized probit regression coefficient (StdYX). $S E=$ standard error. $\mathrm{CI}=$ confidence interval.

Modified exploratory model. Next, percentage of rurality of county of origin was included in the model as a covariate for number of arrests for nonsexual offenses as a control method. This modified model for nonsexual delinquent behavior, shown in Figure 3, produced a poorer fit for the data, $\chi^{2}$ for difference testing $(85, N=263)=7.20, p=0.027, C F I=0.84$, $R M S E A=0.08[C I=0.06,0.09], W R M R=1.29$. 


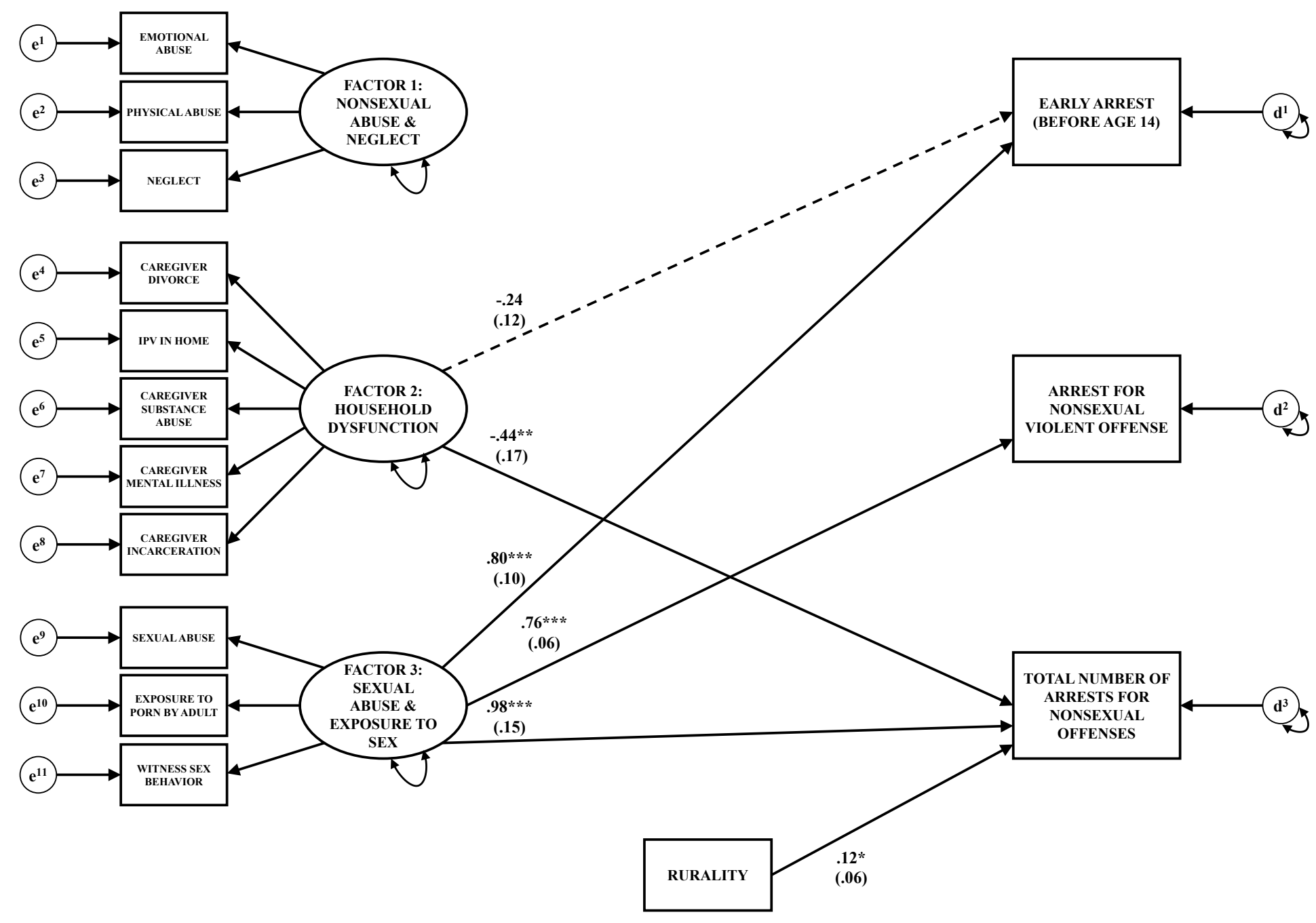

Figure 3. Modified Exploratory Structural Model for Individual Exposures to ACEs, Rurality, and Nonsexual Delinquent Behaviors. Estimates included are standardized (StdYX) regression coefficients and corresponding standard errors. Factor loadings and covariances between latent variables were significant but not included in this figure to simplify depiction. Dotted lines indicate non-significant pathways. Unstandardized and standardized estimates and standard errors for direct pathways and covariances are included in Table 7.

$* p<.05 * * p<.01 * * * p<.001$ 
As shown, $\chi^{2}$ for difference testing resulted in a significant $p$-value, the $C F I$ was lower than the 0.95 cutoff, the $R M S E A$ was greater than the 0.05 cutoff value, and the WRMR was greater than the suggested 1.0 guideline. However, the pathway between rurality and number of arrests for nonsexual offenses was significant $(\beta=0.12, p=0.027)$, suggesting individuals with a greater percentage of rural areas in their counties of origin had a greater number of arrests for nonsexual offenses. Due to this limitation in available data and resulting fit indices, the initial individual exposures model for nonsexual delinquent behavior was retained as the acceptable model at this time. Results for the modified exploratory model for nonsexual delinquent behaviors, including the county covariate, are displayed in Table 7.

Table 7

Unstandardized and Standardized (StdYX) Regression Coefficients, Standard Errors, Critical Ratios, and Confidence Intervals in the Modified Exploratory Model for Nonsexual Delinquent Behaviors

\begin{tabular}{|c|c|c|c|c|c|c|c|}
\hline \multirow[b]{2}{*}{ Parameter } & \multicolumn{2}{|c|}{ Unstandardized } & \multicolumn{5}{|c|}{ Standardized } \\
\hline & $b$ & $S E$ & $\beta$ & $S E$ & $\begin{array}{c}\text { Est./ } \\
S E\end{array}$ & $p$ & $95 \% \mathrm{CI}$ \\
\hline \multicolumn{8}{|l|}{ Direct effects } \\
\hline $\mathrm{HD} \rightarrow$ Early arrest & -.46 & .28 & -.24 & .12 & -1.96 & .050 & {$[-.47, .00]$} \\
\hline $\mathrm{SA} \rightarrow$ Early arrest & 2.56 & .79 & .80 & .10 & 8.10 & .000 & {$[.61, .99]$} \\
\hline $\mathrm{SA} \rightarrow$ Violent arrest $^{\mathrm{a}}$ & 2.72 & .85 & .76 & .06 & 13.41 & .000 & {$[.65, .87]$} \\
\hline $\mathrm{HD} \rightarrow$ No. arrests $^{\mathrm{b}}$ & -1.70 & .80 & -.44 & .17 & -2.67 & .008 & {$[-.76,-.12]$} \\
\hline $\mathrm{SA} \rightarrow$ No. arrests & 6.31 & 2.01 & .98 & .15 & 6.40 & .000 & {$[.68,1.28]$} \\
\hline Rurality $\rightarrow$ No. arrests & .01 & .01 & .12 & .06 & 2.21 & .027 & {$[.01, .23]$} \\
\hline \multicolumn{8}{|l|}{$\underline{\text { Covariances }}$} \\
\hline $\mathrm{NA} \leftrightarrow \mathrm{HD}$ & .53 & .18 & .79 & .06 & 12.37 & .000 & {$[.66, .91]$} \\
\hline $\mathrm{NA} \leftrightarrow \mathrm{SA}$ & .22 & .08 & .55 & .08 & 6.51 & .000 & {$[.38, .71]$} \\
\hline $\mathrm{HD} \leftrightarrow \mathrm{SA}$ & .19 & .08 & .65 & .08 & 8.08 & .000 & {$[.49, .81]$} \\
\hline
\end{tabular}

Note. Model Fit: $\chi_{\text {diff }}^{2}(85, N=263)=7.20, p=0.027, C F I=0.84, R M S E A=0.08[C I=0.06,0.09]$, $W R M R=1.29$. ${ }^{\mathrm{a}}$ Previous arrest for nonsexual violent offense. ${ }^{\mathrm{b}}$ Number of arrests for nonsexual offenses. NA $=$ Nonsexual abuse/neglect. HD $=$ Household dysfunction. SA $=$ Sexual abuse/exposure to sexual boundary concerns in home of origin. Residual variance of each latent response variable is fixed to 1.0 with Theta parameterization option. $b=$ unstandardized regression coefficient. $\beta=$ standardized probit regression coefficient (StdYX). $S E=$ standard error. $\mathrm{CI}=$ confidence interval. 
Alternative model. The alternative model for nonsexual delinquent behavior, shown in Figure 4, theorizes that experiencing household dysfunction leads to early arrest and a greater number of arrests for nonsexual offenses. 


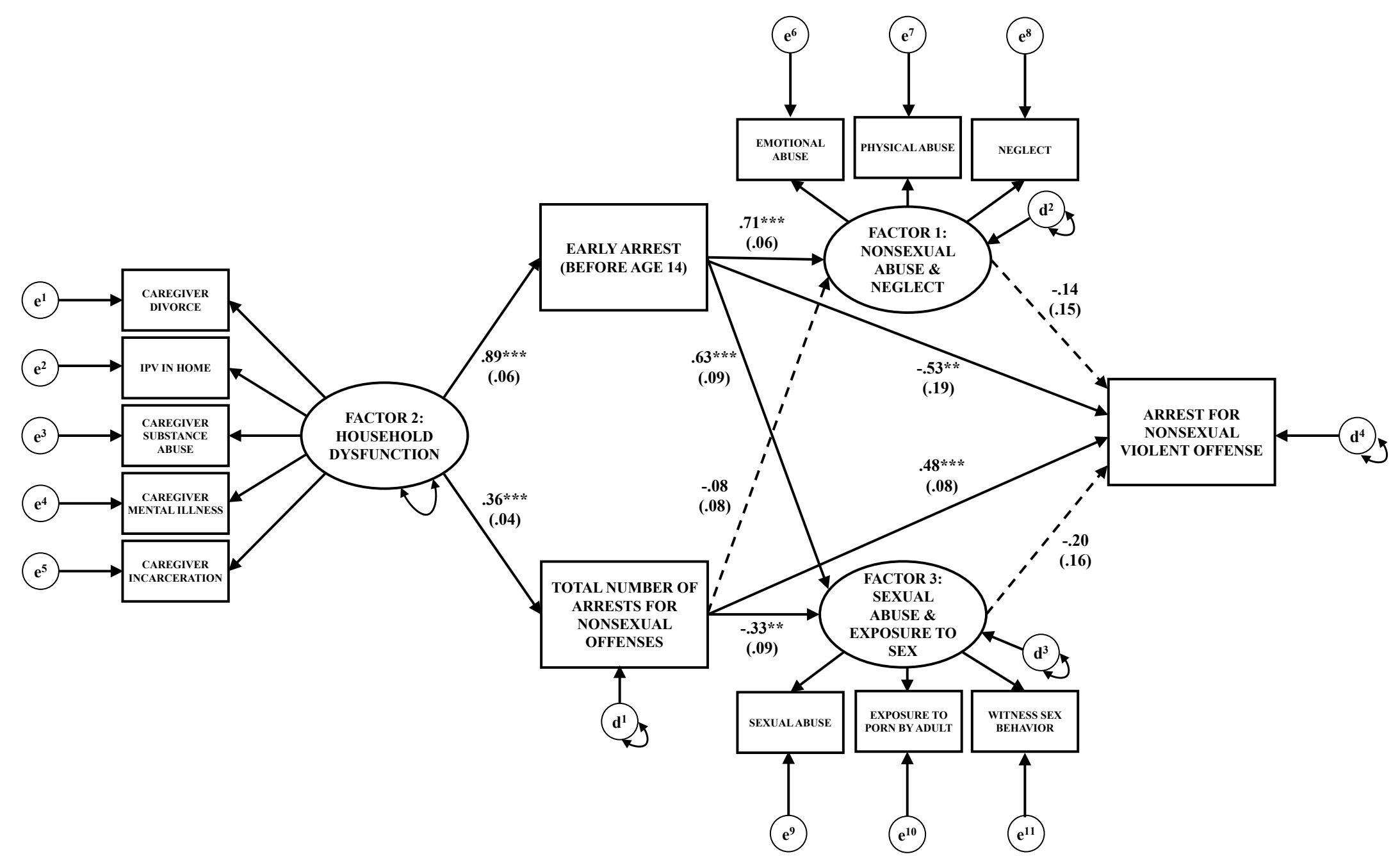

Figure 4. Alternative Structural Model for Nonsexual Delinquent Behaviors. Estimates included are standardized (StdYX) regression coefficients and corresponding standard errors. Factor loadings were significant but not included in this figure to simplify depiction. Dotted lines indicate non-significant pathways. Unstandardized and standardized estimates and standard errors for direct effects and indirect effects are included in Table 8.

$* * p<.01 * * * p<.001$ 
Subsequently, these individuals are more likely to experience nonsexual and sexual abuse and neglect due to environmental factors, such as juvenile detention, out-of-home placements, and punitive responsiveness to delinquency. Due to persistent adversities, these individuals are then theorized to be more likely to be arrested for a violent offense. This alternative model for nonsexual delinquent behavior proved to be a poor fit for the data, $\chi^{2}$ for difference testing $(70, N$ $=285)=1.67, p=0.434, C F I=0.78, R M S E A=0.10[C I=0.08,0.11], W R M R=1.50$. While the alternative model revealed some indicators of a good fit for the data, primarily a non-significant chi-square for difference test, the $C F I$ was lower than the 0.95 cutoff, the RMSEA was greater than the 0.05 cutoff value, and the $W R M R$ was greater than the suggested 1.0 guideline.

Consequently, the alternative model for nonsexual delinquency was determined to be a poorer fit for the data compared to the initial model. Unstandardized and standardized estimates, standard errors, test estimates, and $p$-values for direct effects and indirect effects for the initial structural model for nonsexual delinquent behaviors are shown in Table 8.

Table 8

Unstandardized and Standardized (StdYX) Regression Coefficients, Standard Errors, Critical Ratios, and Confidence Intervals in the Alternative Model for Nonsexual Delinquent Behaviors

\begin{tabular}{|c|c|c|c|c|c|}
\hline \multirow[b]{2}{*}{ Parameter } & Unstandardized & \multicolumn{4}{|c|}{ Standardized } \\
\hline & $S E$ & $S E$ & $\begin{array}{c}\text { Est./ } \\
S E\end{array}$ & $p$ & $95 \% \mathrm{CI}$ \\
\hline
\end{tabular}

$\underline{\text { Direct effects }}$

\begin{tabular}{|c|c|c|c|c|c|c|c|}
\hline $\mathrm{HD} \rightarrow$ Early arrest & 3.57 & 1.57 & .89 & .06 & 14.89 & .000 & {$[.77,1.01]$} \\
\hline HD $\rightarrow$ Early arrest & 1.79 & .58 & .36 & .04 & 8.60 & .000 & {$[.28, .44]$} \\
\hline Early arrest $\rightarrow$ NA & .33 & .09 & .71 & .06 & 11.22 & .000 & {$[.59, .84]$} \\
\hline No. $\operatorname{arrests}^{\mathrm{a}} \rightarrow$ NA & -.03 & .03 & -.08 & .08 & -0.99 & .321 & {$[-.24, .08]$} \\
\hline Early arrest $\rightarrow$ SA & .33 & .13 & .63 & .09 & 6.89 & .000 & {$[.45, .80]$} \\
\hline No. arrests $\rightarrow$ SA & -.14 & .06 & -.33 & .09 & -3.47 & .001 & {$[-.51,-.14]$} \\
\hline $\mathrm{NA} \rightarrow$ Violent arrest $^{\mathrm{b}}$ & -.20 & .24 & -.14 & .15 & -0.88 & .377 & {$[-.44, .17]$} \\
\hline
\end{tabular}


Table 8 Continued

\begin{tabular}{|c|c|c|c|c|c|c|c|}
\hline \multirow[b]{2}{*}{ Parameter } & \multicolumn{2}{|c|}{ Unstandardized } & \multicolumn{5}{|c|}{ Standardized } \\
\hline & $b$ & $S E$ & $\beta$ & $S E$ & $\begin{array}{c}\text { Est./ } \\
S E\end{array}$ & $p$ & $95 \% \mathrm{CI}$ \\
\hline SA $\rightarrow$ Violent arrest & -.25 & .23 & -.20 & .16 & -1.26 & .206 & {$[-.50, .11]$} \\
\hline Early arrest $\rightarrow$ Violent arrest & .36 & .18 & .53 & .19 & 2.73 & .006 & {$[.15, .91]$} \\
\hline No. arrests $\rightarrow$ Violent arrest & .26 & .04 & .48 & .08 & 5.85 & .000 & {$[.32,64]$} \\
\hline \multicolumn{8}{|l|}{$\underline{\text { Indirect effects }}$} \\
\hline $\mathrm{HD} \rightarrow$ Early arrest $\rightarrow \mathrm{NA}$ & 1.17 & .42 & .63 & .07 & 8.76 & .000 & {$[.49, .78]$} \\
\hline $\mathrm{HD} \rightarrow$ No. arrests $\rightarrow \mathrm{NA}$ & -.05 & .06 & -.03 & .03 & -0.99 & .322 & {$[-.09, .03]$} \\
\hline $\mathrm{HD} \rightarrow$ Early arrest $\rightarrow \mathrm{SA}$ & 1.19 & .51 & .56 & .09 & 6.03 & .000 & {$[.38, .74]$} \\
\hline $\mathrm{HD} \rightarrow$ No. arrests $\rightarrow$ SA & -.25 & .12 & -.12 & .04 & -3.18 & .001 & {$[-.19,-.05]$} \\
\hline $\begin{array}{l}\mathrm{HD} \rightarrow \text { Early arrest } \rightarrow \mathrm{NA} \rightarrow \\
\text { Violent arrest }\end{array}$ & -.23 & .29 & -.09 & .10 & -0.87 & .385 & {$[-.28, .11]$} \\
\hline $\begin{array}{l}\mathrm{HD} \rightarrow \text { Early arrest } \rightarrow \mathrm{SA} \rightarrow \\
\text { Violent arrest }\end{array}$ & -.30 & .28 & -.11 & .09 & -1.20 & .231 & {$[-.29, .07]$} \\
\hline $\begin{array}{l}\mathrm{HD} \rightarrow \text { No. arrests } \rightarrow \text { NA } \rightarrow \\
\text { Violent arrest }\end{array}$ & .01 & .02 & .00 & .01 & 0.65 & .513 & {$[-.01, .02]$} \\
\hline $\begin{array}{l}\mathrm{HD} \rightarrow \text { No. arrests } \rightarrow \mathrm{SA} \rightarrow \\
\text { Violent arrest }\end{array}$ & .06 & .06 & .02 & .02 & 1.12 & .262 & {$[-.02, .06]$} \\
\hline \multicolumn{8}{|c|}{$\begin{array}{l}\text { Note. Model Fit: } \chi^{2}{ }_{\text {diff }}(70, N=285)=1.67, p=0.434, C F I=0.78, R M S E A=0.10[C I=0.08,0.11], \\
W R M R=1.50 .{ }^{\mathrm{a}} \text { Number of arrests for nonsexual offenses. }{ }^{\text {b Previous arrest for nonsexual violent }} \\
\text { offense. NA = Nonsexual abuse/neglect. } \mathrm{HD}=\text { Household dysfunction. } \mathrm{SA}=\text { Sexual abuse/exposure to } \\
\text { sexual boundary concerns in home of origin. Residual variance of each latent response variable is fixed } \\
\text { to } 1.0 \text { with Theta parameterization option. } b=\text { unstandardized regression coefficient. } \beta=\text { standardized } \\
\text { probit regression coefficient (StdYX). } S E=\text { standard error. } \mathrm{CI}=\text { confidence interval. }\end{array}$} \\
\hline
\end{tabular}

\section{Sexually Abusive Behaviors}

Individual exposures model. The initial structural model for the association between individual adverse experiences and sexually abusive behaviors, shown in Figure 5, fit the data well, $\chi^{2}$ for difference testing $(68, N=285)=2.57, p=0.276, C F I=0.95, R M S E A=0.04[C I=$ $0.02,0.06], W R M R=0.87$, with all fit indices within the recommended limits. 


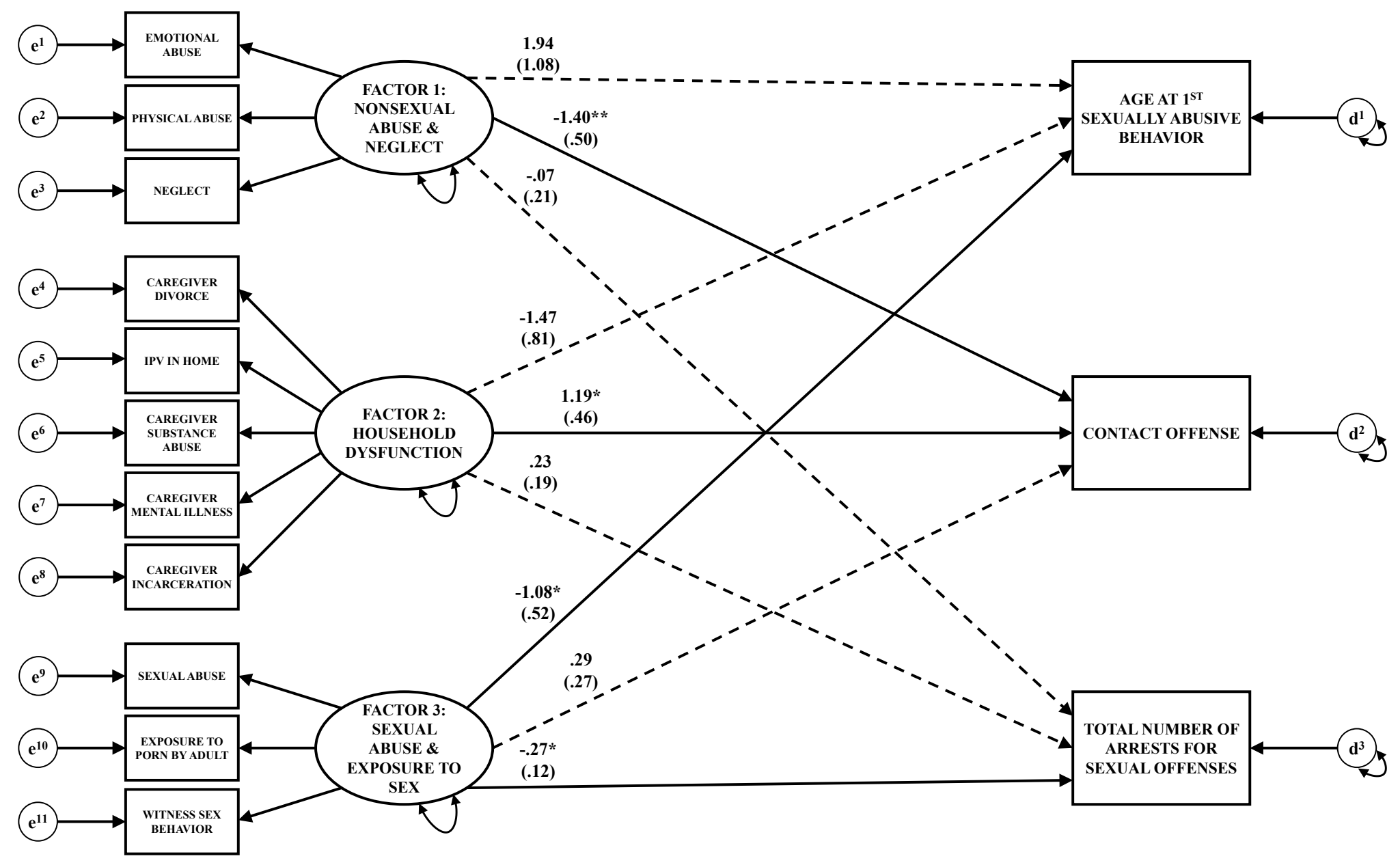

Figure 5. Initial Structural Model for Individual Exposures to ACEs and Sexually Abusive Behaviors. Estimates included are standardized (StdYX) regression coefficients and corresponding standard errors. Factor loadings and covariances between latent variables were significant but not included in this figure to simplify depiction. Dotted lines indicate non-significant pathways. Unstandardized and standardized estimates and standard errors for direct pathways and covariances are are included in Table 9 .

$* p<.05 * * p<.01$ 
However, there were several direct pathways that were not statistically significant including the pathways between: nonsexual abuse/neglect and age at first documented sexually abusive behavior $(\beta=1.84, p=0.060)$; nonsexual abuse/neglect and history of arrest for a sexual offense $(\beta=-0.26, p=0.374)$; household dysfunction and age at first documented sexually abusive behavior $(\beta=-1.37, p=0.056)$; household dysfunction and history of arrest for a sexual offense $(\beta=0.53, p=0.060)$; and, sexual abuse/sexual boundary problems in home and history of contact sexual offending $(\beta=0.27, p=0.319)$. Not experiencing nonsexual abuse and neglect (Factor 1) and experiencing household dysfunction (Factor 2) were differentially associated with a greater likelihood of committing a contact sexual offense. Sexual abuse and exposure to sexual boundary issues were associated with a younger age at first documented sexually abusive behavior and fewer sexual offense arrests. Detailed results for this initial model are included in Table 9.

Table 9

Unstandardized and Standardized (StdYX) Regression Coefficients, Standard Errors, Critical Ratios, and Confidence Intervals in the Individual Exposures Model for Sexually Abusive Behaviors

\begin{tabular}{|c|c|c|c|c|c|c|c|}
\hline \multirow[b]{2}{*}{ Parameter } & \multicolumn{2}{|c|}{ Unstandardized } & \multicolumn{5}{|c|}{ Standardized } \\
\hline & $b$ & $S E$ & $\beta$ & $S E$ & $\begin{array}{c}\text { Est./ } \\
S E\end{array}$ & $p$ & $95 \% \mathrm{CI}$ \\
\hline \multicolumn{8}{|l|}{ Direct effects } \\
\hline NA $\rightarrow$ Age of onset ${ }^{\mathrm{a}}$ & 6.20 & 3.61 & 1.94 & 1.08 & 1.80 & .072 & {$[-.18,4.05]$} \\
\hline HD $\rightarrow$ Age of onset & -7.10 & 4.29 & -1.47 & .81 & -1.82 & .070 & {$[-3.04, .12]$} \\
\hline SA $\rightarrow$ Age of onset & -3.03 & 1.89 & -1.08 & .52 & -2.08 & .038 & {$[-2.09,-.06]$} \\
\hline NA $\rightarrow$ Contact offense & -1.82 & .89 & -1.40 & .50 & -2.81 & .005 & {$[-2.38,-.42]$} \\
\hline HD $\rightarrow$ Contact offense & 2.35 & 1.32 & 1.19 & .46 & 2.57 & .010 & {$[.28,2.10]$} \\
\hline SA $\rightarrow$ Contact offense & .33 & .32 & .29 & .27 & 1.06 & .287 & {$[-.24, .81]$} \\
\hline NA $\rightarrow$ No. arrests $^{b}$ & -.05 & .16 & -.07 & .21 & -0.31 & .754 & {$[-.48, .35]$} \\
\hline $\mathrm{HD} \rightarrow$ No. arrests & .25 & .22 & .23 & .19 & 1.18 & .239 & {$[-.15, .60]$} \\
\hline
\end{tabular}


Table 9 Continued

\begin{tabular}{|c|c|c|c|c|c|c|c|}
\hline \multirow[b]{2}{*}{ Parameter } & \multicolumn{2}{|c|}{ Unstandardized } & \multicolumn{5}{|c|}{ Standardized } \\
\hline & $b$ & $S E$ & $\beta$ & $S E$ & $\begin{array}{c}\text { Est./ } \\
S E\end{array}$ & $p$ & $95 \% \mathrm{CI}$ \\
\hline SA $\rightarrow$ No. arrests & -.17 & .10 & -.27 & .12 & -2.23 & .026 & {$[-.51,-.03]$} \\
\hline \multicolumn{8}{|l|}{ Covariances } \\
\hline $\mathrm{NA} \leftrightarrow \mathrm{HD}$ & .50 & .15 & .88 & .06 & 15.00 & .000 & {$[.77, .99]$} \\
\hline $\mathrm{NA} \leftrightarrow \mathrm{SA}$ & .68 & .21 & .70 & .11 & 6.68 & .000 & {$[.50, .91]$} \\
\hline $\mathrm{HD} \leftrightarrow \mathrm{SA}$ & .33 & .12 & .51 & .12 & 4.44 & .000 & {$[.29, .74]$} \\
\hline
\end{tabular}

Note. Model Fit: $\chi_{\text {diff }}^{2}(68, N=285)=2.57, p=0.276, C F I=0.95, R M S E A=0.04[C I=0.02,0.06]$, $W R M R=0.87 .{ }^{a}$ Age at first documented sexually abusive behavior. ${ }^{b}$ Number of arrests for sexual offenses. NA $=$ Nonsexual abuse/neglect. HD = Household dysfunction. SA = Sexual abuse/exposure to sexual boundary concerns in home of origin. Residual variance of each latent response variable is fixed to 1.0 with Theta parameterization option. $b=$ unstandardized regression coefficient. $\beta=$ standardized probit regression coefficient (StdYX). $S E=$ standard error. $\mathrm{CI}=$ confidence interval.

Alternative model. The alternative model for sexually abusive behavior, shown in

Figure 6, theorizes a full mediation model suggesting that experiencing sexual abuse or exposure to other indicators of sexual boundary problems in one's home of origin (Factor 1) are associated with younger ages at first sexually abusive behavior, contact offending, and a greater number of arrests for sexual offenses. 


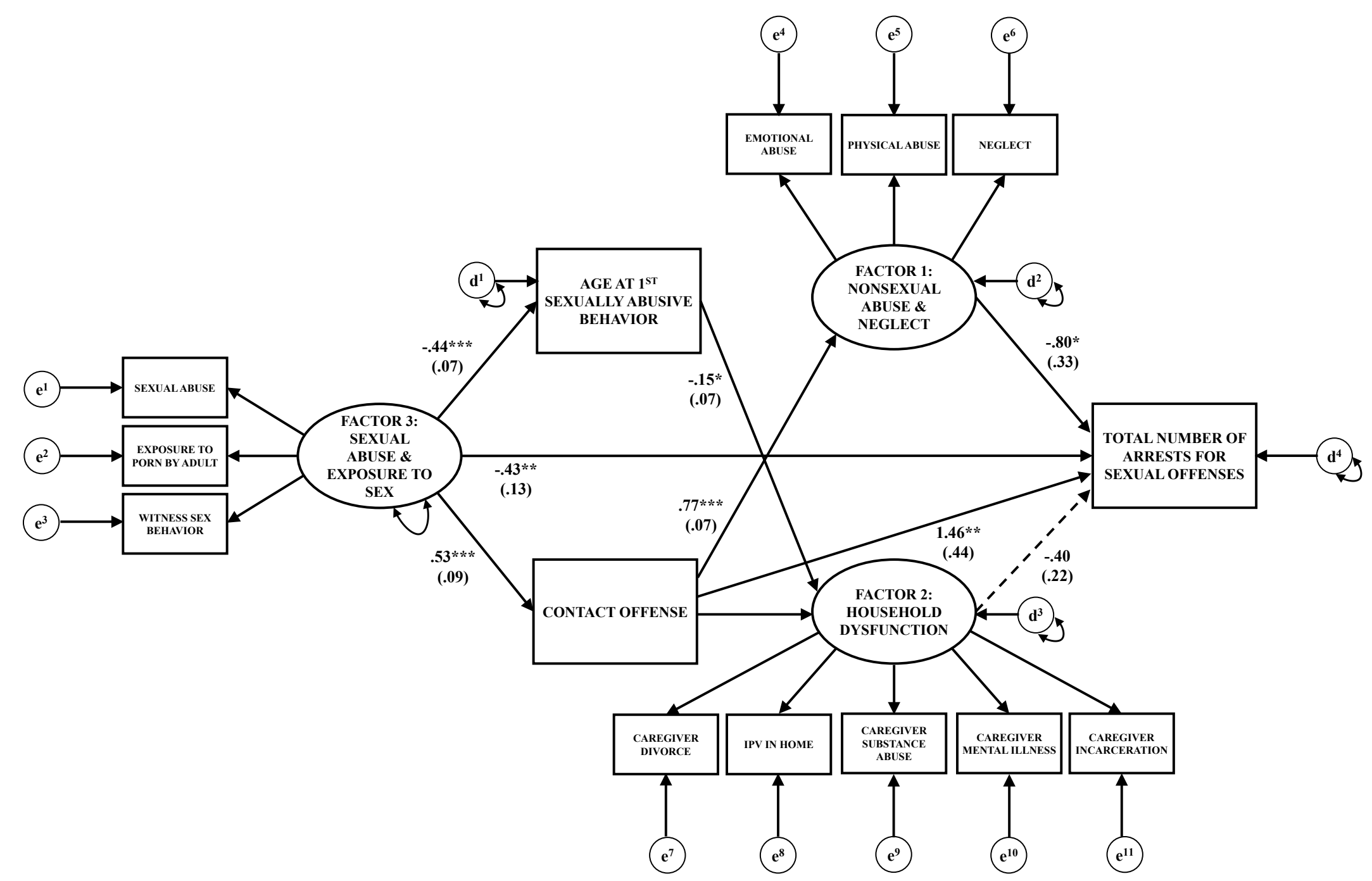

Figure 6. Alternative Structural Model for Sexually Abusive Behaviors. Estimates included are standardized (StdYX) regression coefficients and corresponding standard errors. Factor loadings were significant but not included in this figure to simplify depiction. Dotted lines indicate non-significant pathways. Unstandardized and standardized estimates and standard errors for direct effects and indirect effects are included in Table 10. $* p<.05 * * p<.01 * * * p<.001$ 
In this alternative model, nonsexual abuse/neglect and household dysfunction were hypothesized to mediate the direct relationships due to changes in environment following sexual abuse and offending (e.g., juvenile detention, out-of-home placements) and/or punitive responsiveness to sexual offending behaviors. Due to persistent adversities, these individuals are then theorized to be more likely to be arrested for a greater number of sexual offenses. The first alternative model tested indicated a convergence problem due to the pathway between age at first documented sexually abusive behavior and nonsexual abuse/neglect (Factor 1), suggesting the model was inappropriate for the data. After removing this pathway, the model converged successfully. The trimmed alternative model for sexually abusive behavior proved to be a poor fit for the data, $\chi^{2}$ for difference testing $(71, N=285)=9.11, p=0.011, C F I=0.74, R M S E A=0.10[C I=0.08$, $0.11], W R M R=1.53$. The alternative model revealed several indicators suggesting the model did not fit the data, including a significant chi-square for difference test, the $C F I$ was lower than the 0.95 cutoff, the RMSEA was greater than the 0.05 cutoff value, and the $W R M R$ was greater than the suggested 1.0 guideline. Thus, the alternative model for sexually abusive behavior tested was an inferior fit for the data compared to the initial model, which provides additional support for the initially proposed model. These results are further detailed in Table 10.

Table 10

Unstandardized and Standardized (StdYX) Regression Coefficients, Standard Errors, Critical Ratios, and Confidence Intervals in the Alternative Model for Sexually Abusive Behaviors

\begin{tabular}{|c|c|c|c|c|c|c|c|}
\hline \multirow[b]{2}{*}{ Parameter } & \multicolumn{2}{|c|}{ Unstandardized } & \multicolumn{5}{|c|}{ Standardized } \\
\hline & $b$ & $S E$ & $\beta$ & $S E$ & $\begin{array}{c}\text { Est./ } \\
S E\end{array}$ & $p$ & $95 \% \mathrm{CI}$ \\
\hline \multicolumn{8}{|l|}{$\underline{\text { Direct effects }}$} \\
\hline $\mathrm{SA} \rightarrow$ Age of onset ${ }^{\mathrm{a}}$ & -.92 & .37 & -.44 & .07 & -5.95 & .000 & {$[-.58,-.29]$} \\
\hline SA $\rightarrow$ Contact offense & .45 & .21 & .53 & .09 & 5.97 & .000 & {$[.36, .71]$} \\
\hline $\mathrm{SA} \rightarrow$ No. $^{\text {arrests }}{ }^{\mathrm{b}}$ & -.21 & .11 & -.43 & .13 & -3.27 & .001 & {$[-.68,-.17]$} \\
\hline
\end{tabular}


Table 10 Continued

\begin{tabular}{|c|c|c|c|c|c|c|c|}
\hline \multirow[b]{2}{*}{ Parameter } & \multicolumn{2}{|c|}{ Unstandardized } & \multicolumn{5}{|c|}{ Standardized } \\
\hline & $b$ & $S E$ & $\beta$ & $S E$ & $\begin{array}{l}\text { Est./ } \\
S E\end{array}$ & $p$ & $95 \% \mathrm{CI}$ \\
\hline Age of onset ${ }^{\mathrm{a}} \rightarrow \mathrm{HD}$ & -.03 & .02 & -.15 & .07 & -2.25 & .024 & {$[-.28,-.02]$} \\
\hline Contact offense $\rightarrow$ NA & .64 & .13 & .77 & .07 & 10.61 & .000 & {$[.63, .91]$} \\
\hline Contact offense $\rightarrow$ HD & .38 & .10 & .68 & .07 & 9.37 & .000 & {$[.54, .82]$} \\
\hline Contact offense $\rightarrow$ No. arrests & .84 & .25 & 1.46 & .44 & 3.36 & .001 & {$[.61,2.31]$} \\
\hline NA $\rightarrow$ No. arrests & -.55 & .24 & -.80 & .33 & -2.41 & .016 & {$[-1.44,-.15]$} \\
\hline $\mathrm{HD} \rightarrow$ No. arrests & -.41 & .26 & -.40 & .22 & -1.83 & .067 & {$[-.83, .03]$} \\
\hline \multicolumn{8}{|l|}{ Indirect effects } \\
\hline $\begin{array}{l}\mathrm{SA} \rightarrow \text { Contact offense } \rightarrow \text { No. } \\
\text { arrests }\end{array}$ & .38 & .20 & .78 & .28 & 2.77 & .006 & {$[.23,1.33]$} \\
\hline $\begin{array}{l}\mathrm{SA} \rightarrow \text { Age of onset } \rightarrow \mathrm{HD} \rightarrow \mathrm{No} \text {. } \\
\text { arrests }\end{array}$ & -.01 & .01 & -.03 & .02 & -1.61 & .108 & {$[-.06, .01]$} \\
\hline $\begin{array}{l}\mathrm{SA} \rightarrow \text { Contact offense } \rightarrow \mathrm{NA} \rightarrow \\
\text { No. arrests }\end{array}$ & -.16 & .10 & -.33 & .17 & -1.97 & .048 & {$[-.63,-.00]$} \\
\hline $\begin{array}{l}\text { SA } \rightarrow \text { Contact offense } \rightarrow \mathrm{HD} \rightarrow \\
\text { No. arrests }\end{array}$ & -.07 & .05 & -.15 & .09 & -1.55 & .122 & {$[-.33, .04]$} \\
\hline \multicolumn{8}{|c|}{$\begin{array}{l}\text { Note. Model Fit: } \chi^{2} \text { diff }(71, N=285)=9.11, p=0.011, C F I=0.74, R M S E A=0.10[C I=0.08,0.11], \\
W R M R=1.53 .{ }^{~} \text { Age at first documented sexually abusive behavior. }{ }^{b} \text { Number of arrests for sexual } \\
\text { offenses. NA = Nonsexual abuse/neglect. } \mathrm{HD}=\text { Household dysfunction. } \mathrm{SA}=\text { Sexual abuse/exposure } \\
\text { to sexual boundary concerns in home of origin. Residual variance of each latent response variable is } \\
\text { fixed to } 1.0 \text { with Theta parameterization option. } b=\text { unstandardized regression coefficient. } \beta= \\
\text { standardized probit regression coefficient (StdYX). } S E=\text { standard error. } \mathrm{CI}=\text { confidence interval. }\end{array}$} \\
\hline
\end{tabular}




\section{CHAPTER 4}

\section{DISCUSSION}

Early developmental adversities are risk factors in the etiology and maintenance of delinquent and sexually abusive behaviors according to several prominent theories (e.g., Grady et al., 2016; Lussier, 2015; Moffitt, 1993; Piquero et al., 2012; Stinson, Sales, \& Becker, 2008; Ward \& Beech, 2005). Exposure to adversity is theorized to differentially impact the development and persistence of maladaptive behaviors depending on the event's timing in relation to development, nature of adverse event, environmental influences, and subsequent internal and external impact on the person victimized (Grady et al., 2016; Lussier, 2015; Stinson, Sales, \& Becker, 2008). However, the results of previous inquiries are largely mixed with regard to the manner in which diverse adverse experiences and other contextual variables interact to influence patterns of unwanted and abusive behaviors across samples. Determining developmental antecedents preceding the first and subsequent instances of abusive behaviors may contribute to etiological explanations and improve the effectiveness of primary prevention and intervention efforts. The present study employed SEM to first confirm factors of ACE survey items through CFA and then analyzed conduits between confirmed factors and the onset, nature, and persistence of diverse maladaptive behavior strategies in a sample disproportionality impacted by individual- and community-level adversities.

\section{CFA of ACEs}

The CFA model diverged with previous factor analyses using ACE methodology with samples of adults in the community in two ways (e.g., Felitti et al., 1998; Ford et al., 2014). First, emotional and physical/medical neglect were strongly correlated with one another in the present sample and were incorporated into the factor analysis as one variable to prevent multicollinearity 
concerns. This approach differentiates these findings from studies using the original ACE survey scale (CDC, 2016c), but this approach can likely be attributed to the high frequency of documented histories of various types of neglect in more high-risk, treatment samples, such as the sample used for this study. To demonstrate, nearly a third more of these male youths experienced physical and/or medical neglect compared to adult males in the community (CDC, 2016c).

Second, this study incorporated two additional adversities - being introduced to pornography by an adult and witnessing sexual behaviors between others in one's home of origin - to further detail sexual exposure histories. Including more passive indicators of sexual inappropriateness in the home can be supported from theoretical and empirical standpoints. For instance, the multimodal self-regulation theory theorizes that inappropriate sexual activity in the home of origin may inform cognitions and beliefs that support problematic sexual behavior (Stinson, Sales, \& Becker, 2008). Furthermore, previous studies have demonstrated that individuals who engage in sexually abusive behaviors tend to report earlier onset and more frequent exposure to sexual behavior between others by witnessing others in their environment and/or viewing pornography in comparison to nonsexual offending adolescents (Beauregard et al., 2004; Seto \& Lalumiére, 2010; Seto et al., 2001). Thus, sexually abusive behavior may be learned and normalized through observations during earlier developmental periods and does not necessitate direct sexual victimization for harm to occur. For sexually abused individuals, these additional exposures may infer pervasive sexual inappropriateness in the home environment and serve to exacerbate the effects of direct abuse experiences. Accordingly, attention to more passive indicators of atypical sexual development, in addition to sexual abuse, may be important 
considerations when assessing for ACEs, particularly within populations who later engage in sexual offending behaviors.

Consistent with expectations, the CFA revealed a three-factor model distinguishing nonsexual abuse and neglect, household dysfunction, and sexual abuse and exposures to sexual boundary problems within the home. Additionally, moderate to strong factor loadings indicate unique contributions of exposures to sexual boundary issues as well as commonality across sexual abuse and more passive exposures to sexual problems in the home. A benefit of CFA is that it provides empirical support for the number of factors hypothesized, arrangement and inclusion of factor indicators, and relationships between the factors (Kahn, 2006), which properly considers the interrelatedness of ACEs demonstrated in previous studies (e.g., Baglivio \& Epps, 2016; Dong et al., 2004). Excellent model fit and strong factor indicators necessitate additional study using this three-factor ACE model across samples to determine its reliability and validity. Empirically-validated ACE subscales have the potential for future use. Rather than relying on individual items or a singular cumulative score, using empirically-derived subscales can improve the generalizability of models of varied types of adversity while simultaneously accounting for complex trauma.

\section{ACEs and Pathways to Delinquent and Sexually Abusive Behavior}

Thus far, several offense characteristics have been identified as important considerations in studying the evolution and risk of delinquent and sexual offending behaviors (Carpentier, Leclerc, \& Proulx, 2011; Levenson \& Socia, 2016; Lussier, 2015; Tzoumakis, Lussier, Le Blanc, \& Davies, 2012). Several typologies of adolescents and adults who engage in sexually abusive behaviors have been proposed in the last two decades, including the so-called "sex-only" (i.e., specialist) group who primarily commit sexual offenses versus "sex-plus" (i.e., versatile) 
categorization consisting of those who offend against others in nonsexual and sexual ways (Butler \& Seto, 2002). While these two groups have similarities, patterns of behavior with regard to onset, risk factors, and offense characteristics appear to differ (e.g., Butler \& Seto, 2002; Levenson \& Socia, 2016; Pullman, Leroux, Motayne, \& Seto, 2014). However, empirical support for typology or classification methods that adequately account for the diversity among youth who sexually offend across developmental stages is limited thus far (Cale et al., 2016; Lussier, 2015). Additional research considering the trajectory, nature, and frequency of offending behaviors as well as perpetrator, victim, and environmental characteristics will provide a comprehensive view of pathways to nonsexual and sexual offending in youth.

For the purpose of contributing to this perspective, the current study investigated ACEs as related to three offense qualities: age of onset, persistence as measured by arrest, and nature or seriousness of offenses. Overall, findings support hypotheses and revealed direct influences between ACEs and aspects of nonsexual and sexually abusive behaviors. Moreover, divergent adverse exposures differentiated patterns of maladaptive behaviors, signifying unique developmental considerations for nonsexual versus sexual offending in male adolescents with histories of engaging in sexually abusive behaviors.

Nonsexual delinquent behavior. With respect to the onset and persistence of nonsexual crime, exposure to household dysfunction was associated with an early onset of delinquent behavior and a greater number of nonsexual offense arrests. On the contrary, nonsexual abuse and neglect did not significantly influence the onset and persistence of nonsexual offending. Previous research examining adults in treatment for sexual offending demonstrated a similar link between household dysfunction and a greater number of arrests for nonsexual offenses, though this was not true for nonsexual abuse and neglect (Levenson \& Socia, 2016). A potential 
explanation for these discrepant findings may be rooted in attachment theory and the consequences of varied attachment styles (Benoit, 2004; Bowlby, 1973; Grady et al., 2016). Specifically, household dysfunction may result in inconsistent and unpredictable parenting styles due to caregiver factors, such as substance use, inability to regulate emotions, and/or periodic absences because of incarceration, psychiatric hospitalizations, or other events. As a result, individuals raised in chaotic and dysfunctional homes may develop insecure-resistant attachments and subsequently engage in a range of maladaptive behaviors to elicit attention and responsiveness from his or her environment. Alternatively, emotional and physical abuse in response to expressions of distress or dysregulation may be more relevant to the development of insecure-avoidant attachments and contribute to alternate forms of problematic emotional and behavioral patterns.

Regarding the severity of nonsexual delinquency, violent offense arrests were unrelated to experiences of household dysfunction and nonsexual abuse and neglect, contrary to predictions. This was fairly surprising given the existing research that demonstrates a strong relationship between ACEs and violent offending. For instance, Fox and colleagues (2015) report significant relationships between nonsexual abuse, neglect, household dysfunction, and perpetrating serious and violent offenses as a juvenile. It is relevant to note that many studies highlight the cumulative impact of several types of exposures on the risk of violence and aggression (e.g., Fox et al., 2015; Levenson \& Socia, 2016; Stinson et al., 2016). Therefore, it may be that cumulative childhood adversity is a more telling predictor for violent offending in adolescence, rather than exposure to the ACE survey composite subscales used in the current analysis. It is also important to consider the selectiveness of this particular sample of adolescents, compared to alternate studies. Because these adolescents are receiving treatment in a non-secure 
treatment facility, rather than a secure juvenile detention facility for instance, they may have less markedly violent histories, which may contribute to some of the differences in findings.

Sexual abuse and indicators of sexual boundary problems were associated with later onset of nonsexual delinquency as well as fewer arrests and lower risk of violent offense arrests. These findings may support the notion that sexually victimized youth engage in less versatile offending behaviors, consistent with the high prevalence of sexual abuse and atypical sexual interests amongst juveniles who engage in sexual versus nonsexual offenses (Seto \& Lalumière, 2010). Conversely, these results may be more indicative of less formal court responsiveness to nonsexual crimes committed by sexually victimized youth. Additional investigation into this seemingly complex relationship between sexual abuse and nonsexual behavior is warranted to adequately support these proposed explanations.

Sexually abusive behavior. The results related to the influences of childhood adversity on patterns and trajectories of sexually abusive behavior were informative. Experiencing sexual abuse and sexual boundary problems in the home were associated with a younger age at first documented sexually abusive behavior. This finding substantiates those from previous research that demonstrates a link between sexual victimization and early onset of sexually abusive behavior in samples of youth who have sexually abused others (e.g., Burton et al., 2011; Cooper et al., 1996). A somewhat surprising finding was that individuals with histories of sexual abuse or sexual boundary problems in the home demonstrated less persistent sexually abusive behavior, as operationalized by number of arrests. The relationship between sexual victimization and later arrest for sexual offending behaviors is inconsistent in the current empirical literature, with some studies that have found that CSA is linked to more sexual offense related arrests in adults (e.g., Cooper et al., 1996; Levenson \& Socia, 2016). However, these findings may be impacted by the 
use of arrest as the sole measure of persistence, particularly in a sample of adolescents. To illustrate, Cooper and colleagues (1996) found similar sexual arrest consistencies in a sample of adolescents who had sexually abused others. However, the authors discovered that sexually victimized adolescents had nearly twice the number of victims compared to those without histories of sexual victimization.

Neither household dysfunction nor nonsexual abuse or neglect were associated with the onset and persistence of sexually abusive behavior. It is plausible that these individuals, particularly those with histories of household dysfunction, represent juvenile offenders with substantial self-regulation deficits who persistently engage in versatile offending behaviors as self-regulatory strategies but do not have atypical or non-normative sexual interests, as differentiated in the multimodal self-regulation theory of sexual offending (Stinson, Sales, \& Becker, 2008). Due to low reporting rates for sexual offenses, particularly those committed by juveniles, as well as more frequent diversion to the child protection system rather than the juvenile justice system in certain communities (Finkelhor et al., 2009), additional measures of persistence of sexual offending may provide additional information.

Intriguing relationships emerged between types of adverse experiences and contact sexual offending. Findings demonstrate that individuals who experienced nonsexual abuse and neglect were less likely to commit a contact sexual offense, whereas household dysfunction was linked to a greater likelihood of contact offending. Conversely, there was no significant relationship identified between sexual abuse and sexual boundary problems in the home and perpetrating a contact offense. The pathways revealed here provide contradictory evidence for social learning theories of sexual offending that underlie the sexually abused-abuser hypothesis, which emphasizes that one's own abuse experience and related beliefs supportive of inappropriate 
sexual contact are learned or reinforced as etiological explanations for later offending (see Seto \& Lalumière, 2010; Stinson, Sales, \& Becker, 2008 for critiques). Instead, contact sexual offending in the present sample appears to be an additional maladaptive coping strategy and yet another potential consequence of insecure attachment (Benoit, 2004; Grady et al., 2016) and selfregulatory deficits (Stinson, Sales, \& Becker, 2008), often developed in chaotic households marked by caregiver absence, inconsistency, and unpredictability.

\section{Socioecological Influences}

The final hypothesis involved potential moderating effects of socioecological characteristics, including community violence, economic adversity, and rurality, characterizing each participant's county of origin. Unfortunately, the data did not support a moderated multilevel SEM approach due to too few participants per cluster (i.e., originating from each county). Subsequent investigation into correlations between social and economic environment of county of origin and nonsexual delinquent and sexually abusive behaviors revealed few significant relationships, contrary to original predictions. One intriguing finding was related to the role of rurality. Greater proportion of rurality in county of origin was positively correlated with a greater number of arrests for nonsexual offenses, which supported the relevance of rurality and its inclusion as a covariate within the exploratory modified model for nonsexual delinquent behavior. However, the modified model, with rurality as a covariate, proved to be a poor fit for the data. It is possible that the referral process for this particular facility may also be influencing these results, as most juveniles were referred for treatment by the court as a diversionary measure. Thus, judges and other court officials across counties may differ in their decision-making and knowledge of the facility's existence, and thus the present sample may represent only a unique subset of counties. Therefore, questions pertaining the role of community 
correlates persist and should be a focus of future study. Multilevel SEM would provide clarification of the impact of community characteristics on the relationships between ACE exposures and maladaptive behavioral strategies.

\section{Limitations and Future Directions}

These results should be interpreted in light of several limitations. First, data were collected from archival treatment records of participants, which is a method with both advantages and disadvantages. Archival data offer detailed information and a comprehensive view of each participant's history from a variety of sources, which aided in obtaining reliable data on sensitive items (e.g., abuse histories, documented offending behaviors) that would be generally susceptible to socially desirable responding or recall bias if collected via self-report measures. However, it is also true that there were instances of missing data in available records. There is also some evidence of discrepancies between official records and self-reported arrests, particularly among individuals with histories of child maltreatment and for certain types of offenses. For instance, Maxfield, Weiler, and Widom (2000) reported that individuals with childhood abuse and neglect histories with no official arrest record were more than two times as likely to self-report arrests compared to the control group. On the other hand, across both victimized individuals and non-victimized controls, only around 72 percent of previously arrested individuals self-reported an arrest history, including only around 20 percent of those arrested for rape (Maxfield et al., 2000). Overall, studies have reported moderate to strong concurrent validity between self-reported and official records of arrests (Maxfield et al., 2000; Piquero, Schubert, \& Brame, 2014). Nonetheless, consideration of potentially undocumented offending behaviors and arrests in the interpretation of our findings is necessary. 
Additionally, using secondary county-level data has additional strengths and limitations relevant to the interpretation of these findings. Advantageous characteristics of the CHR\&R program data are the broad availability of information on a variety of measures to facilitate the study of variations across communities, inform a more comprehensive view of single community of interest, and educate the public and policy-makers on a given issue to motivate action (Remington, 2015). In addition, the CHR\&R method is concise, easy to comprehend, and an overall well-established as a reliable source of public health information since its origin in 2010 (Remington, Catlin, \& Gennuso, 2015). One major limitation is the variance in reliability of data depending on measure and across counties, particularly in counties with smaller populations or more rural areas (Remington et al., 2015), which is relevant in the context of the present study's purpose. In an attempt to counteract measurement error that critics argue arises when using county rankings data due to inconsistencies across settings (Arndt, 2015; Remington et al., 2015), the present study used the z-score computed for social and economic environment and percentage of county considered rural, rather than using state rankings. Computed z-scores still depend on other counties in the state but are presented on a standardized scale to aid in county comparisons (Remington et al., 2015). Another design concern is the potential loss of information when combining substantially varied neighborhoods in one overall county, as many disparities in health, economic adversity, and violence may exist across neighborhoods. Locating available measures of county characteristics that better account for inequalities within each county would likely improve the psychometric properties of community correlates. Additionally, using cross-sectional data, such as the kind used for the present study, limits interpretation of causality among variables. Future studies using longitudinal designs would provide support for the validity and directionality of these findings. 
It is important to note that findings for these males who received treatment for sexually abusive behaviors were not compared to a matched control group, such as adolescents with similar victimization histories who have not engaged in sexually abusive behaviors. Additionally, our findings may differ from populations of non-offending and nonsexual offending youth or female adolescents who engage in sexually abusive behaviors due to varied rates of ACEs, formal responsiveness by authorities and/or treatment providers, and societal and legal influences. For example, the present sample had substantially higher rates of ACEs compared to adults in the general, community population (CDC, 2016c); adult males in treatment for sexual offenses (Levenson et al., 2014); and, juvenile justice-involved males (Baglivio et al., 2014). Conversely, in one study, more than three-fourths (78\%) of females who engaged in sexually abusive behavior had been sexually abused compared to two-fifths (44\%) of males who engaged in similar behaviors (Mathews, Hunter, \& Vuz, 1997). As noted, this sample also may differ with regard to rates of violence and characteristics of counties of origin compared to samples from secure juvenile detention centers. Thus, developmental adversity, maladaptive behaviors, and legal involvement inordinately impacts justice-involved populations and may differ based on gender, race, and other characteristics. While the current study's findings are beneficial, similar studies using this model to investigate the influence of childhood adversity and nonsexual delinquent and sexually abusive behaviors across samples are essential. Incorporating additional relevant individual and environmental characteristics is similarly important, including, but not limited to: peer interactions (Finkelhor et al., 2013; Johnson et al., 2002); aggression and impulsivity (Perez, Jennings, \& Baglivio, 2018); psychopathology (Seto \& Lalumière, 2010); and, negative emotionality (Wolff \& Baglivio, 2016). 


\section{Summary and Implications}

In summary, the present study demonstrated divergent developmental pathways describing the onset, nature, and persistence of nonsexual delinquent and sexually abusive behaviors using SEM. Differential exposures to ACEs and other indicators of sexual boundary problems revealed differing patterns of problematic behaviors, suggesting that experiencing diverse types and combinations of adversities during childhood may result in divergent offending pathways. In particular, household dysfunction was associated with a more general pattern of offending behaviors, including earlier onset and more persistent nonsexual offending as well as contact sexual offending. In contrast, sexual abuse and exposure to sexual boundary problems in the home were associated with an early onset of sexually abusive behavior and indicators of less persistent, severe, and versatile offending. Socioecological factors did not prove to be beneficial covariates within the derived models, and including these factors as moderators was implausible due to data limitations. Taken together, this SEM approach permits distinguishing between the impact of varied ACE experiences on the development and nature of maladaptive behavior, while simultaneously accounting for the interrelatedness of ACEs in a sample of male adolescents receiving treatment for sexually abusive behavior and provides direction for future research in this area. 


\section{REFERENCES}

Ainsworth, M. D. S., Blehar, M. C, Waters, E., \& Wall, S. (1978). Patterns of attachment: A psychological study of the strange situation. Hillsdale, NJ: Erlbaum.

Allison, P. D. (2003). Missing data techniques for structural equation modeling. Journal of Abnormal Psychology, 112(4), 545-557. doi: 10.1037/0021-843X.112.4.545

Anderson, K. M., Renner, L. M., \& Bloom, T. S. (2013). Rural women's strategic responses to intimate partner violence. Health Care for Women International, 35(4), 423-441. doi: $10.1080 / 07399332.2013 .815757$

Annan, S. L. (2008). Intimate partner violence in rural environments. Annual Review of Nursing Research, 26(1), 85-113. doi: 10.1177/1078390311401024

Arndt, S. (2015). Just how useful are health rankings? The problem with ranks. Health Services Research, 50(5), 1403-1406. doi: 10.1111/1475-6773.12350

Asparouhov, T., \& Muthén, B. O. (2010). Weighted least squares estimation with missing data (Mplus Technical Report). Retrieved from: http://www.statmodel.com.

Association for the Treatment of Sexual Abusers. (2012). Adolescents who have engaged in sexually abusive behavior: Effective policies and practices. Retrieved from http://www.atsa.com.

Association for the Treatment of Sexual Abusers. (2017). Practice guidelines for assessment, treatment, and intervention with adolescents who have engaged in sexually abusive behavior. Retrieved from http://www.atsa.com.

Averill, J. B., Padilla, A. O., \& Clements, P. T. (2007). Frightened in isolation: Unique considerations for research of sexual assault and interpersonal violence in rural areas. Journal of Forensic Nursing, 3(1), 42-46. doi: 10.1111/j.1939-3938.2007.tb00091 
Baglivio, M. T., \& Epps, N. (2016). The interrelatedness of adverse childhood experiences among high-risk juvenile offenders. Youth Violence and Juvenile Justice, 14(3), 179-198. doi: $10.1177 / 1541204014566286$

Baglivio, M. T., Epps, N., Swartz, K., Sayedul Huq, M., Sheer, A., \& Hardt, N. S. (2014). The prevalence of adverse childhood experiences (ACE) in the lives of juvenile offenders. Journal of Juvenile Justice, 3(2), 1-23.

Baglivio, M. T., Wolff, K. T., Epps, N., \& Nelson, R. (2017). Predicting adverse childhood experiences: The importance of neighborhood context in youth trauma among delinquent youth. Crime \& Delinquency, 63(2), 166-188. doi: 10.1177/0011128715570628

Bandura, A. (1969). Principles of behavior modification. New York, NY: Holt, Rinehart, and Winston.

Bandura, A. (1977). Self-efficacy: Toward a unifying theory of behavioral change. Psychological Review, 84, 191-215.

Barnett, C., \& Mencken, F. C. (2002). Social disorganization theory and the contextual nature of crime in nonmetropolitan counties. Rural Sociology, 67(3), 372-393. doi: 10.1111/j.1549-0831.2002.tb00109.x

Beaudry-Cyr, M., Jennings, W. G., Zgoba, K. M., \& Tewksbury, R. (2017). Examining the continuity of juvenile sex offending into adulthood and subsequent patterns of sex and general recidivism. International Journal of Offender Therapy and Comparative Criminology, 61(3), 251-268. doi: 10.1177/0306624X15594442

Beauregard, E., Lussier, P., \& Proulx, J. (2004). An exploration of developmental factors related to deviant sexual preferences among adult rapists. Sexual Abuse: A Journal of Research and Treatment, 16(2), 151-161. doi: 10.1177/107906320401600205 
Belanger, K., \& Stone, W. (2008). The social service divide: Service availability and accessibility in rural versus urban counties and impact on child welfare outcomes. Child Welfare, 87(4), 101-124.

Benoit, D. (2004). Infant-parent attachment: Definitions, types, antecedents, measurement and outcomes. Paediatrics \& Child Health, 9(8), 541-545.

Bentler, P. M. (1990). Comparative fit indices in structural models. Psychological Bulletin, 107, 238-246.

Berg, M. T., \& DeLisi, M. (2005). Do career criminals exist in rural America? Journal of Criminal Justice, 33(4), 317-325. doi: 10.1016/j.jcrimjus.2005.04.002

Bergman, L. R., \& Trost, K. (2006). The person-oriented versus the variable-oriented approach: Are they complementary, opposites, or exploring different worlds?. Merrill-Palmer Quarterly, 52(3), 601-632. doi: 10.1353/mpq.2006.0023

Bouffard, L. A., \& Muftić, L. R. (2006). The" rural mystique": Social disorganization and violence beyond urban communities. Western Criminology Review, 7(3), 56-66.

Bowlby, J. (1969). Attachment and loss, vol. 1: Attachment. New York, NY: Basic Books.

Bowlby, J. (1973). Attachment and loss, vol. 2: Separation. New York, NY: Basic Books.

Braithwaite, J. (2015). Sexual violence in the backlands: Towards a macro-level understanding of rural sex crimes. Sexual Abuse: A Journal of Research and Treatment, 27(5), 496-523. doi: $10.1177 / 1079063214521471$

Bretherton, I. (1992). The origins of attachment theory: John Bowlby \& Mary Ainsworth. Developmental Psychology, 28(5), 759-775. 
Bretherton, I. (2005). In pursuit of the internal working model construct and its relevance to attachment relationships. In K. E. Grossmann, K. Grossmann, \& E. Waters (Eds.), Attachment from infancy to adulthood: The major longitudinal studies (pp. 13 -47). New York, NY: Guildford Press.

Bruley, C., Hatfield, J., \& Markel, P. (2012). Rural court sentencing as a predictor of re-arrest rates for domestic-violence offenders. Journal of Rural Mental Health, 36(1), 18-23. doi: $10.1037 / \mathrm{h} 0094776$

Burton, D. L., Duty, K. J., \& Leibowitz, G. S. (2011). Differences between sexually victimized and nonsexually victimized male adolescent sexual abusers: Developmental antecedents and behavioral comparisons. Journal of Child Sexual Abuse, 20(1), 77-93.

doi: $10.1080 / 10538712.2011 .541010$

Butler, S. M., \& Seto, M. C. (2002). Distinguishing two types of adolescent sex offenders. Journal of the American Academy of Child \& Adolescent Psychiatry, 41(1), 83-90. doi: 10.1097/00004583-200201000-00015

Caldwell, M. F. (2010). Study characteristics and recidivism base rates in juvenile sex offender recidivism. International Journal of Offender Therapy and Comparative Criminology, 54(2), 197-212. doi: 10.1177/0306624X08330016

Cale, J., Smallbone, S., Rayment-McHugh, S., \& Dowling, C. (2016). Offense trajectories, the unfolding of sexual and non-sexual criminal activity, and sex offense characteristics of adolescent sex offenders. Sexual Abuse: A Journal of Research and Treatment, 28(8), 791-812. doi: $10.1177 / 1079063215580968$ 
Carpentier, J., Leclerc, B., \& Proulx, J. (2011). Juvenile sex offenders: Correlates of onset, variety, and desistance of criminal behavior. Criminal Justice and Behavior, 38(8), 854873. doi: $10.1177 / 0093854811407730$

Cebulak, W. (2004). Why rural crime and justice really matter. Journal of Police and Criminal Psychology, 19(1), 71-81. doi:10.1007/bf02802576

Centers for Disease Control and Prevention. (2016a). About behavioral risk factor surveillance system ACE data. Retrieved from http://www.cdc.gov.

Centers for Disease Control and Prevention. (2016b). Adverse childhood experiences study: Major findings. Retrieved from http://www.cdc.gov.

Centers for Disease Control and Prevention. (2016c). Adverse childhood experiences study: Prevalence of individual adverse childhood experiences. Retrieved from http://www.cdc.gov.

Chaffin, M., Berliner, L., Block, R., Johnson, T. C., Friedrich, W. N., Louis, D. G., ... Silovsky, J. F. (2008). Report of the ATSA task force on children with sexual behavior problems. Child Maltreatment, 13(2), 199-218. doi: 10.1177/1077559507306718

Chaffin, M., Letourneau, E., \& Silovsky, J. F. (2002). Adults, adolescents, and children who sexually abuse children: A developmental perspective. The APSAC Handbook on Child Maltreatment $\left(2^{\text {nd }}\right.$ ed. $)$, 205-232.

Cooper, C. L., Murphy, W. D., \& Haynes, M. R. (1996). Characteristics of abused and nonabused adolescent sexual offenders. Sexual Abuse: A Journal of Research and Treatment, 8(2), 105-119. doi: 10.1177/107906329600800205

Cordner, A. (2013). An examination of criminal justice offenders in Pennsylvania. The Center for Rural Pennsylvania. Retrieved from http://www.rural.palegislature.us. 
Crowell, J., \& Waters, E. (2005). Attachment representations, secure-base behavior, and the evolution of adult relationships: The Stony Brook adult relationship project. In K. E. Grossmann, K. Grossmann, \& E. Waters (Eds.), Attachment from infancy to adulthood: The major longitudinal studies (pp. 223-244). New York, NY: Guildford Press.

Deller, S. C., \& Deller, M. W. (2011). Structural shifts in select determinants of crime with a focus on rural and urban differences. Western Criminology Review, 12(3), 120-128.

Dong, M., Anda, R. F., Felitti, V. J., Dube, S. R., Williamson, D. F., Thompson, T. J., ... \& Giles, W. H. (2004). The interrelatedness of multiple forms of childhood abuse, neglect, and household dysfunction. Child Abuse \& Neglect, 28(7), 771-784.

doi: 10.1016/j.chiabu.2004.01.008

Evans, G. W. (2004). The environment of childhood poverty. American Psychologist, 59, 77-92.

Felitti, V. J., Anda, R. F., Nordenberg, D., Williamson, D. F., Spitz, A. M., Edwards, V., ... \& Marks, J. S. (1998). Relationship of childhood abuse and household dysfunction to many of the leading causes of death in adults: The adverse childhood experiences (ACE) study. American Journal of Preventive Medicine, 14(4), 245-258.

doi: 10.1016/S0749-3797(98)00017-8

Finkelhor, D., Ormrod, R., \& Chaffin, M. (2009). Juveniles who commit sex offenses against minors (NCJ Publication No. 227763). Washington, DC: U.S. Department of Justice.

Finkelhor, D., Shattuck, A., Turner, H., \& Hamby, S. (2013). Improving the adverse childhood experiences study scale. JAMA Pediatrics, 167, 70-75.

doi: $10.1001 /$ jamapediatrics.2013.420 
Finkelhor, D., Shattuck, A., Turner, H., \& Hamby, S. (2015). A revised inventory of adverse childhood experiences. Child Abuse \& Neglect, 48, 13-21. doi: $10.1016 /$ j.chiabu.2015.07.011

Finkelhor, D., Turner, H. A., Shattuck, A., \& Hamby, S. L. (2015). Prevalence of childhood exposure to violence, crime, and abuse: Results from the National survey of children's exposure to violence. JAMA Pediatrics, 169(8), 746-754.

doi: 10.1001/jamapediatrics.2015.0676

Fleckman, J. M., Drury, S. S., Taylor, C. A., \& Theall, K. P. (2016). Role of direct and indirect violence exposure on externalizing behavior in children. Journal of Urban Health, 93(3), 479-492. doi: 10.1007/s11524-016-0052-y

Font, S. A., \& Maguire-Jack, K. (2015). Decision-making in child protective services: Influences at multiple levels of the social ecology. Child Abuse \& Neglect, 47, 70-82. doi: 10.1016/j.chiabu.2015.02.005

Ford, D. C., Merrick, M. T., Parks, S. E., Breiding, M. J., Gilbert, L. K., Edwards, V. J., ... \& Thompson, W. W. (2014). Examination of the factorial structure of adverse childhood experiences and recommendations for three subscale scores. Psychology of Violence, 4(4), 432-444. doi: 10.1037/a0037723

Fox, B. H., Perez, N., Cass, E., Baglivio, M. T., \& Epps, N. (2015). Trauma changes everything: Examining the relationship between adverse childhood experiences and serious, violent, and chronic juvenile offenders. Child Abuse \& Neglect, 46, 163-173.

doi: 10.1016/j.chiabu.2015.01.011 
Fowler, P. J., Tompsett, C. J., Braciszewski, J. M., Jacques-Tiura, A. J., \& Baltes, B. B. (2009). Community violence: A meta-analysis on the effect of exposure and mental health outcomes of children and adolescents. Development and Psychopathology, 21(1), $227-$ 259. doi: $10.1017 / \mathrm{S} 0954579409000145$

Fraley R. C., \& Shaver P. R. (2000). Adult romantic attachments: Theoretical development, emerging controversies, and unanswered questions. Review of General Psychology, 4(2), 132-154. doi: 10.1037//1089-2680.4.2.132

Gallup-Black, A. (2004). Rural and urban trends in family and intimate partner homicide: 1980 - 1999. U.S. Department of Justice, National Institute of Justice (Brief No. 2003-IJ-CX1003). Retrieved from http://www.ncjrs.gov.

Gamm, L., Stone, S., \& Pittman, S. (2010). Mental health and mental disorders-A rural challenge: A literature review. Rural Healthy People, 1, 97-114.

Garbarino, J., \& Kostelny, K. (1997). What children can tell us about living in a war zone. In J. D. Osofsky (Ed.), Children in a violent society (pp. 32-41). New York, NY: The Guilford Press.

Grady, M. D., Levenson, J. S., \& Bolder, T. (2016). Linking adverse childhood effects and attachment: A theory of etiology for sexual offending. Trauma, Violence, \& Abuse, 1-12. doi: $10.1177 / 1524838015627147$

Hall, K. L., Stinson, J. D., \& Moser, M. R. (2018). Impact of childhood adversity and out-ofhome placement for male adolescents who have engaged in sexually abusive behavior. Child Maltreatment. doi: 10.1177/1077559517720726 
Harris, A. J., \& Socia, K. M. (2014). What's in a name? Evaluating the effects of the "sex offender" label on public opinions and beliefs. Sexual Abuse: A Journal of Research and Treatment, 28(7), 660-678. doi: 10.1177/1079063214564391

Hazan, C., \& Shaver, P. (1987). Conceptualizing romantic love as an attachment process. Journal of Personality and Social Psychology, 52, 511-524. doi: $10.1037 / 0022-3514.52 .3 .511$

Heatherton, T. F., \& Wagner, D. D. (2011). Cognitive neuroscience of self-regulation failure. Trends in Cognitive Sciences, 15, 132-139. doi: 10.1016/j.tics.2010.12.005

Hetling, A., \& Zhang, H. (2010). Domestic violence, poverty, and social services: Does location matter? Social Science Quarterly, 91(5), 1144-1163. doi: $10.1111 / \mathrm{j} .1540-6237.2010 .00725 . \mathrm{x}$

Hoeve, M., Stams, G. J. J., van der Put, C. E., Dubas, J. S., van der Laan, P. H., \& Gerris, J. R. (2012). A meta-analysis of attachment to parents and delinquency. Journal of Abnormal Child Psychology, 40(5), 771-785. doi: 10.1007/s10802-011-9608-1

Housing Assistance Council. (2012). Taking stock: Rural people, poverty, and housing in the $21^{\text {st }}$ century. Retrieved from http://www.ruraldataportal.org

IBM Corp. (2016). IBM SPSS Statistics for Macintosh, Version 24.0 [Statistical Software]. Armonk, NY: IBM Corp.

Jespersen, A. F., Lalumière, M. L., \& Seto, M. C. (2009). Sexual abuse history among adult sex offenders and non-sex offenders: A meta-analysis. Child Abuse \& Neglect, 33(3), 179192. doi: 10.1016/j.chiabu.2008.07.004 
Johnson, J. G., Cohen, P., Gould, M. S., Kasen, S., Brown, J., \& Brook, J. S. (2002). Childhood adversities, interpersonal difficulties, and risk for suicide attempts during late adolescence and early adulthood. Archives General Psychiatry, 59, 741-749. doi: 10.1001/archpsyc.59.8.741

Jutte, D. P., Miller, J. L., \& Erickson, D. J. (2015). Neighborhood adversity, child health, and the role for community development. Pediatrics, 135(S2), S48-S57. doi: 10.1542/peds.2014-3549F

Kahn, J. H. (2006). Factor analysis in counseling psychology research, training, and practice: Principles, advances, and applications. The Counseling Psychologist, 34, 684-718.

Kaylen, M. T., \& Pridemore, W. A. (2013). The association between social disorganization and rural violence is sensitive to the measurement of the dependent variable. Criminal Justice Review, 38(2), 169-189. doi: 10.1177/0734016813476715

Kline, R. B. (2016). Principles and Practice of Structural Equation Modeling ( $\left.4^{\mathrm{rd}} \mathrm{ed}.\right) . \mathrm{New}$ York: Guilford Press.

Knight, R. A., \& Sims-Knight, J. E. (2003). The developmental antecedents of sexual coercion against women: Testing alternative hypotheses with structural equation modeling. Annals of the New York Academy of Sciences, 989, 72-85.

Koenigsberg, H. W., Siever, L. J., Lee, H., Pizzarello, S., New, A. S., Goodman, M., ... \& Prohovnik, I. (2009). Neural correlates of emotion processing in borderline personality disorder. Psychiatry Research: Neuroimaging, 172(3), 192-199.

doi: 10.1016/j.pscychresns.2008.07.010

Kubrin, C. E., \& Weitzer, R. (2003). New directions in social disorganization theory. Journal of Research in Crime and Delinquency, 40(4), 374-402. doi: 10.1177/0022427803256238 
Lanier, C., \& Maume, M. O. (2009). Intimate partner violence and social isolation across the rural/urban divide. Violence Against Women, 15(11), 1311-1330. doi: $10.1177 / 1077801209346711$

Lee, J. K., Jackson, H. J., Pattison, P., \& Ward, T. (2002). Developmental risk factors for sexual offending. Child Abuse \& Neglect, 26(1), 73-92.

Letourneau, E. J., \& Miner, M. H. (2005). Juvenile sex offenders: A case against the legal and clinical status quo. Sexual Abuse: A Journal of Research and Treatment, 17(3), 293-312. doi: 10.1007/s11194-005-5059-y

Levenson, J. S., \& Grady, M. (2016). The influence of childhood trauma on sexual violence and sexual deviance in adulthood. Traumatology, 22(2), 94-103. doi: 10.1037/trm0000067

Levenson, J. S., \& Socia, K. M. (2016). Adverse childhood experiences and arrest patterns in a sample of sexual offenders. Journal of Interpersonal Violence, 31(10), 1883-1911. doi: $10.1177 / 0886260515570751$

Levenson, J. S., Willis, G., \& Prescott, D. (2014). Adverse childhood experiences in the lives of male sex offenders and implications for trauma-informed care. Sexual Abuse: A Journal of Research and Treatment, 28(4), 340-359. doi: 10.1177/1079063214535819

Leventhal, T., \& Brooks-Gunn, J. (2011). Changes in neighborhood poverty from 1990 to 2000 and youth's problem behaviors. Developmental Psychology, 47(6), 1680-1698.

Lewis, S. H. (2008). Sexual assault in rural America. Enola, PA: National Sexual Violence Resource Center.

Liang, X., \& Yang, Y. (2014). An evaluation of WLSMV and Bayesian methods for confirmatory factor analysis with categorical indicators. International Journal of Quantitative Research in Education, 2(1), 17-38. doi: 10.1504/ijqre.2014.060972 
Lussier, P. (2015). Juvenile sex offending through a developmental life course criminology perspective: An agenda for policy and research. Sexual Abuse: A Journal of Research and Treatment, 1-30, doi: 10.1177/1079063215580966

Lussier, P., van den Berg, C., Bijleveld, C., \& Hendriks, J. (2012). A developmental taxonomy of juvenile sex offenders for theory, research, and prevention. Criminal Justice and Behavior, 39, 1559-1581. doi: 10.1177/0093854812455739

Maguire-Jack, K., \& Font, S. A. (2017). Intersections of individual and neighborhood disadvantage: Implications for child maltreatment. Children \& Youth Services Review, 72, 44-51. doi: 10.1016/j.childyouth.2016.10.015

Marans, S., \& Adelman, A. (1997). Experiencing violence in a developmental context. In J. D. Osofsky (Ed.), Children in a violent society (pp. 202-222). New York, NY: The Guilford Press.

Marshall, W. L., Hudson, S. M., \& Hodkinson, S. (1993). The importance of attachment bonds in the development of juvenile sex offending. In H. E. Barbaree, W. L. Marshall, \& S. M. Hudson (Eds.), The juvenile sex offender (pp. 164-181). New York, NY: Guilford Press.

Mathews, R., Hunter, J. A., \& Vuz, J. (1997). Juvenile female sexual offenders: Clinical characteristics and treatment issues. Sexual Abuse: A Journal of Research and Treatment, 9(3), 187-199. doi: 10.1177/107906329700900304

Maxfield, M. G., Weiler, B. L., and Widom, C. S. (2000). Comparing self-reports and official records of arrests. Journal of Quantitative Criminology, 16(1), 87-110. doi: 10.1023/A:1007577512038 
McCall-Hosenfeld, J. S., Weisman, C. S., Perry, A. N., Hillemeier, M. M., \& Chuang, C. H. (2014). "I just keep my antennae out": How rural primary care physicians respond to intimate partner violence. Journal of Interpersonal Violence, 29(14), 2670-2694. doi: $10.1177 / 0886260513517299$

McCann, K., \& Lussier, P. (2008). Antisociality, sexual deviance, and sexual reoffending in juvenile sex offenders: A meta-analytical investigation. Youth Violence and Juvenile Justice, 6, 363-385. doi: 10.1177/1541204008320260

McCuish, E. C., \& Lussier, P. (2017). Unfinished stories: From juvenile sex offenders to juvenile sex offending through a developmental life course perspective. Aggression and Violent Behavior, 37, 71-82. doi: 10.1016/j.avb.2017.09.004

Merrick, M. T., Ports, K. A., Ford, D. C., Afifi, T. O., Gershoff, E. T., \& Grogan-Kaylor, A. (2017). Unpacking the impact of adverse childhood experiences on adult mental health. Child Abuse \& Neglect, 69, 10-19. doi: 10.1016/j.chiabu.2017.03.016

Mersky, J. P., Topitzes, J., \& Reynolds, A. J. (2012). Unsafe at any age linking childhood and adolescent maltreatment to delinquency and crime. Journal of Research in Crime and Delinquency, 49(2), 295-318. doi: 10.1177/0022427811415284

Minzenberg, M. J., Fan, J., New, A. S., Tang, C. Y., \& Siever, L. J. (2008). Frontolimbic structural changes in borderline personality disorder. Journal of Psychiatric Research, 42(9), 727-733. doi: 10.1016/j.jpsychires.2007.07.015

Moffitt, T. E. (1993). Life-course persistent and adolescence limited antisocial behavior: A developmental taxonomy. Psychological Review, 100, 674-701. doi: 10.1037/0033-295X.100.4.674 
Morenoff, J. D., Sampson, R. J., \& Raudenbush, S. W. (2001). Neighborhood inequality, collective efficacy, and the spatial dynamics of urban violence. Criminology, 39, 517559.

Mustaine, E. E., Tewksbury, R., Huff-Corzine, L., Corzine, J., \& Marshall, H. (2014). Community characteristics and child sexual assault: Social disorganization and age. Journal of Criminal Justice, 42(2), 173-183. doi: 10.1016/j.jcrimjus.2013.06.016

Muthén, B. O. (2017, August 10). Comparing non-nested models [Online forum comment]. Retrieved from http://www.statmodel.com/discussion/messages/23/620.html?1506065460

Muthén, L. K., \& Muthén, B. O. (1998-2017a). Mplus User’s Guide, Eighth Edition. Los Angeles, CA: Muthén \& Muthén.

Muthén, L. K., \& Muthén, B. O. (1998-2017b). Mplus (Version 8.0). [Statistical Software]. Los Angeles, CA: Muthén \& Muthén.

Nikulina, V., Widom, C. S., \& Czaja, S. (2011). The role of childhood neglect and childhood poverty in predicting mental health, academic achievement and crime in adulthood. American Journal of Community Psychology, 48, 309-321. doi: 10.1007/s10464-010-9385-y

Osgood, D. W., \& Chambers, J. M. (2000). Social disorganization outside the metropolis: An analysis of rural youth violence. Criminology, 38, 81-116.

Osofsky, J. D. (1997). Children and youth violence: An overview of the issue. In J. D. Osofsky (Ed.), Children in a violent society (pp. 3-8). New York, NY: The Guilford Press.

Overstreet, S. (2000). Exposure to community violence: Defining the problem and understanding the consequences. Journal of Child and Family Studies, 9(1), 7-25. 
Peek-Asa, C., Wallis, A., Harland, K., Beyer, K., Dickey, P., \& Saftlas, A. (2011). Rural disparity in domestic violence prevalence and access to resources. Journal of Women's Health, 20(11), 1743-1749 7p. doi: 10.1089/jwh.2011.2891

Perez, N. M., Jennings, W. G., \& Baglivio, M. T. (2016). A path to serious, violent, chronic delinquency: The harmful aftermath of adverse childhood experiences. Crime \& Delinquency, 64(1), 3-25. doi: 10.1177/0011128716684806

Piquero, A. R., Jennings, W. G., \& Barnes, J. C. (2012). Violence in criminal careers: A review of the literature from a developmental life-course perspective. Aggression and Violent Behavior, 17(3), 171-179. doi: 10.1016/j.avb.2012.02.008

Piquero, A. R., Schubert, C. A., \& Brame, R. (2014). Comparing official and self-report records of offending across gender and race/ethnicity in a longitudinal study of serious youthful offenders. Journal of Research in Crime and Delinquency, 51(4), 526-556. doi: $10.1177 / 0022427813520445$

Proctor, B. D., Semega, J. L., \& Kollar, M. A. (2016). Income and poverty in the United States: 2015 (Report No. P60-256). Washington, DC: U.S. Department of Commerce.

Pullman, L. E., Leroux, E. J., Motayne, G., \& Seto, M. C. (2014). Examining the developmental trajectories of adolescent sexual offenders. Child Abuse \& Neglect, 38(7), 1249-1258. doi: $10.1016 /$ j.chiabu.2014.03.003

Ratcliffe, M., Burd, C. Holder, K., \& Fields, A. (2016). Defining rural at the U.S. Census Bureau: American Community Survey and geography brief (Report No. ACSGEO-1). Washington, DC: U.S. Census Bureau. 
Reavis, J. A., Looman, J., Franco, K. A., \& Rojas, B. (2013). Adverse childhood experiences and adult criminality: How long must we live before we possess our own lives? The Permanente Journal, 17(2), 44-48. doi: 10.7812/tpp/12-072

Remington, P.L. (2015). County health rankings and the cult of the imperfect. Health Services Research, 50(5), 1407-1412. doi: 10.1111/1475-6773.12351.

Remington, P. L., Catlin, B. B., \& Gennuso, K. P. (2015). The county health ranking: Rationale and methods. Population Health Metrics, 13(11). doi: 10.1186/s12963-015-0044-2.

Roux, A. D. (2003). The examination of neighborhood effects on health: Conceptual and methodological issues related to the presence of multiple levels of organization. Neighborhoods and Health, 45-64.

Ruback, B. R. (1993). Comment on Bachman (1993): The victim-offender relationship does affect victim's decisions to report sexual assaults. Criminal Justice and Behavior, 20, 271-279.

Ruback, B. R., \& Menard, K. S. (2001). Rural-urban differences in sexual victimizations and reporting: Analyses using UCR and crisis center data. Criminal Justice and Behavior, 28, 131-155.

Ruback, R. B., Shaffer, J. N., \& Clark, V. A. (2011). Easy access to firearms: Juveniles' risks for violent offending and violent victimization. Journal of Interpersonal Violence, 26(10), 2111-2138. doi: 10.1177/0886260510372948

Sampson, R. J. (2012). Great American city: Chicago and the enduring neighborhood effect. Chicago, IL: University of Chicago Press. 
Sampson, R. J., \& Groves, W. B. (1989). Community structure and crime: Testing social disorganization theory. The American Journal of Sociology, 94(4), 774-802. doi: $10.1086 / 229068$

Sampson, R. J., Raudenbush, S. W., \& Earls, F. (1997). Neighborhoods and violent crime: A multilevel study of collective efficacy. Science, 277(5328), 918-924.

Schonberg, M. A., \& Shaw, D. S. (2007). Risk factors for boy's conduct problems in poor and lower-middle-class neighborhoods. Journal of Abnormal Child Psychology, 35(5), 759772. doi: 10.1007/s10802-007-9125-4se

Seto, M. C., \& Lalumiére, M. L. (2010). What is so special about male adolescent sexual offending? A review and test of explanations through meta-analysis. Psychological Bulletin, 136(4), 526-575. doi: 10.1037/a0019700

Seto, M. C., Maric, A., \& Barbaree, H. E. (2001). The role of pornography in the etiology of sexual aggression. Aggression and Violent Behavior, 6, 35-53.

Shamblin, S. R., Williams, N. F., \& Bellaw, J. R. (2012). Conceptualizing homelessness in rural Appalachia: Understanding contextual factors relevant to community mental health practice. Journal of Rural Mental Health, 36(2), 3-9. doi: 10.1037/h0095809

Shaw, C. R., \& McKay, H. D. (1942). Juvenile delinquency in urban areas. Chicago, IL: University of Chicago Press.

Sickmund, M., \& Puzzanchera, C. (2014). Juvenile offenders and victims: 2014 National report. Pittsburgh, PA: National Center for Juvenile Justice.

Simons, D. A., Wurtele, S. K., \& Durham, R. L. (2008). Developmental experiences of child sexual abusers and rapists. Child Abuse \& Neglect, 32(5), 549-560.

doi: 10.1016/j.chiabu.2007.03.027 
Simpson, J. A., \& Belsky, J. (2008). Attachment theory within a modern evolutionary framework. In J. Cassidy \& P. R. Shaver (Eds.), Handbook of attachment: Theory, research, and clinical applications ( $2^{\text {nd }}$ ed., pp. 131-157). New York, NY: Guilford Press.

Sroufe, L. A., Carlson, E. A., Levy, A. K., \& Egeland, B. (1999). Implications of attachment theory for developmental psychopathology. Development and Psychopathology, 11(1), 113.

Steiger, J. H. (1990). Structural model evaluation and modification: An internal estimation approach. Multivariate Behavioral Research, 25, 173-180.

Steiger, J. H., \& Lind, J. C. (1980). Statistically based tests for the number of common factors. Paper presented at the annual meeting of the Psychometric Society, Iowa City, IA.

Stinson, J. D., Becker, J. V., \& Sales, B. D. (2008). Self-regulation and the etiology of sexual deviance: Evaluating causal theory. Violence and Victims, 23(1), 35-51. doi:10.1891/0886-6708.23.1.35

Stinson, J.D., Quinn, M.A., \& Levenson, J.S. (2016). The impact of trauma on the onset of mental health symptoms, aggression, and criminal behavior in an inpatient psychiatric sample. Child Abuse \& Neglect, 61, 13-22. doi: 10.1016/j.chiabu.2016.09.005

Stinson, J.D., Robbins, S.B., \& Crow, W.C. (2011). Self-regulatory deficits as predictors of sexual, aggressive, and self-harm behaviors in a psychiatric sex offender population. Criminal Justice and Behavior, 38(9), 885-895. doi: 10.1177/0093854811409872

Stinson, J.D., Sales, B.D., \& Becker, J.V. (2008). Sex offending: Causal theories to inform research, prevention, and treatment. Washington, DC: American Psychological Association. 
Sun, I. Y., Tripplet, R., \& Gainey, R. R. (2004). Neighborhood characteristics and crime: A test of Sampson and Groves model of social disorganization. Western Criminology Review, $5(1), 1-16$.

Tewksbury, R., Mustaine, E. E., \& Covington, M. (2010). Offender presence, available victims, social disorganization, and sex offense rates. American Journal of Criminal Justice, 35, 1-14. doi: 10.1007/s12103-010-9070-6

Tolan, P. H. (2016). Community violence exposure and developmental psychopathology. In D. Cicchetti (Ed.), Developmental Psychopathology: Risk, resilience, and intervention (vol. 4, $3^{\text {rd }}$ ed., pp. 43-85). Hoboken, NJ: John Wiley \& Sons.

Topitzes, J., Mersky, J. P., \& Reynolds, A. J. (2012). From child maltreatment to violent offending: An examination of mixed-gender and gender-specific models. Journal of Interpersonal Violence, 27(12), 2322-2347. doi: 10.1177/0886260511433510

Tzoumakis, S., Lussier, P., Blanc, M. L., \& Davies, G. (2012). Onset, offending trajectories, and crime specialization in violence. Youth Violence and Juvenile Justice, 11(2), 143-164. doi: $10.1177 / 1541204012458440$

United States Census Bureau. (2014). Measuring America: How census measures poverty. Retrieved from: http://www.census.gov.

United States Census Bureau. (2017). Geographic terms and concepts - Block. Retrieved from: http://www.census.gov.

United States Department of Agriculture. (2013). Rural America at a glance: 2013 edition (Economic Brief No. 24). Washington, DC: Economic Research Service. University of Wisconsin Population Health Institute. (2017). County health rankings 2017 [Data file and code book]. Retrieved from http://www.countyhealthrankings.org 
Wadsworth, M. E., Evans, G. W., Grant, K., Carter, J. S., \& Duffy, S. (2016). Poverty and the development of psychopathology. In D. Cicchetti (Ed.), Developmental Psychopathology: Risk, resilience, and intervention (vol. 4, $3^{\text {rd }}$ ed., pp. 136-179). Hoboken, NJ: John Wiley \& Sons.

Wadsworth, M. E., Raviv, T., Reinhard, C., Wolff, B., Santiago, C. D., \& Einhorn, L. (2008). An indirect effects model of the association between poverty and child functioning: The role of children's poverty-related stress. Journal of Loss and Trauma, 13(2-3), 156-185. doi: $10.1080 / 15325020701742185$

Wang, J., \& Wang, X. (2012). Structural equation modeling: Applications using Mplus. West Sussex, United Kingdom: John Wiley \& Sons, Ltd.

Wanklyn, S. G., Ward, A. K., Cormier, N. S., Day, D. M., \& Newman, J. E. (2012). Can we distinguish juvenile violent sex offenders, violent non-sex offenders, and versatile violent sex offenders based on childhood risk factors? Journal of Interpersonal Violence, 27(11), 2128-2143. doi: 10.1177/0886260511432153

Ward, T. (2014). The explanation of sexual offending: From single factor theories to integrative pluralism. Journal of Sexual Aggression, 20(2), 130-141.

doi: $10.1080 / 13552600.2013 .870242$

Ward, T., \& Beech, A. (2005). An integrated theory of sexual offending. Aggression and Violent Behavior, 11, 44-63.

Ward, T., Hudson, S. M., Marshall, W. L., \& Siegert, R. (1995). Attachment style and intimacy deficits in sexual offenders: A theoretical framework. Sexual Abuse: A Journal of Research and Treatment, 7(4), 317-335. 
Weatherburn, D., \& Schnepel, K. T. (2015). Economic adversity and crime: Old theories and new evidence. Australian Journal of Social Issues, 50(1), 89-108.

Weston, R., \& Gore, P. A. (2006). A brief guide to structural equation modeling. The counseling psychologist, 34(5), 719-751. doi: 10.1177/0011000006286345

Widom, C. S., \& Maxfield, M. G. (2001). An update on the “cycle of violence” (Research in Brief No. 184894). Washington, DC: National Institute of Justice.

Wodahl, E. J. (2006). The challenges of prisoner reentry from a rural perspective. Western Criminology Review, 72(2), 32-47.

Wolff, K. T., \& Baglivio, M. T. (2016). Adverse childhood experiences, negative emotionality, and pathways to juvenile recidivism. Crime \& Delinquency, 63(12), 1495-1521. doi: $10.1177 / 0011128715627469$

Yu, C. Y., \& Muthén, B. O. (2002). Evaluation of model fit indices for latent variable models with categorical and continuous outcomes [Unpublished dissertation]. Retrieved from http://www.statmodel.com/download/Yudissertation.pdf

Zimmerman, G. M., \& Posick, C. (2016). Risk factors for and behavioral consequences of direct versus indirect exposure to violence. American Journal of Public Health, 106(1), 178188. 


\section{VITA}

\section{KELCEY (HALL) PUSZKIEWICZ}

Education:

Professional Experience:

Publication:

Presentations:
B.S. Psychology and Criminal Justice, Loyola University Chicago, Chicago, Illinois, 2012

M.A. Clinical Psychology, Ball State University, Muncie, Indiana, 2014

Ph.D. Psychology, with concentration in Clinical Psychology, East Tennessee State University, Johnson City, Tennessee, 2019

Graduate Student Clinician, Cherokee Health Systems, Morristown, Tennessee 2017-2018

Graduate Student Clinician, Alternative Community Corrections Program, Johnson City, Tennessee 2016-2017

Graduate Student Clinician, East Tennessee State University Behavioral Health and Wellness Clinic, Johnson City, Tennessee, 2015-2017

Graduate Research Assistant, East Tennessee State University, Department of Psychology, Johnson City, Tennessee, 20142016

Graduate Student Clinician, Indianapolis Counseling Center, Indianapolis, Indiana, 2013-2014.

Hall, K. L., Stinson, J. D., \& Moser, M. R. (2018). Impact of childhood adversity and out-of-home placement for male adolescents who have engaged in sexually abusive behavior. Child Maltreatment, 23(1), 63-73. doi: 10.1177/1077559517720726

Puszkiewicz, K. L., \& Stinson, J. D. (2018, April). Early childhood adversity, socioecological influences, and delinquent behaviors in a treatment sample of male adolescents. Presented at the Appalachian Student Research Forum, East Tennessee State University. Johnson City, Tennessee.

Puszkiewicz, K. L., \& Stinson, J. D. (2017, October). Early sexual exposure and sexually abusive behaviors in adolescent males. Poster presented at the $36^{\text {th }}$ Annual Research and Treatment Conference of the Association for the Treatment of Sexual Abusers. Kansas City, Missouri.

Hall, K. L., Stinson, J. D., Levenson, J. S., Quinn, M. A., \& Forgea, V. E. (2017, August). ACEs and adult criminality in a sample of university students. Poster presented at the Annual Meeting of American Psychological Association 
(Division 41: American Psychology-Law Society). Washington, DC.

Hall, K. L., \& Stinson, J. D. (2016, November). Victimperpetrator relationship in childhood abuse: Impact on outcome in individuals who engage in sexual misconduct across clinical and non-clinical samples. Oral presentation at the Student Clinical Case and Data Blitz at the $35^{\text {th }}$ Annual Research and Treatment Conference of the Association for the Treatment of Sexual Abusers. Orlando, Florida.

Hall, K. L., Stinson, J. D., \& Eisenbrandt, L. L. (2016, March). Impact of childhood adversity and out-of-home placement in adolescents with sexual behavior problems. Poster presented at the meeting of American Psychology-Law Society (AP-LS) Conference. Atlanta, Georgia.

Hall, K. L., \& Stinson, J. D. (2015, October). Experiences of childhood adversity and environmental responsiveness to trauma in juvenile sex offenders in residential treatment. Poster presented at the $34^{\text {th }}$ Annual Research and Treatment Conference of the Association for the Treatment of Sexual Abusers. Montreal, Quebec, Canada.

Hall, K. L., LeMay, C. C., Stinson, J. D., \& Quinn, M. A. (2015, April). An examination of the ACE study and complex trauma in high-risk forensic inpatients. Poster presented at the Appalachian Student Research Forum, East Tennessee State University. Johnson City, Tennessee.

Hall, K. L., \& Stinson, J. D. (2015, April). They always come back: A discussion of re-entry and treatment needs among offenders in rural communities. Oral presentation at the Appalachian Student Research Forum, East Tennessee State University. Johnson City, Tennessee.

Honors and Awards:

Poster Award Recipient, Social \& Behavioral Sciences, Doctoral Students, Second Place, Appalachian Student Research Forum, East Tennessee State University, 2018

Graduate Student Research Travel Grants, Department of Psychology, East Tennessee State University, 2016-2017

Graduate Student Research Travel Grants, Graduate Student Association of Psychology, East Tennessee State University, 2016

Grant Harris and Marnie Rice Student Poster Award Recipient, $34^{\text {th }}$ Annual Research \& Treatment Conference for the Association for the Treatment of Sexual Abusers, 2015 